\title{
Domains of organizational effectiveness of gerontology centers in higher education
}

\author{
Allison Hale Nichols \\ West Virginia University
}

Follow this and additional works at: https://researchrepository.wvu.edu/etd

\section{Recommended Citation}

Nichols, Allison Hale, "Domains of organizational effectiveness of gerontology centers in higher education" (1999). Graduate Theses, Dissertations, and Problem Reports. 3134.

https://researchrepository.wvu.edu/etd/3134

This Dissertation is protected by copyright and/or related rights. It has been brought to you by the The Research Repository @ WVU with permission from the rights-holder(s). You are free to use this Dissertation in any way that is permitted by the copyright and related rights legislation that applies to your use. For other uses you must obtain permission from the rights-holder(s) directly, unless additional rights are indicated by a Creative Commons license in the record and/ or on the work itself. This Dissertation has been accepted for inclusion in WVU Graduate Theses, Dissertations, and Problem Reports collection by an authorized administrator of The Research Repository @ WVU.

For more information, please contact researchrepository@mail.wvu.edu. 
DOMAINS OF ORGANIZATIONAL EFFECTIVENESS OF GERONTOLOGY

CENTERS IN HIGHER EDUCATION

by

Allison H. Nichols

West Virginia University

Submitted to the

College of Human Resources and Education

In Partial Fulfillment of the Requirements for

The Degree of Doctor of Education

Department of Educational Leadership

\author{
1999 \\ Morgantown, West Virginia \\ Richard A. Hartnett, Ed.D., Committee Chair \\ Ernest R. Goeres, Ph.D. \\ Helen M. Hazi, Ph.D. \\ Michele L Kreidler, Ph.D. \\ F. Carson Mencken, Ph.D. \\ Anne H. Nardi, Ph.D.
}

Key Words: centers, institutes, higher education, organizational effectiveness, gerontology

Copyright 1999, Allison H. Nichols. 


\begin{abstract}
This is an exploratory study that focuses on organizational effectiveness of gerontology centers and institutes at American universities. The study was modeled after studies of organizational effectiveness in higher education by Kim Cameron of Brigham Young University. The study identifies six domains of effectiveness that are important to gerontology centers and the structural and functional models and characteristics of gerontology centers that may predict the domain in which it is effective. The target population of the study was dominant coalition members of 87 gerontology centers, namely, administrators and faculty members who have the most influence on policy, direction, and performance. Gerontology center directors were asked to fill out a two-part questionnaire that included structural and functional characteristics of their center (Part A) and rankings of organizational effectiveness (Part B). Part $B$ of the questionnaire was also completed by faculty and administrators associated with each center. A factor analysis was used on the rankings of effectiveness (Part B) to determine domains of effectiveness. A median analysis was used to determine which centers were effective in each domain. Finally, single and multiple regression analysis was used to determine the structural and functional models and significant characteristics of centers that may predict the domain of effectiveness. This study identified six domains of organizational effectiveness of gerontology centers: non-academic and community openness, career goal satisfaction of students, staff and faculty, resource acquisition, organizational health, faculty and staff job satisfaction, and quality faculty. The predictor models for each domain include: non-academic--demographics, organizational goals, and organizational mission; career goal satisfaction--financial indicators; resource acquisition--organizational structure and financial indicators; organizational health--none; faculty and staff job satisfaction--organizational goals and organizational mission; and quality faculty--organizational goals and organizational activities. Description of centers effective in each domain, based on the significant predictor characteristics, are included.
\end{abstract}




\section{TABLE OF CONTENTS}

Acknowledgments $\quad x$

$\begin{array}{lll}\text { Chapter 1. } & \text { Introduction }\end{array}$

A. Statement of the Problem 5

B. Scope of the Study 6

1. Limitations 6

2. Delimitations 6

C. Significance of the Study 8

1. Contribution to the Literature on Organizational Effectiveness 8

2. Contribution to the Literature on Centers and Institutes 9

3. Contribution to the Literature on Gerontology Centers and Institutes $\quad 10$

D. Definition of Terms 12

Chapter 2. Review of the Literature 13

A. Organizational Configuration of Institutions of Higher Education 13

1. Organizational Structure Theory 13

2. Social Systems Theory 14

3. Social Systems Theory and the Impetus to Create Centers and Institutes in Higher Education

B. Characteristics of Centers and Institutes within Higher Education 21

1. Functions of Centers and Institutes 21

2. Relationship of Centers to Academic Departments 22 
3. Placement of Centers within the Institution 23

4. Funding of Centers

5. Internal Structure of Centers and Institutes

C. Gerontology Institutes and Centers 25

1. History of Gerontology Centers 25

2. Characteristics of Gerontology Centers 26

3. Organizational Structure and Dimensions of External Environment $\quad 27$

4. Functions and Organizational Goals of Gerontology Centers 28

5. Resources and Financial Factors 29

6. Relationship of Gerontology Centers to Constituents

7. Future of Gerontology Centers 30

D. Organizational Effectiveness 31

1. Definition of Effectiveness 31

2. Domains of Organizational Effectiveness 34

3. Constituencies of Organizational Effectiveness

4. Measurement of Organizational Effectiveness

5. Criteria for Measurement of Organizational Effectiveness in Gerontology Centers 
1. Research Problem 37

2. Expected Outcomes 37

3. Instruments 38

4. Validity 41

5. Reliability 43

B. Description of the Population 44

C. Scope and Methodology of the Study 44

1. Procedures 44

$\begin{array}{lll}\text { Chapter } 4 . \quad \text { Data Analysis } & 50\end{array}$

A. Introduction to the Findings 50

B. Findings 50

1. Domains of Organizational Effectiveness Of Gerontology Centers 50

2. Gerontology Centers and the Effectiveness Domains

3. Predictive Models 58

4. Predictive Variables 62

Chapter 5. Conclusions and Recommendations 64

A. Statement of the Problem 64

B. Research Procedures 64

C. Research Questions 65

D. Conclusions 66

1. What are the domains of organizational effectiveness of gerontology centers? 66

2. What are the structural and functional characteristics of centers which may predict domain in which a gerontology center will be effective?

3. What are the specific characteristics of gerontology centers that may predict the 
domain of effectiveness? $\quad 76$

E. Implications 79

E. Recommendations 83

1. Recommendations for Further Studies 83

2. Recommendations for Gerontology Centers 84

Bibliography $\quad 86$

$\begin{array}{ll}\text { Appendices } & 99\end{array}$

A List of Gerontology Centers and Institutes at College and Universities in the United States 99

B Part A - Characteristics of Centers and Institutes 103

C Part B - Assessment of Organizational Characteristics of Centers and Institutes

D Shortened Version - Part A - Characteristics of Centers and Institutes

E Rotated Factor Pattern 118

F Alpha Correlations of Domain Variables $\quad 120$

G Median Analysis $\quad 124$

H Regression Analysis of Organizational Structure and Domains of Organizational Effectiveness

I Regression Analysis of Financial Issues and Domains of Organizational Effectiveness--Acquisition of Resources 132

$\mathrm{J} \quad$ Regression Analysis of Financial Issues and Domains of Organizational Effectiveness--Career Goal Satisfaction

K Regression Analysis of Organizational Activities and Domains of Organizational Effectiveness

L Regression Analysis of Organizational Goals and Domains Of Organizational Effectiveness--Non-academic

M Regression Analysis of Demographics and Domains of Organizational Effectiveness--Non-academic 
N Regression Analysis of Organizational Mission and Domains of Organizational Effectiveness--Non-academic

O Regression Analysis of Organizational Mission and Domains of Organizational Effectiveness--Faculty and Staff Satisfaction

P Predictor Variables for Resource Acquisition

Adequacy of Funding

Adequacy of Resources

Stability for Five Years

Type of Budget

Likelihood Center will be Permanent

Impetus for Starting Center

Expenditures on the Physical Plant

Permanent Faculty

Administrative Staff

Activities: Community Projects

Type of Facility

Relationship of the Center to the Institution

Mission: Research

Job of Director: Teaching

Q Predictor Variable for Career Goal Satisfaction

Likelihood Center will be Permanent

Job of Director: Budgeting

Permanent Faculty

Stability for Five Years

R Predictor Variables for Organizational Health

Adequacy of Space

Whose Resources Faculty Use

Percentage of Director's Time in Teaching

S Predictor Variables for Quality of Faculty 
Goal: Student Satisfaction

Job of Director: Fundraising

Activities with State Agencies

Percentage of Director's Time Fundraising

Relationship Between Director and Subdivisions

T Predictor Variables for Non-Academic

Center Mission Compatibility to Mission of Institution 165

Goal: Personal Development

Job of Director: Political Activity

Goal: Academic Development

Funding Source: Endowments

Year of Founding

Source of Funding: Federal Funds

Goal: Acquiring Resources

Mission: Instruction

Activity: Adult Education

U Predictor Variables for the Domain of Faculty and Staff Job Satisfaction

Goal: Academic Development

To Whom the Director Reports

Mission: Instruction

Percentage of Director's Time in Political Activity

Goal: Community Interaction

Activities with State Agencies

Activities: Community Projects

Relationship Between Director and the Subdivisions 182

Academic Appointment of the Director 


\section{TABLES}

Table 1 Gerontology Centers which Responded to the Questionnaire $\quad 47$

Table 2 Gerontology Centers--Non-respondents 48

Table 3 Gerontology Centers which are Effective in each Domain $\quad 55$

Table 4 Effectiveness Domains of each Gerontology Center 56

Table $5 \quad$ Number of Centers Effective in each Domain 57

Table 6 Domains of Organizational Effectiveness on other Predictor Domains 59

Table $7 \quad$ Effectiveness Domains and their Predictors 63 


\section{ACKNOWLEDGMENTS}

The author wishes to express her sincere appreciation and gratitude to:

Dr. Kim Cameron, Brigham Young University, for allowing me to use his assessment of organizational effectiveness in higher education which he developed for his own research in the 1980s.

The committee members, particularly Dr. Richard Hartnett, Chair, for his guidance and encouragement.

Dr. Carson Mencken, Department of Sociology and Anthropology, for allowing me to audit his course in regression analysis and for guiding me in my statistical analysis.

Last, but not least, to my husband who stood by with his full support over the years, and to my daughter with whom I will be sharing graduation celebrations this spring. 


\section{CHAPTER 1 \\ INTRODUCTION}

Gerontology, as an academic discipline, has a fairly short history. Although courses in aging could be found at colleges and universities as early as 1957, degrees, minors and certificate programs were not founded until after the passage of the Older American's Act in 1965. Since the traditional academic disciplines did not always welcome gerontology as a legitimate discipline, gerontology programs were often located within centers or institutes and focused on multi-disciplinary studies of normal aging (Maddox, 1988). The Duke University Center for the Study of Aging and Human Development was one of the earliest gerontology centers. There were 410 gerontology programs in 1985, but the number increased to 692 in 1992 (Peterson, Wendt \& Douglass, 1994).

Gerontology/geriatric programs are most frequently found at a large institution and at institutions offering graduate level instruction. They are least frequently found on small campuses and at those offering only an associate or bachelor's degree (Peterson, Wendt \& Douglass, 1994). These programs offer a range of degrees, certifications and other award designations. The largest percentage of programs serve bachelors level students (33.4\%), followed by masters $(25.1 \%)$, doctorate/post-doctorate (18\%), combined (13\%), associate $(8 \%)$, and other (3\%).

Gerontology centers tend to be independent of academic departments. Half (50\%) of the gerontology administrators surveyed in 1992 (Peterson, Wended \& Douglass, 1994) reported to a president, vice president or dean, and the title most often held by gerontology program administrators was director (39\%). The financial resources of these centers are modest; only $50 \%$ of programs report having a budget to administer.

Gerontology centers are multi-disciplinary in nature; bringing together three major discipline areas; sociology, biology, and psychology. Many are 
connected with disciplines in the health sciences such as nursing, medicine, dentistry, social work and allied health. Peterson divides programs into four program orientations: liberal arts, professional, scientific, and a combination of two orientations.

Based upon an unpublished survey of the literature on gerontology centers by Nichols (1995), the functions most often mentioned in the literature about gerontology centers are curriculum and instruction and continuing education/professional development. To a lesser degree, gerontology centers are involved in research. Research at gerontology centers covers a broad range of topics and disciplines including: medicine, biology, psychology, health issues, public policy issues, social relationships in later life, and gains and deficits of growing old,

The constituents of gerontology centers include university students, administrators and faculty members from a variety of academic disciplines upon which the center impacts. Gerontology centers differ from other academic units in the type of constituents which unlike other centers includes the community outside of the institution such as state agencies, community agencies, elderly individuals and groups, and businesses.

Future challenges for gerontology centers in higher education include 1) maintaining an interdisciplinary balance in training programs, 2) developing the next generation of scholars and clinicians, 3) translating research into practice, 4) encouraging the development of disciplines which create a greater awareness of the diversity of social relationships within later life, e.g., anthropological gerontology and corporate gerontology, and 5) creating an international network of gerontological courses with common principles of curriculum design ( Maddox, 1988; Mullins, 1988).

Given the challenges facing the growing aging population, and therefore facing gerontology centers, it is important to evaluate their effectiveness. This study attempts to look at organizational effectiveness in gerontology centers in higher education. There are many ways to evaluate organizational 
effectiveness, and the literature identifies four major approaches. These include the goal approach, the systems approach, the process approach, and the ecological or participant satisfaction approach. The goal approach defines organizational effectiveness as the ability of an organization to achieve its goals. Advocates of the goal approach include Georgopolous and Tannenbaum (1957); Etzioni (1964); Price (1972); Campbell (1977); and Scott (1977). The system resource model defines effectiveness as the organization's ability to secure an advantageous bargaining position in its environment, and to capitalize on that position to acquire scarce and valued resources (Hoy \& Miskel, 1991). The process approach equates organizational effectiveness with internal organizational health, efficiency, and procedures, and is advocated by Argyris (1964), Bennis (1966), and Likert (1967), Steers (1977), Pfeffer and Salancik (1977), Beckhard (1969) (organizational development), Bennis (1966) (organizational health), and Nadler and Tushman (1980). The ecological or participant satisfaction model defines organizational effectiveness by the extent to which constituents of the organization are satisfied and their needs and expectations are being met. Theorists who have studied this approach include Connolly (1980) (constituency satisfaction); Keeled (1980); Pfeiffer and Sayanci, (1978) (strategic constituencies) and Miles and Cameron (1982); Zammuto, (1982) (legitimacy).

There are problems with taking any of these approaches to the exclusion of any of the others. Integrated models take the position that all four of these approaches are important for measuring effectiveness. Examples of integrated model approaches are Parsons (1960); Goodman \& Pens (1977); Steers (1975); Campbell (1977); Cameron (1978; 1981, a \& b, 1983). An integrated model is used in this study, namely the integrated approach taken by Cameron in his 1978 and 1981 studies of organizational effectiveness in institutions of higher education. This approach looks at the effectiveness of goal achievement, resource acquisition, organizational processes, and constituent satisfaction, all through the perceptions of administrative personnel and associated faculty. 
This exploratory study focuses on characteristics of gerontology institutes and centers at American universities and colleges and organizational effectiveness. It identifies domains of effectiveness that are important to gerontology centers, and determines if certain characteristics of gerontology institutes and centers can explain differences in organizational effectiveness. 


\section{A. Statement of the Problem and Research Questions}

Organizational effectiveness in gerontology centers and institutes in American universities and colleges has not been systematically studied. This exploratory study focuses on characteristics organizational effectiveness of gerontology institutes and centers at American universities and colleges. This study determines characteristics of gerontology institutes and centers that can explain differences in organizational effectiveness. Since this study is exploratory, no hypotheses are offered.

\section{Research Questions}

1. What are the domains of organizational effectiveness of gerontology centers?

2. What are the structural and functional models (i.e., organizational/external environment, strategic emphasis, organizational goal preferences, financial indicators, demographics) which may predict the domain in which a gerontology center will be effective?

3. What are the specific characteristics of gerontology centers that may predict the domain in which a gerontology center will be effective? 


\section{B. Scope of the Study}

\section{Limitations}

a. This study targets dominant coalition members of gerontology centers, namely, administrators and faculty members who have the most influence on policy, direction, and performance at all (96) gerontology centers and institutes listed in the 1992 National Directory of Gerontology Programs in Gerontology and Geriatrics which is produced by the Association of Gerontology in Higher Education.

b. This study focuses on the organizational level of gerontology centers. Center directors at all 96 institutes and centers were sent and asked to complete both Part A (characteristics of centers) and Part B (perceptions of effectiveness) of the questionnaire (Appendix I). In addition to completing the questionnaire, each director was asked to supply names of administrators/faculty members working for or associated with the center, under the following categories: 1) central administrators with responsibility for the center, 2) project or program administrators or directors, 3) directors of subunits, and 4) faculty members involved in planning and implementing for the center. These individuals were sent and asked to complete Part B of the questionnaire which was designed to probe perceptions of organizational effectiveness.

c. This study employed a quantitative analysis of data, using three statistical procedures: factor analysis, median analysis, and regression analysis.

$d$. The names of the centers which fall under each of the domains of organizational effectiveness are not identified to protect the privacy of the institutions who agreed to participate.

\section{Delimitations}

a. This is an exploratory study which identifies areas of organizational effectiveness in gerontology centers. Further research will be required to examine these domains in depth. 
b. This study is based on the perceptions of administrators and faculty involved in gerontology centers, not on quantifiable data such as enrollments, financial information, and resources.

c. Directors selected the other administrators and faculty who responded to the organizational effectiveness rating assessment. These individuals do not represent a random sample of all possible administrators and faculty members. 


\section{Significance of the Study \\ 1. Contribution to the literature on organizational effectiveness in higher education.}

Cameron (1978) constructed nine dimensions of organizational effectiveness in institutions of higher education which are: student educational satisfaction; student academic development; student career development; student personal development; faculty and administrator employment satisfaction; professional development and quality of the faculty; system openness and community interaction; and ability to acquire resources and organizational health. In a subsequent study, Cameron (1981) combined these nine dimensions into four domains of organizational effectiveness in colleges and universities. Those domains are external adaptation, which deals with student career development, system openness, and community interaction; morale, which is concerned with student educational satisfaction, administrator satisfaction, and organizational health; academic orientation, which deals with student academic development, professional development, quality of faculty, and ability to acquire resources; and extracurricular, which deals only with student personal development. These domains were identified by a study (Cameron, 1978), of administrators and faculty members at colleges and universities in the northeast United States with a wide variety of characteristics.

Other studies have expanded upon the ideas of Kim Cameron with respect to organizational effectiveness in higher education. One study, (Smart \& Hamm, 1993) applied Cameron's criteria to community colleges and found that organizational effectiveness differed according to the mission of the college. Two studies (Lysons, 1993 and Lysons \& Hatherly, 1992) applied Cameron's criteria to higher education institutions in Australia and the United Kingdom.

This proposed study adds to the literature on organizational effectiveness in colleges and universities because it studies organizational effectiveness of institutes and centers, units within colleges and universities which combine some of the characteristics of academic departments, as well as some 
characteristics of non-academic administrative units. The domains of effectiveness may or may not be the same as the ones proposed by Cameron and others for colleges and universities.

\section{Contribution to the literature on centers and institutes in higher education.}

Most of the literature on institutes and centers in higher education was written in the early 1970s by a handful of authors (Ikenberry, 1970; Ikenberry \& Friedman, 1972; Friedman, 1977; Totman, 1976). This literature describes research institutes and centers which mushroomed in the 1960s. The 1960s was called the golden age for institutes and centers (Friedman, 1977), and the studies of those centers reflected a need to examine their place on American campuses. In the 1970s, a number of centers and institutes was established around current issues of the day and their constituencies: women's studies; African American or black studies; regional studies; and gerontology. These institutes and centers have not been studied in any significant way, thus far. They may differ significantly from the centers and institutes of the 1960s, because their mission is more than just research. In fact, an unpublished study by Nichols (1995) of literature describing women studies, African American studies, management studies, and gerontological studies, found that this type of center emphasizes teaching over research. One might hypothesize that organizational effectiveness in these centers would be defined differently than in a research center.

The literature on centers and institutes is mostly descriptive.

Characteristics of institutes are described and a classification of institutes and centers in higher education has been proposed by lkenberry (1970) and Ikenberry and Friedman (1972). Ikenberry and Friedman's classifications of research institutes and centers include standard, adaptive, and shadow units. Standard centers have sufficient resources to meet their goals and objectives, employ permanent professional staff, have adequate equipment, and occupy 
permanent space. They are also called "complete bureaucracies" (Norman, 1971). Adaptive institutes, on the other hand, are created in response to government or foundation funding. They are continually undergoing change, redefining their goals, securing and releasing staff, and initiating and terminating projects. They have a reasonably strong hierarchical management arrangement and maintain a nucleus of faculty members who have ties to the institute. The director determines the activities in response to the funding agency's directives. An adaptive institute has some office space, as well as basic equipment, but often uses equipment belonging to other departments. Most of the professional personnel are not housed at the center. These units are also called "truncated bureaucracies." Shadow institutes have no staff, no space, no budget, and often no visible accomplishments. However, they do have a designated director. These may be called "nucleated bureaucracies," that is, the organization is assembled on demand or on an ad hoc basis (Norman, 1971).

This study adds to the literature on institutes and centers in several ways: 1) very little has been written in the past 20 years about institutes and centers; 2) centers and institutes have been described and classified, but organizational effectiveness has not been evaluated or addressed; and 3) gerontology centers represent a different kind of center than the ones described in the literature of the 1970s, because their primary mission is teaching-related rather than research, thus they are deserving of study.

\section{Contribution to the literature on gerontology centers and institutes.}

Organizational effectiveness in gerontology centers has not yet been explored. Peterson, et. al. (1991) observed successfulness factors of 21 gerontology programs at 10 university and colleges. Successfulness, in Peterson's (1991) study, was defined in terms of longevity and institutionalization. Four hypotheses resulted from Peterson's (1991) study concerning stability of gerontology programs and its relationship to: 1) its 
placement in the institution; 2) its ability to locate and secure funding; 3) the extent to which the program has influence over the instructional offerings and its faculty is involved in instruction; and 4) the institutionalization of the program, defined as the ability of the program to continue after a dominant leader withdraws. Other studies of individual gerontology programs describe a program's accomplishments based upon goal outcomes. But organizations often are successful in areas outside of their stated goals, and in addition, goals can be low, harmful or misplaced.

This study contributes to the literature on gerontology centers and institutes by studying organizational effectiveness across the whole population of gerontology centers and institutes in the United States. It draws upon the Peterson, et. al. (1991) study by looking at how characteristics of gerontology centers and institutes explain the domain of organizational effectiveness. 


\section{DEFINITION OF TERMS}

\section{Centers in higher education}

Centers within higher education are administrative units with the functions of coordination, administration, and conduct of programmatic research, education, and service. They may be independent units or may relate administratively to a college or academic department.

\section{Gerontology}

The study of aging: aging processes, social issues of aging, human development, cognition, adult education, public policy and aging, etc.

\section{Gerontology centers}

Centers within institutions of higher education which focus on the study of aging and all of the issues related to older adults. Their function includes research, academic programing, adult and continuing education, and service to elders.

\section{Organizational effectiveness}

The ability of an organization to achieve its goals, obtain resources, function internally and with units in its environment, and satisfy its constituents. 


\section{CHAPTER 2 \\ REVIEW OF THE LITERATURE}

The review of related literature discusses: 1) organizational configuration of institutions of higher education, 2) characteristics of centers and institutes within higher education, 3) gerontology centers and institutes, and 4) organizational effectiveness.

\section{A. Organizational Configuration of Institutions of Higher Education}

\section{Organizational Structure Theory}

Institutions of higher learning can be described as professional bureaucracies (Mintzberg, 1979). They are bureaucracies because they contain most of the following elements in Weber's 1947 definition: division of labor and specialization, impersonal orientation, hierarchy of authority, rules and regulations, career orientation, efficiency, and ideal type (Weber, 1947). They are professional bureaucracies because they permit both decentralization and standardization and because they rely on the expertise and skills of their professionals to operate effectively (Hoy \& Miskel, 1991). Examples of the need for standardization in the structure of universities are 1) students must meet the same standards for graduation as comparable schools, 2) standards must be met for professional training, 3) students must be moved through the process within a certain time period, and 4) financial aid requirements must be adhered to. On the other hand, decentralization also exists in institutions of higher learning because faculty members control classroom activities, their own professional activities, and many aspects of curriculum design. In addition, outside organizations such as academic associations, state and community groups, and funding agencies also have a lot to say about what goes on within the institution.

The concept of professional bureaucracy helps, in part, to explain the emergence of centers. Early in the history of centers at universities, centers 
were created by central administrators, but many of those which were created from 1960-1970 were initiated by faculty members, department chairs, and deans (Norman, 1971). Professional bureaucracies allow faculty members to branch out on their own and create new units which will enhance their individual and professional needs, apart from administrative initiation.

Another organizational structure theory which helps to explain the existence of centers and institutes on university campuses is loose-coupling theory. Institutes of higher education are often described as loosely coupled structures because organizationally they have ambiguous goals, unclear technologies, fluid participation, uncoordinated activities, loosely connected structural elements and a structure that will have little effect over outcomes (Hoy \& Miskel, 1991). Loose coupling theorists (Weick, 1976; Meyer, 1978; Orton \& Weick, 1990; Meyer \& Rowan, 1978) focus on the disconnection of behavior and outcomes in organizations. Subsystems in organizations, such as universities, are tied loosely together, rather than through tight, bureaucratic linkages.

Coupled events are responsive and each event preserves its own identity as well as separateness (Hoy \& Miskel, 1991). Centers and institutes frequently operate within the institution with little or no connection to academic departments.

Academic departments usually have little or no control over how the work is done at the centers or even who is doing the work. Even though centers are often funded because they promise collaboration and interdisciplinary work, the reality is that collaboration and/or interdisciplinary work is rarely achieved at centers (Friedman, 1977; Stahler, 1994)

\section{Social Systems Theory}

In order to understand how centers and institutes relate to other units in higher education, it is necessary to discuss social systems theory. A university or college, of which centers and institutes are a relatively new part, is an open social system. A social system, according to social theorists (Abott, 1965; Getzels \& Guba, 1957; Leavitt, Dill \& Eyring, 1973; Lipham, 1988; Scott, 1981, 
1987; Nadler \& Tuchman, 1989; Hoy \& Miskel, 1991; Etzioni, 1964; Olsen, 1968), is a bounded set of elements (i.e., subunits, subsystems, activities) which interact and form a single activity which has a distinctive total unity beyond its component parts (Hoy \& Miskel, 1991). Everything outside of this single activity is called the environment. In an open social system, there is constant feedback between the environment and the social system, and open systems incorporate aspects of the environment, but are distinguished from the environment by a clearly defined boundary.

Getzel and Guba, 1957, developed a social system model which included two important elements: institutional or bureaucratic expectations (roles and expectations, and individual or work motives (personalities and needs). They said that within an open social system these two elements work together to affect the products or outcomes of the system. Organizations, such as universities and colleges, define through social processes, the roles they want people to play. These definitions include position and status, appropriate behavior, mandatory expectations, and flexible expectation. In academic life, professorial positions carry a certain status based upon rank, they are expected to behave in a certain professional way and their behavior is formally defined by such tenets as "academic freedom." Professors are expected to show up for class, serve on committees, publish in disciplinary journals, and advise students. The details of these expectations are flexible and dependent on the dynamics of the academic department.

Getzel and Guba, 1957, maintained that in an open social system it is not enough to look at the institutional element, but one must also consider the individual element. Individuals occupy the positions in the organization, and to a large extent determine how the institutional roles will be played out. Individuals bring their own personalities, motivation, need for achievement, security, acceptance, and perception of the environment.

A third element has been added to the social system model, which is the work group (Getzels, Lipham, \& Campbell, 1968; Leavitt, 1965; Nadler \& 
Tuchman, 1989). The work group is the result of the combination of the individual element and the institutional element. It contains informal norms and formal expectations. Academic departments or disciplines are examples of work groups in the university setting.

Finally, the open social system interacts with its environment in the form a continuous flow of feedback. The environment inputs resources, values, technology, history, community, state, and national demands (Hoy \& Miskel, 1991), and evaluates the outputs of the social system (i.e., adaptation, goal achievement, integration, and latency) while again imputing information, ideas and demands into the system. To a large extent, centers and institutes have resulted from input from the environment.

\section{Social systems theory and the impetus to create centers and institutes in higher education}

Initially colleges included few subunits or subsystems. Early college students were taught by a master and tutors. The master taught the basic curriculum which consisted of theology, rhetoric, and mathematics. As colleges expanded and universities developed, the curriculum grew to include subjects that were once part of the "extra-curriculum," and academic departments arose. This led to the professionalization of the professorship and development of academic disciplines as we know them today. Academic departments remain the cornerstones of university life and the chief academic subsystems within the university. Professors identify with their academic discipline, and tenure and promotion are dependent on the professor's ability to publish in professional journals created by the discipline and to rise within professional networks. Other subsystems within the university, which became necessary as colleges and universities expanded, include administrative subsystems and student-service subsystems. In many ways, centers and institutes bridge the gap between administrative and academic subsystems. 
Libraries, observatories and museums may be considered the oldest university centers and institutes because they were the earlier university units established outside of the traditional academic departments. The Harvard Observatory, created in 1844, was the largest observatory of the time (Geiger, 1990). By 1900 it had five faculty members and 40 assistants. The Harvard Observatory was funded by public subscription, while many of the early observatories and museums were funded by private gifts which became sustaining endowments. Most writers agree, however, that the earliest known centers and institutes were the agriculture experimental stations established at land-grant universities in late 1800's (Ikenberry \& Friedman, 1972). Agricultural experimental stations came about as a result of the Morrill Act of 1862 which made available land grants to the States that funded universities that were dedicated to the scientific study of agriculture and mechanics. Many of these land-grant universities have become major centers of research, housing a host of institutes and centers.

Before the Morrill Act of 1862, the Hatch Act of 1887, and the "Wisconsin Idea," colleges and universities saw themselves as responsible only for teaching the basic liberal arts or classic curriculum. After these events, universities began to emphasize research and public service. Land-grant universities required research and public service, along with instruction, as part of a professor's responsibilities. This change came as result of input from the university environment. Research and public service, up until this point, did not fit within the framework of an academic department. Gradually, academic departments began to embrace research and social service as part of their function, but only within the domains of its discipline. In order words, research was seen as a way to develop the discipline, and public service was defined as service to the discipline (e.g., committee assignments, book reviews, tenure and promotion activities).

Programmatic research, however, which was funded by foundations, industry and government agencies, and which often required interdisciplinary 
collaboration, had to be carried out under a different auspice than the academic department. Programmatic research is research which is intended to further the particular programs of the sponsoring agency (Geiger, 1990). Hence, in the language of social systems theory, there evolved a need for a new work group within the university system which defined roles of academics in a different way.

Research centers and institutes began to appear between World War I and World War II and were funded by donations from large philanthropic foundations and industry. Massachusetts Institute of Technology and the University of Michigan benefitted greatly from money from industry at this time. MIT's Research Laboratory in Applied Chemistry was established in the early 1900 's. Before WWII, institutes and centers were not perceived to be a threat to academic departments or to administration, as they would become after WWII, because so few researchers were involved and research centers were not seen as a significant departure from the academic department.

University centers began to increase after WWII due to input from the environment. This input was the need for new technologies. After WWII, during the decade of 1940-1950, the U.S. government began its first significant support of research in the areas of defense and health (Ikenberry and Friedman, 1972). Between 1940 and 1950, the total expenditures for research by the federal government grew to $\$ 222$ million, and about 117 research institutes and centers were created. This was largely due to the emergence of new technologies such as atomic energy, radar, and jet propulsion. Federal legislation was the impetus for establishing some institutes and centers such as the water research centers at each of the 50 land-grant universities. While in WWI, the government enlisted university scientists into the military and then stationed them at laboratories to conduct research, in WWII, the government contracted with universities to conduct war research (Geiger, 1990). Federally Funded Research Development Centers (FFRDCs) evolved directly out of wartime arrangements. Universities held the contracts to manage these large laboratories, but the government paid the costs. 
Even with new external funding, the growth in the number of institutes and centers grew comparatively slow until the launching of Sputnik in October 1957 (Friedman, 1977, Geiger, 1990). The launching of Sputnik made Americans realize that the United States was under-investing in basic scientific research and education. University research and development rose 371\% from 1958 to 1968 (Geiger, 1990) due to increased federal funding of basic research. This was however, a change from the previous funding of programmatic research for wartime projects. Research centers and institutes proliferated during this time, and the era is referred to as "the golden age for institutes and centers."

Friedman, ( 1977) says, "By the late 60s, institutes and centers paralleled, and in and in some instances reveled academic departments." During this time, research centers became institutionalized on campuses.

After 1968, funding for research in the basic sciences became tighter and many universities began again to seek funding for programmatic research. During the 1970s and 1980s, research at universities increased greatly, but it became more and more programmatic. The federal contribution decreased and fell to the levels of the early 1960s, and industrial funding, which is programmatic in nature, became more prominent. In addition, institutions, themselves, began investing more money in research and the procurement of research dollars.

To leave the reader with the impression that the impetus to create centers and institutes came only from the environment would be misleading. Two other factors, one dealing with the individual element of a social system and the other with the institutional element must be discussed in order to understand how centers developed in higher education.

First, with regard to the individual element, centers and institutes emerged on university campuses partly because of an entrepreneurial faculty who saw heading a center or institute as a career move. In the late 19th century and early 20th century, many of the great universities were headed by entrepreneurial presidents such as Elliot at Harvard, Gilman at Johns Hopkins, Butler at Columbia and Harper at Chicago. After WWII, at the same time as centers and 
institutes began to emerge, the age of the great college presidents passed and was replaced by the age of the managerial president. Managerial presidents presided over large cooperative universities. To fill the gap, institutes and centers offered entrepreneurial scholars opportunities to regain power. The new power to be acquired at centers and institutes lay in the ability to work with funding agencies, control funds, and control access to research support (Ikenberry \& Friedman, 1972). Centers provided the academic entrepreneur opportunity for travel, time for research, secretarial assistance, space, equipment, and/or graduate assistants. The position of director of a center provided an attractive substitute for the position of departmental chair or college dean. These new centers became new work groups in the university social system which allowed academics to meet their individual needs: needs which were not being met within the academic department. At the same time, a division began between traditional academic departments and centers based upon their ability to meet individual needs of academic staff. Academic departments could still meet the need for achievement within one's discipline which centers and institutes could not meet, while centers appealed to the entrepreneurial spirit and the need for control over a research project.

Second, with regard to the institutional element, the creation of centers and institutes provided a means for central administration to set up another subunit under its control which would benefit the institution. The roles and rules within this subunit would then be defined by the institution. Administrators began to see that research units bettered the standing of many universities, even mediocre institutions. Geiger (1990) says, "Creating organized research units has been one way that 'have-not' institutions have been able to compete in selected areas against a more prestigious rival." Ikenberry and Friedman (1972, $19,20)$ list the following institutional reasons for creating institutes and centers: 1) recruitment and retention of faculty, 2) increased coordination and communication between departments and programs, 3) strengthened graduate education and research programs, 4) resolution of internal conflicts, 5) 
establishment of new institutional goals, 6 ) renovation and reform of existing departments, 7) creating of special areas of academic emphasis, specialization, and 8) enhancement of institutional visibility and prestige.

\section{B. Characteristics of Centers and Institutes within Higher Education}

Most of the literature in higher education on centers and institutes was written in the late 1960s and early 1970s, following the "golden years" of centers and institutes from 1958-1968 (Friedman, 1977). This body of work is descriptive and evaluative in nature, a response to a new phenomenan in higher education which had grown rapidly in the previous decade. These historical and descriptive works were published largely by the Pennsylvania State University Center for the Study of Higher Education and concentrate on centers and institutes at large, research, land-grant institutions (Ikenberry, 1970; Ikenberry, \& Friedman, 1972; Friedman, 1977; Norman, 1971).

\section{Function of centers and institutes}

Historically, the major function of institutes and centers within higher education has been the coordination, administration, and conduct of programmatic research, although there was a time period before 1968 when basic science research was prominent. Many believe centers can handle these functions more efficiently than academic departments because 1) center goals are flexible, 2) centers can concentrate on specific projects and provide space and resources for those projects, 3) centers can hire staff on a temporary basis, 4) funding agencies prefer to deal with centers because they can handle funds more efficiently, and 5) centers can carry on interdisciplinary activities more

effectively (Ikenberry \& Friedman, 1972; Stahler \& Tash, 1994; Friedman, 1977). To a lesser degree, other functions of centers and institutes include service (conferences, seminars, workshops, public service) and instruction (Ikenberry, 1970; Friedman, 1977). 
Recently academic research centers have been looked upon as a vital link between industry and higher education (Steiner, 1995; Bitting, \& Spriggs, 1995). Both federal and state government initiatives are sponsoring research which is based upon "real world" problems and is encouraging industry-academic collaboration. Centers play a role with the connected industry in technology transfer, management structure, funding, contract negotiation, intellectual property rights and evaluation (Bitting \& Spriggs, 1995). Businesses have also linked with academic management and business education centers. These centers conduct surveys, disseminate information, maintain a library, and host conferences (Hoffman \& Petry, 1991).

\section{Relationship of centers to academic departments}

The tension between academic departments and centers is a prevalent theme in the literature. Differences between centers and academic departments cited in the literature include 1) task-oriented centers vs. theoretically-oriented departments (Norman, 1971; Ikenberry \& Friedman, 1972); 2) departmental control of faculty concerns, and thus faculty loyalty (control of funds, faculty appointments, academic rank, salaries, promotion and tenure, and university decision-making by departments) vs. center control of research project activities alone (Ikenberry \& Friedman, 1972; Totman, 1976); 3) style of management of a center by a director vs. management of a department by chairman reflecting a difference in style (Stahler \& Tash, 1994); and 4) disciplinary activities within academic departments vs. interdisciplinary activities available at centers (Friedman, 1977).

\section{Placement of a center within the institution}

The literature supports the idea that the placement of a center or institute has significant effect upon its function. Three possibilities are discussed: 1) independent, under a vice president or provost; 2) incorporated within a college or department; and 3) independent corporations (Norman, 1971; Totman, 1976; 
Ikenberry, 1970). A relationship has been found between the source of initiation of a center and where it resides within the university structure (Norman, 1971). Reporting lines also have been found to depend upon where the center is placed within the institution (Norman, 1971). Finally, the placement of a center or institute determines how it is perceived by the university community. For example, large independent units are sometimes a threat to departments and colleges, while smaller college-affiliated centers are often too restricted in the activities they are able to carry out. Departmental centers have difficulty establishing interdisciplinary research and service projects, while large independent centers have problems attracting a faculty with disciplinary interests (Norman, 1971).

\section{Funding of centers}

Centers and institutes are almost always funded, at least in part, by outside agencies, either federal or state agencies, or private foundations. The type of funding has been shown to be related to the area of concentration. For example, agriculture, conservation, and physical and earth sciences are generally funded by federal funds; regional and area studies, social sciences,

and education centers by foundations; and engineering by business and industry (Ikenberry, 1970). A correlation was also found between the placement of the center within the university and the source of funding (Ikenberry, 1970).

\section{Internal structure of centers and institutes}

Institutes and centers have been categorized in the literature as standard, adaptive, and shadow institutes (Ikenberry \& Freidman, 1972). According to Ikenberry and Freidman, a standard institute has sufficient resources to meet its goals and objectives, employs a permanent professional staff, is able to invest in equipment, and occupies permanent space. Adaptive institutes, on the other hand, are created in response to government or foundation funding. They are continually undergoing change, redefining their goals, securing and releasing 
staff, and initiating and terminating projects. They have a reasonably strong hierarchical management arrangement and maintain a nucleus of faculty who have ties to the center. They have some office space and basic equipment, but most personnel are not housed at the center. The director dictates (in response to funding agencies) what the center will do. Shadow institutes have no staff, no space, no budget, and often no visible accomplishments. Norman (1971) describes these three structures as: 1) "complete bureaucracies," that is, a unit with full managerial hierarchy and resources necessary for task performance; 2) "truncated bureaucracies," that is, the lower managerial levels and some of the needed resources are not stored within the organization until the specific nature of the task is known; and 3) "enucleated bureaucracies," that is, the organization is assembled on demand or on an ad hoc basis. Totman (1976) classifies centers as facilitative and autonomous units. Facilitative units further the purpose of the faculty affiliated with the unit by providing a context in which research can be offered to the faculty member without having to be concerned with the goals or mission of the center. Autonomous units, on the other hand, have their own distinct mission and/or research projects that exist regardless of the interests of the affiliated faculty.

\section{Gerontology Institutes and Centers}

\section{History of gerontology centers}

The body of literature which discusses the history of gerontology centers in general includes Maddox (1988); Simson \& Wilson (1981); Craig, (1981); Peterson (1986); Pullen (1989); Teicher \& Corcoran (1984); Thornton (1992); Peterson, Wendt, \& Douglass (1994). Courses in aging could be found at colleges and universities as early as 1957 (57 campuses). The number of campuses offering courses in gerontology, geriatrics, or aging has increased greatly since 1957 to 1,639 campuses according to a 1992 survey (Peterson, Wendt \& Douglass, 1994). Gerontology/geriatric/aging programs (instruction which results in a degree, certificate, specialization, concentration, minor, fellowship, or a research and/or clinical programs) were founded after the 
passage of the Older American's Act in 1965. These programs were often located within centers or institutes and concentrated on multi-disciplinary studies of normal aging (Maddox, 1988). There were 410 of these programs in 1985, but the number increased to 692 in 1992 (Peterson, Wendt \& Douglass, 1994). The Duke University Center for the Study of Aging and Human Development was one of the earliest gerontology centers. Its major focus was research, specifically longitudinal studies of normal aging (Maddox, 1988). Since then, like other gerontology programs at large universities, Duke has broadened its programs to include emphases on the biomedical aspects of aging and geriatrics, and more recently to policy issues (Maddox, 1988).

There is a body of literature which gives a historical perspective on specific gerontology/geriatric programs. These programs include University of Oregon Center for Gerontology (Bader, 1988); University of Connecticut Health Center (Lawson, 1986); the Southeast Florida Center on Aging at Florida International University (Rothman, 1989); York College of the City University of New York (Yee \& Barley, 1987); and the University of North Texas, Center for Studies in Aging (Martin, 1991).

\section{Characteristics of gerontology centers}

Gerontology/geriatric programs are most frequently found in largest institutions and in institutions offering graduate level instruction ( $91 \%$ of the campuses have 20,000+) and is least frequently found on small campuses and those offering only an associate or bachelor's degree (less than $65 \%$ of campuses 5,000 and under) (Peterson, Wendt \& Douglass, 1994). Only 52\% of community colleges offer gerontology instruction. Of the historically black colleges and universities which responded to Peterson's 1992 survey, 71\% reported having a gerontology program, which was a 41\% increase from 1985 (Peterson, Wendt \& Douglass, 1994). The number of academic units offering gerontology/geriatric instruction on a particular campus ranges from one to eight. The mean is 1.4 per campus (Peterson, Wendt \& Douglass, 1994). Large 
campuses and those offering doctoral instruction were most likely to report having multiple units involved in gerontology/geriatric instruction (Peterson, et.al. 1994). The term center or institute was used by $34 \%$ of the responding campuses in the 1992 survey (Peterson, Wendt \& Douglass, 1994).

Gerontology programs offer a range of degrees, certifications and other award designations. Peterson's study (1994) showed that $20 \%$ of responding programs offered degrees or majors; $26 \%$ culminated in a certificate, and $54 \%$ resulted in some other designation such as a concentration, emphasis, minor, option, specialization, track, or fellowship. There was a mean of 22.7 students enrolled in each gerontology/geriatric program and 9.17 students graduating from each program the year prior to the 1992 survey (Peterson, Wendt \& Douglass, 1994). Seventy-eight percent of the programs offer their own credit courses. The largest percentage of programs serves bachelors level students (33.4\%), followed by masters (25.1\%), doctorate/post-doctorate (18\%), combined $(13 \%)$, associate $(8 \%)$, and other $(3 \%)$. Literature which describes standards and guidelines for gerontology programs include Rich, Connelly \& Douglass (1980); Johnson, et. al. (1980); Connelly \& Rich (1989); Donahue (1960); Peterson (1984); Peterson \& Bolton (1980); Van Orman (1984); and Ernst, et.al. (1982).

\section{Organizational structure and dimensions of external environment:}

As mentioned, the placement of a center within the university is important to its effectiveness in reaching its goals and the goals of the university. The literature which discusses the placement of gerontology centers and their design with regard to hierarchy includes Bader (1988); Friedsam (1986); Keyser-Jones, (1986); and Peterson (1987); Peterson, Wendt, Douglass (1994). Half (50\%) of the gerontology administrators surveyed in 1992 (Peterson, Wendt \& Douglass, 1994) report to a president, vice president or dean. The title held by gerontology program administrators was most often director (39\%), followed by no title $(23 \%)$, coordinator (20\%), chairperson (13\%) and dean (4\%) (Peterson, Wendt \& 
Douglass, 1994). Only $9 \%$ of responding program administrators in the 1992 survey had the authority to recommend tenure for faculty. This was down from 20\% in 1985.

Peterson, et. al. (1994), measured perception of administrative support of gerontology programs using three measures: 1) centrality of the program to the school's mission, 2) extent to which their program contributed to the prestige of the school, and 3) perception of the level of moral support received from campus administration. The majority of the responding gerontology programs in the study chose middle to middle-high levels of perceived support, showing a perception of moderate support. However, $10-13 \%$ of the respondents perceived lack of support (Peterson, et. al., 1994).

\section{Functions and organizational goals of gerontology centers}

When asked to use a word that best characterizes their programs, directors of gerontology/geriatric programs used these descriptive terms (listed from most mentioned to least mentioned): 1) gerontology, 2) multi-disciplinary, 3) social work, 4) sociology, 5) health, 6) nursing, 7) administration, 8) psychology, 9) medicine, 10) human development, 11) mental health, and 12) research (Peterson, Wendt \& Douglass, 1994). Peterson divides programs into four program orientations: liberal arts, professional, scientific, and a combination of two orientations. Of the responding institutions, $13 \%$ were designated as liberal arts, $27 \%$ professional, $7 \%$ scientific, and $39 \%$ a combination of two orientations.

Based upon an unpublished survey of the literature on gerontology centers by the author of this document (Nichols, 1995), the function of gerontology centers most often mentioned in the literature about gerontology centers is curriculum and instruction (Romaniuk, 1984; Lawson, 1986; Puglisi, 1987; Ashton, 1988; Bolton, 1989; Rothman, 1989; Martin, 1991; Batsche \& Moneson, 1993; Brower \& Yurchuck, 1993; Ewald, 1993; Kroft, 1993; Wendt \& Peterson, 1993a \& b; Ewald, 1993, Newbern, 1994; Clark, 1994; Friedsam, 1995; Greaves, et. al., 1995; Luckie, 1996; Mazzoni, 1997). Two other areas 
related to curriculum and instruction are faculty development (Friedsam, 1986; Keyser-Jones, 1986; Puglisi, 1987; Bolton, 1989; Pullen, 1989; John, et. al., 1992; Wendt \& Peterson, 1993a \& b; Olsen, 1994) and continuing education/professional development (Friedsam, 1986; Keyser-Jones, 1986; Pullen, 1989; Rothman, 1989; Wendt \& Peterson, 1993a \& b). Educational goals of gerontology programs have included 1) growth in formal gerontological education, 2) a reemphasis on the liberal arts, 3) more specialized training with substantive content in nursing, medicine, dentistry, public health, social work and other disciplines (Everhart, et. al., 1996; Johnson \& Rosick, 1997), 4) creation of an international network of gerontological courses with common principles of curriculum design, and 5) development of the next generation of scholars and clinicians ( Maddox, 1988; Mullins, 1988;).

To a lesser degree, gerontology centers are involved in research (Adelman, 1986; Keyser-Jones, 1986; Lawson, 1986; Malone-Beach, 1992; Rothman, 1989), service activities (Bass, 1986; Keyser-Jones, 1986; Lawson, 1986; Rothman, 1989; Malone-Beach, 1992; Rachal, 1996; Camp \& Brookover, 1997). Research at gerontology centers covers a broad range of topics and disciplines including: medicine, biology, psychology, health issues, public policy issues, social relationships in later life, gains and deficits of growing old, workforce issues, ethics, care management, demographics and economics, to name just a few (Maddox, 1988; Mullens, 1988; Fairchild, 1988; Bass \& Caro, 1995).

Other functions of gerontology programs include credentialing (Peterson, 1984 \& 1987, 1998 ; Romaniuk, 1984; Seltzer, 1985; Friedsam, 1986; Johnson, 1995; Euster \& Reaves, 1995) and career development for students (Filinson, 1993; Martin, 1991;Masunagi, et. al., 1998).

\section{Resources and financial factors}

The descriptive literature of gerontology centers discusses resources acquired by these centers. Such resources include faculty and endowed 
positions (Bell, 1986; Phillipose, et. al., 1991; Friedsam, 1986; Wendt \& Peterson, 1993a \& b); funding (Craig, 1981; Rothman, 1989; Simson \& Wilson, 1981); and outside partnerships and cooperative arrangements (Bass, 1986; Malone-Beach, 1992). In Peterson's survey (1994), only 50\% of the responding programs report having a budget to administer, and most of those budgets were modest.

\section{Relationship of gerontology centers to their constituents}

Gerontology is a multi-disciplinary field of study. Important constituents of gerontology centers include members of the academic disciplines upon which they impact. There is a literature on the rationale for maintaining gerontology as a separate discipline vs. inserting gerontology content into existing disciplines and professional schools. This literature includes discussion of the need for certification of programs, the relationship of undergraduate to graduate programs, the need for continuing and community education, and the feasibility of interdisciplinary work. These articles include Fortune \& Rathbone (1981); Thomas \& Ship (1981); Simonson \& Pratt (1982); Coccaro (1983); Callender (1984); Peterson (1984); Romaniuk \& Arling (1984); Teicher \& Corcoran (1984); Friedsam (1986); Mann, et. al. (1987); Puglisi (1987); Wilber \& Zarit (1987); Duthie (1988); Maddox (1988); Netting \& Wilson (1988); Bolton (1989); Cavallaro, ML (1992); Reed (1992); Brower \& Yurchuck (1993); Ewald (1993); Jones \& Rikli (1993); Euster \& Reaves (1995); and Johnson, et. al. (1995); Blumberg, et. al. (1997); Rosin \& Abramowitz (1997).

Another important constituent of gerontology centers is the community outside of the institution which may include state agencies, community agencies, elderly individuals and groups, and businesses. A concern of gerontology centers is whether their graduates are prepared to meet the demands of the job market (Newborn, et.al, 1994; Newborn \& Kennedy, 1994; Reuben \& Beck, 1994; Euster \& Reaves, 1995; Watt \& Meredith, 1995). 


\section{Future of gerontology centers/programs}

Future challenges for gerontology in higher education include addressing the issues of aging which will be faced in the 21 st century: 1) age-related differences between young vs. old, 2) prevention and independence issues, and 3) the balance between the gains and deficits of growing old (Maddox, 1988; Mullens, 1988). Educationally, progress needs to be made toward: 1) maintaining interdisciplinary balance in training programs, 2) developing the next generation of scholars and clinicians, 3) translating research into practice, 4) encouraging the development of disciplines which create a greater awareness of the diversity of social relationships within later life, e.g., anthropological gerontology and corporate gerontology, and 5) creating an international network of gerontological courses with common principles of curriculum design (Mullens, 1988; Maddox, 1988)

\section{Organizational Effectiveness}

Although there is a great deal of literature on organizational effectiveness in sociology, business and management, and higher education literature, there is little agreement on the definition of organizational effectiveness, the criteria of effectiveness, the constituencies to be surveyed, and the methods of assessment. Many scholars have rejected the notion that one universal model of effectiveness can be developed (Cameron \& Whetten, 1983; 1996).

\section{Definitions of effectiveness}

The literature identifies four major approaches to defining organizational effectiveness. These include the goal approach, the systems approach, the process approach, and the ecological or participant satisfaction approach.

The goal approach defines organizational effectiveness as the ability of an organization to achieve its goals. Advocates of the goal approach include Georgopolous \& Tannenbaum, 1957; Etzioni, 1964; Price, 1972; Campbell, 
1977; and Scott, 1977. A problem identified with the goal approach is that organizations may pursue multiple and often contradictory goals (Perrow, 1970; Hall, 1972; Dubin, 1976), and the goals of the organization, which are stated in official documents, may not be the real or operative goals of those working in the organization (Hoy \& Miskel, 1991). The goal approach assumes that decision makers have agreed upon a set of goals, and that there are few enough goals to be administered, defined \& understood by participants (Hoy \& Miskel, 1991). An example of the goal approach is a study (Fjortof \& Smart, 1994) of 332 colleges and universities examining organizational culture and level of consensus about mission on the institution's organization effectiveness.

The system resource model defines effectiveness as the organization's ability to secure an advantageous bargaining position in its environment, and to capitalize on that position to acquire scarce and valued resources (Hoy \& Miskel, 1991). In other words, organizational effectiveness is the ability to acquire resources from its environment. This model was proposed by Yuchtman, \& Seashore, 1967. A problem identified with the system resource approach is that it assumes that organizations are open systems that exploit their environments, and that in effective organizations, the internal operations, including: bureaucratic expectations; informal groups; leadership decisions; communication processes; and individual needs, work together to impact the environment (Hoy \& Miskel, 1991), which is often not the case. In fact, many organizational units within higher education function well with only the resources provided within the system. An example of a study using the system resource model is one by Cameron and Smart (1997) examining the association between financial difficulties of institutions of higher education and their organizational effectiveness which showed that institutions facing downsizing and financial decline can remain effective if negative organizational attributes are not allowed to emerge. Taylor and Massy, 1996 give "vital benchmarks" to help colleges and universities measure organizational effectiveness using a system resource model. 
The process approach equates organizational effectiveness with internal organizational health, efficiency, and procedures (Cameron, 1981a), and is advocated by Argyris (1964), Bennis (1966), Likert (1967), Steers (1977), Pfeffer and Salancik (1977), Beckhard (1969) (organizational development), Bennis (1966) (organizational health), and Nadler and Tushman (1980). In process approach, researchers would look at management style, interpersonal relationships, work procedures, etc. A problem with the process approach is that organizations which are internally quite turbulent can be effective in a number of ways.

The ecological or participant satisfaction model defines organizational effectiveness by the extent to which constituents of the organization are satisfied and their needs and expectations are being met. Theorists who have studied this approach include Connolly, 1980 (constituency satisfaction); Keeley, 1980; Pfeffer \& Salancik, 1978 (strategic constituencies) and Miles \& Cameron, 1982; Zammuto, 1982 (legitimacy). States, one of the important constituents of many universities, have issued educational mandates for measuring institutional effectiveness (Hudgins, 1993).

Integrated models take the position that all four of these models are important in measuring effectiveness, and combine the models. Examples of integrated model approaches are Parsons, 1960; Goodman \& Pennings, 1977; Steers, 1975; Campbell, 1977; Cameron, 1978; 1983. Cameron's integrated model is used in this study.

\section{Domains of organizational effectiveness}

The literature supports the assumption that there are multiple criteria (Campbell, 1977 - 30 categories; Steers, 1975 - 15 categories; Cameron, 1978, 1983 - 9 categories) for organizational effectiveness and that these do not remain constant because: 1) they shift as organizations move through their life cycles (Quinn \& Cameron, 1983); 2) each organization or type of organization requires a unique set of effectiveness criteria (Rice, 1961; Hall, 1972; Scott, 
1977; and Cameron, 1978); 3) effectiveness in one domain may not necessarily relate to effectiveness in another domain (Cameron, 1978); 4) constituent groups prefer different criteria, and institutional culture affects organizational culture (Smart, et. al., 1996). For example, administrators prefer structural or bureaucratic indicators, teachers prefer process standard indicators, and students, taxpayers, and politicians prefer product or outcome and efficiency measures (Hoy \& Miskel, 1981).

Nine criteria or dimensions of effectiveness at institutions of higher education were developed by Cameron, 1978 after asking college and university administrators to select criteria of effectiveness from a list of 130 variables taken from the literature on organizational effectiveness. These dimensions include 1) student educational satisfaction, 2) student academic development, 3)student career development, 4) student personal development, 5) faculty and administrator employment satisfaction, 6) professional development and quality of the faculty, 7) systems openness and community interaction, 8) ability to acquire resources, 9) organizational health - benevolence, vitality and viability in the internal processes and practices. In a study (Cameron (1981b) Cameron empirically identified domains that typify colleges and universities and assessed levels of effectiveness in each of those domains. These four domains include 1) external adaptation, which deals with student career development, system openness, and community interaction; 2) morale, which is concerned with student educational satisfaction, administrator satisfaction, and organizational health; 3) academic orientation, which deals with student academic development, professional development, quality of faculty, and ability to acquire resources; and 4) extracurricular, which deals only with student personal development. These domains have been tested by others on different populations ((Smart \& Hamm, 1993 (community colleges), Lysons, 1993, 1996 and Lysons \& Hatherly, 1992 (colleges in Australia and the United Kingdom) Cameron, et. al., 1994 (non-academic sectors of colleges and universities) and 
Clott, 1995 (academic deans of American Assembly of Collegiate Schools of Business).

\section{Constituencies of organizational effectiveness}

Effectiveness criteria always reflect the values and biases of constituencies or stakeholders (Hoy \& Miskel, 1991). Therefore effectiveness criteria must be drawn from a number of perspectives (Piffner \& Sherwood, 341960; Steers, 1975; Katz \& Kahn, 1978). There is, however, a rationale for tapping into information from the major decision makers and directors of organizations. According to Cameron (1978), the best sources of information about organizational effectiveness are decision makers because they: 1) are the source allocators, 2) are the determiners of organizational policy; 3) explicators of organizational goals; 4 ) are the most likely group to identify the cause and effect relationships within an organization and to specify the preferred hierarchy of outcomes; 5) are the representatives in the bargaining process within an organization; and 6) are among the major users of information about organizational effectiveness (Cameron, 1978).

\section{Measurement of Organizational Effectiveness}

The literature is vague about how to measure organizational effectiveness. Since criteria of effectiveness vary, studies rarely build upon one another. Researchers have had difficulty separating criteria of effectiveness from determinants of effectiveness (Goodman \& Pennings, 1977) and determining the relationships among various effectiveness dimensions (Cameron, 1978).

Organizational effectiveness can be measured by using director observation of organizational behavior, relying on the verbalization of relevant constituencies, and/or using written, formal communication and reports. According to R. Kahn (1977), direct observations of behavior are, in many instances, difficult and expensive and the behaviors that are readily observable 
are seldom the organizational outcomes in which the researchers are interested. Verbalizations can get at more variables of interest to the observers, but they are based on the perspective of the constituent. Formal documents and organizational records are called "objective criteria" (Campbell, 1977) and are viewed by some as inappropriate because effectiveness criteria should always be subjective (Campbell, 1977).

Measuring organizational effectiveness in institutions of higher education has a unique set of problems. When senior faculty members and administrators were asked to rate the importance of a series of goals to their institution, they rated all the goals as important (Gross \& Grambsch, 1968). To avoid this problem, Cameron (1981b) asked respondents from universities and colleges to rate the extent to which their institution is typified by certain characteristics of effective institutions that represent a particular domain.

\section{Criteria for measuring organizational effectiveness in gerontology centers}

Although the literature on centers and institutes does not refer specifically to organizational effectiveness, several authors give suggestions for

"successfulness." The factors for successfulness most commonly mentioned are: administrative support in terms of initiating, coordinating, and planning (Totman, 1976; Stahler \& Tash, 1994); financial support (Totman, 1976; Peterson, et.al, 1991; Ikenberry \& Friedman, 1972; Stahler \& Tash, 1994); leadership and management (Totman, 1976; Peterson, et. al., 1991; Stahler \& Tash, 1994); policies regarding faculty and instructional offerings (Peterson, et. al., 1991; Ikenberry \& Friedman, 1972); associations inside and outside the university (Totman, 1976; Stahler \& Tash, 1994); appropriate placement of the center in the university (Peterson, et. al., 1991; Ikenberry \& Friedman, 1972; Stahler \& Tash, 1994); and a fit between the goals of the center and the goals of the institution (Ikenberry \& Friedman, 1972; Totman, 1976; Stahler \& Tash, 1994). 


\section{CHAPTER 3 \\ METHODS AND PROCEDURES}

\section{A. Design of the Study}

Organizational effectiveness in gerontology centers and institutes in American universities and colleges has not been systematically studied. This exploratory study focuses on characteristics of gerontology institutes and centers at American universities and colleges and organizational effectiveness. It determines characteristics of gerontology institutes and centers that can explain differences in organizational effectiveness. Since this study is exploratory, no hypotheses is offered.

\section{Research Questions}

1. What are the domains of organizational effectiveness of gerontology centers?

2. What are the structural and functional models (i.e., organizational/external environment, strategic emphasis, organizational goal preferences, financial indicators, demographics) which may predict the domain in which a gerontology center will be effective?

3. What are the specific characteristics of gerontology centers that may predict the domain in which a gerontology center will be effective?

\section{Expected Outcomes}

This study results in:

a. Domains of effectiveness of gerontology centers,

b. Gerontology centers identified under each effectiveness domain, 
b. Structural/functional models which may predict domains of organizational effectiveness of gerontology centers,

d. Characteristics of gerontology centers and institutes which can be used to correctly classify centers and institutes into their organizational effectiveness domains.

\section{Instruments}

A two-part survey instrument was used to collect data for this project.
a. Part A (Characteristics of Gerontology Centers)

A survey questionnaire (Appendix II) was designed to collect characteristics of each gerontology center/institute. This questionnaire was sent to directors of gerontology centers and institutes listed in the National Directory of Gerontology and Geriatric Programs. The characteristics of gerontology centers were gathered from literature on institutes and centers and literature on gerontology centers and organized under four factors: 1) organizational structure and external environment, 2) strategy of administrators, 3) organizational goal preferences, and 4) institutional demographics. Items explored under these four factors include:

1. Organizational structure and dimensions of the external environment

a. placement in the institution

b. reporting lines of director

c. perceived permanence/stability

d. adequacy of physical plant

f. faculty and staff relationships to center

2. Strategic emphases of administration

a. leadership style

b. emphasis placed on job functions of director

3. Organizational goal preferences

a. mission (research, instruction, service)

b. activities of center 
C. goals

1. satisfaction (student, faculty/administrator)

2. development (academic, career, personal, professional)

3. collaboration (interdisciplinary, community)

4. resource acquisition

4. Financial indicators

a. source of revenues

b. percentage of revenues from each source

c. expenditures

d. adequacy of revenues and resources

5. Organizational demographics
a. age of institute
b. number of faculty members (permanent and affiliated)
c. type of facility
d. general expenditure
e. amount of sponsored research

\section{b. Part B (Ratings of Organizational Effectiveness)}

Questions from the survey questionnaire used in a study by Kim Cameron (1981) to explore organizational effectiveness of higher education institutions, were adapted for use in this project and are included in Part B of the survey questionnaire (Appendix III). Cameron's questionnaire was designed to focus on organizational effectiveness dimensions of colleges and universities and therefore minor word changes had to be made to adapt it to gerontology centers. The questionnaire asks respondents to rate the extent to which a gerontology center is typified by certain characteristics of effective centers. Part B was sent to the directors of gerontology centers, as well as other administrators and faculty members associated with the center and recommended by the director.

The following is a list of effectiveness factors which were probed in the survey: 
1. Student academic development

a. amount of extra work and study by students

b. level of student academic attainment

c. number students going on to graduate school

d. amount of student academic development

c. emphasis on outside academic activities

2. Professional development and quality of the faculty

a. faculty attendance at professional conferences

b. faculty publications

c. teaching at the cutting edge

3. Ability to acquire resources

a. national reputation of faculty

b. drawing power for local students

c. drawing power for national students

d. drawing power for faculty

e. drawing power for financial resources

f. ability to acquire resources

4. Student educational satisfaction

a. manifested student dissatisfaction

b. received student complains

c. attrition resulting from dissatisfaction

d. school spirit displayed

5. Faculty and administrator employment satisfaction

a. faculty preference for this institution over others

b. administrator preference for this institution over others

c. faculty satisfaction with employment

d. administrator satisfaction with the center

6. Organizational health

a. student/faculty relations

b. intergroup relations 

c. amount of feedback obtained
d. typical communication type
e. presence of cooperative environment
f. flexibility of administration
g. levels of trust
h. amount of conflict and frustration
i. problem solving styles used
j. use of talents and expertise
k. types of supervision and control
I. types of adequacy of recognition and rewards
m. decision making styles
n. amount of power associated with participation
o. equity of treatment and rewards
p. organizational health
q. long-term planning and goal setting
r. intellectual orientation

7. Student career development

a. number of students employed in major field

b. extent to which career goals are met

c. number of career oriented courses

d. number of students obtaining jobs of first choice

e. importance of career education for job attainment

8. System openness and community interaction

a. community service employees

b. professional activities outside of the college

c. emphasis on community relations

d. community programs sponsored

e. adaptiveness to external environment

9. Student personal development

a. opportunities for personal development 

b. non-academic growth
c. emphasis on non-academic activities
d. importance of personal development

\section{Validity}

The question of validity in this study deals with whether or not the domains which emerge from the factor analysis on the organizational effectiveness questionnaire are a meaningful measure of a gerontology center's organizational effectiveness, and if there is a relationship between a center's score in a domain and its effectiveness in that domain. Since this is an exploratory study, and organizational effectiveness in gerontology centers has never been measured, the validity of Cameron's organizational effectiveness measures for gerontology centers, cannot be addressed at this point. However, attempts to validate measures of organizational effectiveness in higher education have been undertaken. In Cameron's first study (1978), he used three steps to validate the criteria of organizational effectiveness which he used, and would use in subsequent studies. He employed both a questionnaire and interviews to gather both subjective and objective data on organizational effectiveness in higher education. His first subjects were four or five top administrators from six colleges in New England. In the interview process, respondents were asked: "What organizational characteristics do effective colleges possess? What is it at this institution that makes a difference in terms of its effectiveness? What would one have to change in order to make this institution more effective? Think of an institution of higher education that you judge to be effective; what is it that makes the institution effective? Of the 130 items generated from the literature, which ones are not relevant to the effectiveness of this school? Of the 130 items, which ones are not measurable or for which are data not available?" On the basis of the data gathered from the interviews, criteria were developed to measure the nine dimensions. A questionnaire was sent asking respondents to rate the extent to which their college possessed certain organizational 
characteristics. Finally, questions were asked designed to obtain objective data from the records of each institution.

Cameron (1986) reported evidence of external validity of the dimensions.

First, six of the nine dimensions were significantly and positively associated with financial health. Second, looking at enrollments over a seven-year period, of the ten institutions having the highest overall effectiveness scores, only one experienced a decline in enrollment; while of the ten schools with the lowest effectiveness scores, seven experienced enrollment declines. Thirdly, institutions ranking high in the Gourman Report (overall academic rating) for 1980, correlated at 0.745 with schools rating high in Cameron's domain of academic effectiveness.

Other studies have tested the discriminant validity of the dimensions of organizational effectiveness in predicting groups of institutions effective within an effectiveness dimension. Cameron's (1981) four groups of colleges and universities were: scholarly, professional technical, prestige turmoil, and undistinguished regional. The Australian study (Lysons, 1993) was successful in predicting four groups of institutions in Australia which strikingly resembled Cameron's types. Another study (Smart and Hamm, 1993) found that scores on the nine effectiveness dimensions could account for differences in the respondents' perceptions of organizational effectiveness across three groups of two-year colleges, controlling for differences in size and the degree of financial difficulty.

\section{Reliability}

A number of studies attempted to determine if the nine domains of effectiveness, which resulted from Cameron's 1978 study of six colleges in New England, would emerge in different populations of higher educational institutions or units. In Cameron's 1981 study of 41 colleges and universities, the same nine dimensions of effectiveness as in the 1978 study emerged with internal consistency reliabilities for each of the dimensions ranging from .83 to .99 . 
Average within-dimension correlations were higher than the outside dimension correlations at the $p<.001$ level for each dimension, indicating that internal consistency and discriminant validity were acceptable. Again in Cameron's 1986 study of 29 colleges and universities, the same nine dimensions emerged from the study. Internal consistency reliabilities ranged from .72 to .92 with a mean coefficient of .82. In 1988, a study by Lysons and Ryder tested the reliability of Cameron's nine original dimensions of organizational effectiveness in a largescale research program involving Australian higher educational institutions. It defined four of Cameron's dimensions discretely: staff satisfaction, student personal development, organizational systems openness, and health. Another test of Cameron's approach was a 1992 study by Lysons and Hatherly. The findings showed that the scales developed by Cameron demonstrated "considerably higher levels of reliability in the U.K. than in Australia" (Lysons and Hatherly, 1992, p.221). This was attributed to stronger cultural traditions between the U.S. and the U.K. than between the U.S. and Australia. In Lysons and Hatherly's study, five of Cameron's nine scales were discretely defined: student career and personal development; staff employment satisfaction; organizational systems openness, and organizational health. Other dimensions were defined: student educational satisfaction; staff development and quality; and ability to acquire resources, although the two latter factors were linked to student academic development. Another study (Smart and Hamm 1993) studied the applicability of Cameron's nine dimensions to two-year institutions. A factor analysis of the effectiveness items was performed to measure the reliability of the nine dimensions which resulted in strong support for the overall dimensionality of Cameron's scales. The only substantial variation was the combined loading of the items on the system openness and community interaction and ability to acquire resources scales on a common factor. Eightysix percent of the items loaded on the proper factor. 
In sum, the professional literature provides strong evidence of both the reliability and the validity of the measures of organizational effectiveness that is used in this study of gerontology centers.

\section{B. Description of the Population}

All gerontology institutes listed as such in the 1992 National Directory of Educational Programs in Gerontology and Geriatrics were selected for inclusion in the study. There were 96 gerontology institutes and centers listed. In addition to completing the questionnaire, each director was asked to supply names of administrators/faculty working for, or associated with, the center, under the following models: 1) central administrator with responsibility for the center, 2) project or program administrators or directors, 3 ) directors of subunits, and 4) faculty members involved in planning and implementing for the center. These individuals were sent and asked to complete Part B of the questionnaire (Appendix II) which probes perceptions of organizational effectiveness.

\section{Scope and Methodology of the Project \\ 1. Procedures}

a. Pilot study

1. Parts $A$ and $B$ were piloted with directors from centers and institutes at West Virginia University. The centers and institutes included in this pilot were:

Robert Dilger, Ph.D.

WVU Institute for Public Affairs

Helen M. Bannan, Ph.D.

Women Studies

Y.V. Reddy, Ph.D.

W.V.U. Concurrent Engineering Research Center

Richard A. Bajura, Ph.D.

National Research Center for Coal and Energy 
Darrell R. Dean, Ph.D.

Harley O. Staggers National Transportation Center

Fred R. Butcher, Ph.D.

Mary Babb Randolph Cancer Center

Andrew Isserman, Ph.D.

Regional Research Institute

Charles C. Blue, Jr.,

Center for Black Culture and Research

Ronald C. Althouse, Ph.D.

W.V.U. Survey Research Center

Emory L. Kemp, Ph.D.

Institute for the History of Technology

and Industrial Archaeology

Stanley J. Kloc, MBA

Small Business Development Center

Minor changes were made to the survey instrument based on the pilot questionnaires. For instance, political science and public administration were added to the list of disciplines of permanent faculty and state legislature was added to the list of choices for the impetus for establishing the center. Advisory committee was added to the list of those who select activities for the center. Two questions were dropped from the survey based on the pilot study because respondents did not answer them and they did not seem to add anything important to the study. They were questions about the need for additional equipment and improved facilities.

b. Questionnaire distribution and collection of data

Parts $A$ and $B$ of the questionnaire were sent to 96 directors of gerontology centers and institutes. After one month, a letter was sent to those directors who had not returned their questionnaires. Phone calls were then made to the directors who had not returned their questionnaires. Through the 
process of retrieving questionnaires, it was discovered that nine of the centers/institutes no longer existed and therefore the list of gerontology centers and institutes was reduced to 87 (Appendix I). Collection of questionnaires proved problematic. Blank questionnaires were returned with comments stating that the survey was too long, it was not relevant to their center, and the director and affiliates did not have time to complete it. After consultation with the chair of the dissertation committee, Part A was shortened by excluding questions which were often not being answered, particularly those that asked for information about the parent institution. Part A was reduced from eight pages to four pages. This effort did help to increase the return. In all, 42 center directors returned questionnaires or $48 \%$.

The study is limited by the low number of returned questionnaires. However, of the centers that responded, $74 \%$ were at large public universities, $9 \%$ were at large private universities, and $17 \%$ were at small private colleges. Similarly, of the centers that did not return their questionnaires (See Table 2), $73 \%$ were at large public universities, $22 \%$ were from large private universities, and $5 \%$ were from small colleges. This group of universities sufficiently parallels the universities that did return the questionnaires in size and type. It is safe to make the assumption that the responses from these gerontology centers would not have been significantly different from those that returned the questionnaires. 


\section{Table 1}

GERONTOLOGY CENTERS THAT RESPONDED TO QUESTIONNAIRE

Andrus Gerontology Center

Brookdale Center on Aging

Buehler Center on Aging

Center on Aging

Center for Policy Research

Center on Aging

Center on Aging

Center on Aging

Center for the Study of Aging

Center on Aging and Aged

Center on Aging

Center on Aging

Center for Aging and Health

Center for Gerontology

Center on Aging

Gerontology Center

Gerontology Center

Gerontology Center

Gerontology Center

Gerontology Center

Gerontology Center

Gerontology Institute

Gerontology Center

Gerontology Center

Gerontology Program

Gerontology Center

Graham \& Jean Stanford Center on Aging

Inst. Life Span Development \& Gerontology

Institute of Aging

Institute for Aging and Environment

Institute of Gerontology

Institute in Gerontology

Institute on Aging

Institute of Gerontology

Institute of Gerontological Studies

Institute of Gerontology

Policy Center and Aging

Pruett Gerontology Center

Rengel Institute

Resource Center on Gerontology

Scripps Gerontology Center

Travelers Center on Aging
University of Southern California

Hunter College

Northeastern University

Univ. of Texas Medical Branch

Syracuse University

University of Hawaii

Univ. of Colorado/Colorado Spr.

University of Kansas Medical Ctr.

University of Vermont

Indiana University

Univ. of Texas Health Sci. Ctr

West Virginia University

University of California, Davis

Virginia Polytechnic Institute

University of lowa

University of Utah

Georgia State University

Rhode Island College

University of Evansville

Boston University

Pennsylvania State University

Univ. of Massachusetts/ Boston

American River College

Univ. of Arkansas/Little Rock

Santa Clara University

West Chester University

University of Nevada, Reno

University of Akron

Temple University

University of Wisconsin

University of Denver

Saint Joseph College

Portland State University

Utica College

West Virginia State College

Univ. of the District of Columbia

Brandeis University

Abilene Christian University

SUNY, Albany

University of North Dakota

Miami University, Ohio

University of Connecticut 


\begin{tabular}{|c|c|}
\hline Arizona Center on Aging & University of Arizona \\
\hline Center on Aging & University of California, Berkley \\
\hline Center on Aging & Ball State University \\
\hline Center for Studies in Aging & University of North Texas \\
\hline Center for the Study on Aging & University of Alabama \\
\hline Center on Aging & University of New Mexico \\
\hline Center for the Study of Aging \& Health & NYU \\
\hline Center on Aging and Health, & Case Western Reserve University \\
\hline Center on Aging & University of New Mexico \\
\hline Center for Gerontological Studies & University of Florida \\
\hline Center for Aging & Kansas State University \\
\hline Center on Aging & University of Kansas Medical Center \\
\hline Center on Aging & Florida International University \\
\hline Center for Gerontology & Brown University \\
\hline Center on Aging & Meharry Medical Center \\
\hline Center for Geriatrics & Emory University \\
\hline \multirow{2}{*}{\multicolumn{2}{|c|}{$\begin{array}{l}\text { Center for Adult Development and Aging Univ. of Miami } \\
\text { Center for Study of Human Development Duke University }\end{array}$}} \\
\hline & \\
\hline Center for Aging & University of Alabama, Birmingham \\
\hline Center for Geriatrics/Gerontology, & Columbia University \\
\hline Center for the Study of Aging & Illinois State University \\
\hline Center on Aging & Long Island University \\
\hline Gerontology Center & University of Georgia \\
\hline Gerontology and Aging Studies & University of Illinois, Urbana \\
\hline Gerontology Program & California State University, Sacramento \\
\hline Gerontology Center & University of Illinois at Chicago \\
\hline Gerontology Center & University of Kansas \\
\hline Institute on Aging & Incarnate Word College \\
\hline Institute on Aging & University of Washington \\
\hline Institute for Health/Policy/Aging & Rutgers University \\
\hline Institute of Gerontology & University of Michigan \\
\hline Institute of Gerontology & Wayne State University \\
\hline Institute of Gerontological Studies & Baylor University \\
\hline Institute of Gerontology & Southeast Missouri State \\
\hline Institute on Aging & Temple \\
\hline Multidisciplinary Center on Aging & SUNY, Buffalo \\
\hline Paul Stricht Center on Aging & Wake Forest \\
\hline Pepper Instit. on Aging \& Public Policy & Florida State Univ. \\
\hline Roybal Institute for Applied Gerontology & California State Univ., LA \\
\hline Suncoast Gerontology Center & Univ. Of South Florida \\
\hline Third Age Center & Fordham University \\
\hline University Center on Aging & San Diego State \\
\hline Urban Center on Aging & University of Louisville \\
\hline enter on Agi & Virginia Commonwealth Univ \\
\hline
\end{tabular}


As questionnaires were returned from directors, Part B was sent to 121 constituents named on the questionnaires or approximately three individuals for each responding institution. These names included directors of subunits, project directors, affiliated faculty, and other administrators in the institution. Some directors did not give names of constituents because they did not want to bother their colleagues or because they were the only staff member involved in the institute or center. If no names were given, the Directory of Gerontology and Geriatric Programs was examined to see if there were any other names listed to whom a questionnaire could be sent. If there were none, a questionnaire was sent to the president, provost, dean at the home institution, or the chair of the department which appeared to be involved in the center or institute. One month later, a letter was sent to delinquent constituents. Seventy-two Part B questionnaires were returned in this part of the study or $59.5 \%$. Overall, the rate of return from both Part A and B of questionnaire was $54.8 \%$.

\section{c. Type of Analysis of Data}

1 Factor analysis was used with data from Part B of the questionnaire to determine domains of effectiveness of gerontology centers.

2. Cronbach Coefficient Alpha Correlations were run on each of the factors to determine if they should remain in the analysis.

3. A median analysis was performed to determine which gerontology centers were effective in each of the domains of organizational effectiveness. Centers whose mean scores on each of the domains were above the median were included in each domain group.

4. Multiple regression analysis was used to determine structural and functional models of institutions of higher education which may predict the domain of effectiveness of gerontology centers. Each of the models was analyzed separately.

5. Regression analysis was used to determine predictor variables for each of the domains of organizational effectiveness. 


\section{CHAPTER 4 \\ DATA ANALYSIS}

\section{A. Introduction to the Findings}

The findings from this study are contained in this chapter. The first section in this chapter discusses the results of the factor analysis which was performed on the ratings of organizational effectiveness or dependent variables (Part B of the questionnaire). Cronbach Coefficient Alpha Correlations were performed on each factor to determine if any factor should be eliminated from further analysis. Each factor or grouping resulting from this analysis is described and named as a domain of organizational effectiveness for gerontology centers. The resulting domains of organizational effectiveness in gerontology centers are used in subsequent analysis in this study.

The second section in this chapter discusses the results of a median analysis which was performed on each factor with each of the centers to determine which gerontology centers were effective under each of the domains of organization effectiveness.

The third section in this chapter discusses the results of a multiple regression analysis performed with groups of independent variables (Part A of the questionnaire) and the domains or organizational effectiveness to determine structural and functional models which may predict organizational effectiveness of gerontology centers.

The fourth section of this chapter discusses the results of a regression analysis performed on all independent variables and the domains of organizational effectiveness to determine predictor variables or characteristics of centers which may predict the domain of organizational effectiveness in which gerontology centers fall.

\section{B. Findings}

\section{Domains of Organizational Effectiveness of Gerontology Centers}

A factor analysis was used with data from Part B of the questionnaire to determine domains of organizational effectiveness in gerontology centers. The 
six factors listed below emerged with at least three variables loading on the factors with correlations of .5 or above. (See Appendix $V$ for the complete factor analysis.)

Factor 1-- Non-Academic and Community Openness - the extent to which the gerontology center emphasizes the personal, non-academic needs of students and is involved in the community.

(Ques 2) provides opportunity for student personal development

(Ques 3) responsive to community needs

(Ques 8) students maintain commitment to center

(Ques 9) alumni show support in activities

(Ques 15) important to student-personal development

(Ques 17) outside activities enhance personal development

(Ques 19) center-community relations

(Ques 21) student development in non-academics

Factor 2--Career Goal Satisfaction - the extent to which the center helps students and faculty prepare for career opportunities.

(Ques 26) graduates who enter jobs related to field

(Ques 27) students enrolled to fill career goals

(Ques 29) students obtain jobs of first choice

(Ques 32) number of administrators opting to leave

(Ques 33) faculty satisfied with employment

Factor 3--Resource Acquisition - the ability of the gernotology center to acquire resources from the external environment, such as good students and faculty and financial support.

(Ques 4) has ability to obtain financial resource

(Ques 5) center can attract leading faculty members

(Ques 6) center can attract leading students

(Ques 8) center can obtain resources 
Factor 4--Organizational Health - the benevolence, vitality, and viability in the internal processes and practices at the institution.

(Ques 44) interdepartmental relations

(Ques 46) equity of treatment and rewards

(Quest 49) type of communication that is typical

(Ques 50) general social environment

(Ques 53) conflicts and friction in the center

(Ques 54) resolution of disagreements or conflicts

(Ques 56) organizational health of the center

(Ques 57) long-term planning and goal setting

Factor 5--Quality Faculty - the extent of professional attainment and development of the faculty and the amount of stimulation toward professional development provided by the center.

(Ques 25) faculty and national reputation

(Ques 38) percentage of faculty publishing a book or article

(Ques 39) faculty teaching at the cutting edge

(Ques 41) faculty engaged in professional development

Factor 6--Student Satisfaction - the degree of satisfaction of students with their experience at the gerontology center.

(Ques 11) large number of students drop out

(Ques 12) aware of student complaints

(Ques 30) students' training helpful for jobs

(Ques 52) general levels of trust among people

Factor 7-- Faculty and Staff Job Satisfaction - the extent to which faculty and staff feel their efforts at the gerontology center is being recognized and rewarded. 
(Ques 47) recognition for good work from supervisors

(Ques 48) information and feedback received

(Ques 51) flexibility of the administration

(Ques 55 ) use of talents by faculty and administrators

Cronbach Coefficient Alpha Correlations were run on each of the seven factors (Appendix VI). All of the Cronbach Coefficient Alphas were above .60 except student satisfaction. Therefore, the domain of student satisfaction was dropped from the analysis.

\section{Gerontology Centers and the Effectiveness Domains}

In order to determine which centers were effective in each of the six domains of organizational effectiveness, median scores for each gerontology center were calculated for each factor. Centers having a mean score of .5 or higher are above the median for that effectiveness domain, and were considered effective in that domain. The results of the median analysis are in Appendix VII and summarized in Table 2. (The numbers next to each domain indicate the number of the gerontology centers in this study which is effective in that domain.) Six gerontology centers did not score above the median on any organizational effectiveness factor; eight scored above the median in only one factor; fourteen scored above the median in two factors; six on three factors; six on four factors; one on five factors and one on six factors (See Table 3). The number of gerontology centers effective in each domain of organizational effectiveness ranged from 12 to 18 (See Table 4).

Among the 42 gerontology centers there were 15 unique combinations of effectiveness domains. The following combinations appeared:

Resource Acquisition/Quality of Faculty/Non-Academic/Career Goal (2)

Faculty and Staff Job Satisfaction/Organizational Health (5)

Quality of Faculty/Non-Academic (2)

Faculty and staff job satisfaction (2) 
Organizational Health (2)

Non-Academic (2)

No center was effective in career goal satisfaction or quality of faculty if they were not also effective in another domain. Also, except for two centers which were only effective in the domain of Faculty and Staff Job Satisfaction, all centers effective in Faculty and Staff Job Satisfaction were also effective in organizational health. More gerontology centers were effective in Non-Academic and Community Openness than in any other domain. 
TABLE 3

GERONTOLOGY CENTERS WHICH ARE EFFECTIVE IN EACH DOMAIN OF ORGANIZATIONAL EFFECTIVENESS

Acquisition of Resources

Quality of Faculty
Centers: $1,4,7,9,12,14,21,29,31,32,33$, $35,37,39,40$

Centers: 4, 9, 10, 17, 21, 26, 28, 29, 30, 31, $37,39,40$

Faculty and staff job satisfaction Centers: 3, 8,16, 17, 19, 23, 24,25, 28, $29,31,32,36,37,40$

Organizational Health

Non-Academic

Career goal satisfaction
Centers: 2, 3, 8, 14, 15, 16, 18, 23, 24, 25, $28,32,33,34,36,37,40$

Centers: 1, 2, 4, 5, 7, 9, 10, 14, 17, 21, 22, $23,26,27,29,32,40,42$

Centers: 4, 5, 7, 9, 10, 15, 21, 23, 29, 31, $35,39,40,42$ 


\section{TABLE 4-EFFECTINENESS DOMANSS OF EACH GERONTOLOGY CENTER}

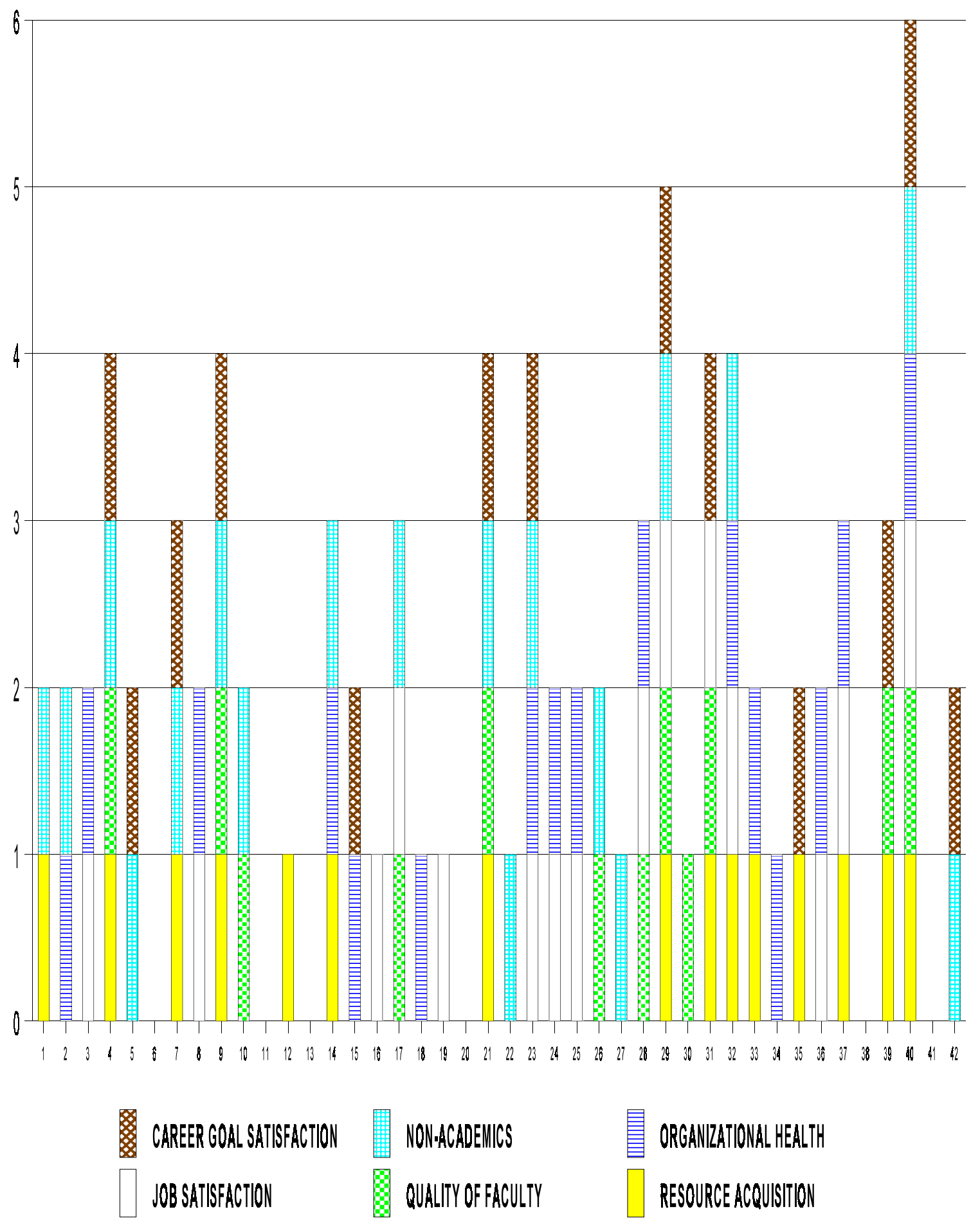


TABLE 5.....NUMBER OF CENTERS EFFECTIVE IN EACH DOMAN

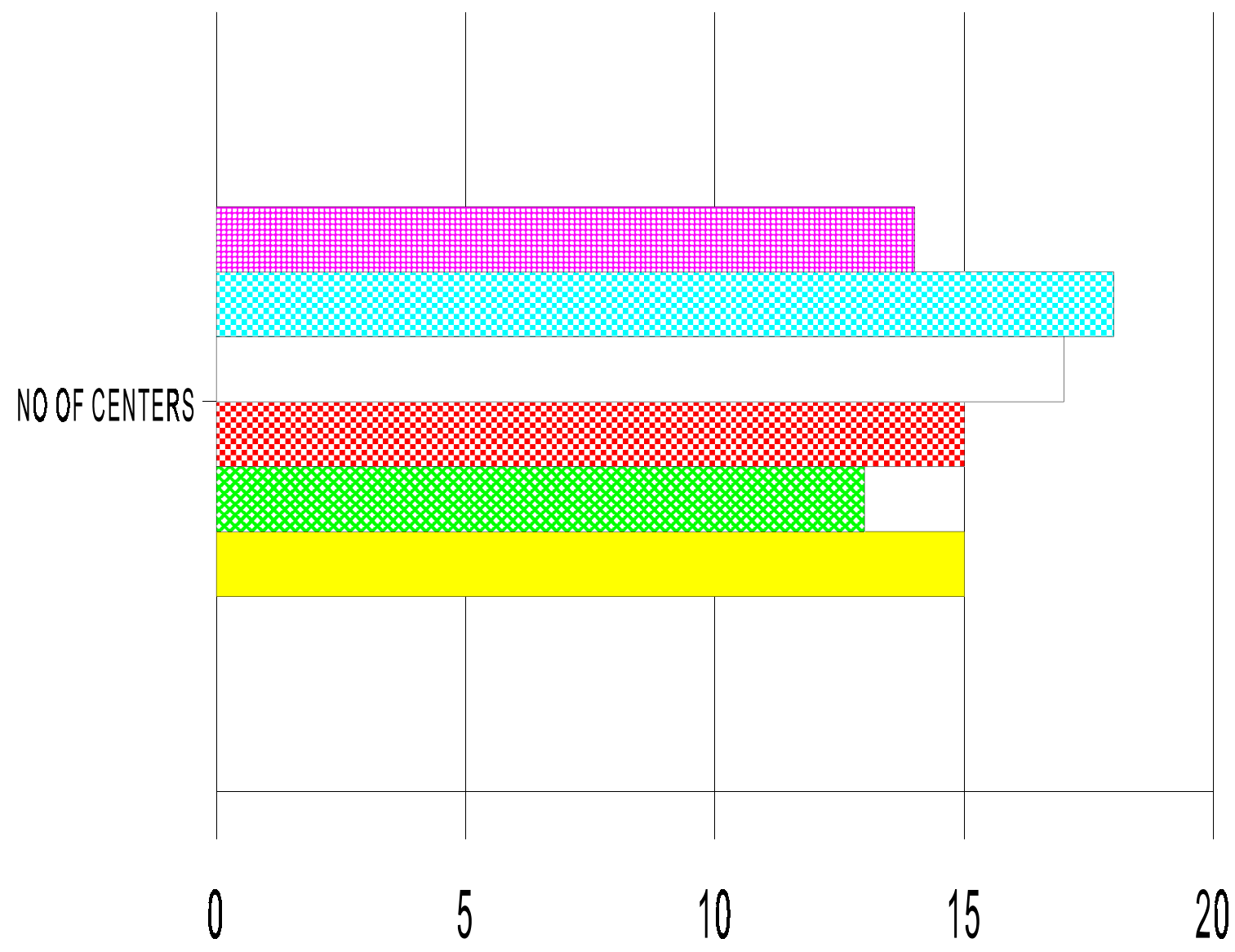

CAREER GOAL SATISFACTION

NON-ACADEMICS AND COMMUNITY OPENNESS

ORGANZZATONAL HEALTH

J JOB SATISFACTION

QUALITY OF FACULTY

ACQUIITIION OF RESOURCES 


\section{Predictive Models}

Multiple regression analysis was used to determine the structural and functional variable models which may predict organizational effectiveness in each of the six domains of organizational effectiveness in gerontology centers. The variables were divided into the following models for analysis:

1. Organizational structure and the dimensions of the external environment

\section{$\underline{\text { Variables }}$}

a) Relationship of the center to other units

b) Likelihood that the center will have permanency in the institution

c) The length of time the center has held its current position in the institution

d) Type of faculty appointments

e) Input of the director into tenure and promotion

f) Whether or not the center has a permanent clerical staff

2. Strategic emphasis of administrators

Variables

a) leadership style

b) emphasis placed on job functions of director

3. Organizational goal preferences

Variables

a) mission (research, instruction, service)

a) activities at the center

b) goals

4. Financial indicators

Variables

a) source of revenues

b) expenditures

c) type of budget line

d) adequacy of revenues and resources 
e) stability of funding

5. Organizational demographics

Variables

a) age of center

b) number of permanent faculty

c) number of affiliated faculty

d) type of facility

e) general revenues

f) research revenues

Predictor models (groups of related variables) which were statistically significant emerged for five of the six domains: Acquisition of Resources, Career Goal Satisfaction, Quality of Faculty, Non-academic Faculty, and Staff Job Satisfaction. There were no predictor models for the organizational health domain. The multiple regression analysis used in this section can be found in Appendices VIII-XV.

TABLE 6

DOMAINS OF ORGANIZATIONAL EFFECTIVENESS AND THEIR PREDICTOR MODELS

Domains Predictor Models

\begin{tabular}{|c|c|}
\hline Acquisition of Resources & $\begin{array}{l}\text { organizational structure. } 0001^{* * * *} \\
\text { financial indicators. } 0001^{* * * *}\end{array}$ \\
\hline Career goal satisfaction & financial indicators $.0504^{* * *}$ \\
\hline Organizational Health & none \\
\hline Quality of Faculty & organizational goals/activities $.0241^{* \star \star *}$ \\
\hline Non-academic & $\begin{array}{l}\text { demographics } .0024^{\star * * *} \\
\text { organizational goals/goals } .0644^{\star \star} \\
\text { organizational goals/mission } .0435^{\star * *}\end{array}$ \\
\hline Faculty and staff job satisfaction & organizational goals/mission $.0649^{\star *}$ \\
\hline
\end{tabular}

${ }^{* * * *}<.03^{* * *} .03-.0599^{* *}>.0599$ 
Table 5 lists the domains of organizational effectiveness with their corresponding predictor variable models. These predictor models may be used to examine the effectiveness of gerontology centers in future studies. Not all of the variables in a model are significant, but the variables together explain a significant portion $\left(R^{2}\right)$ of the difference of responses in the domain from the mean.

Acquisition of Resources may be predicted using the models of organizational structure and financial indicators. The most important variables to the Acquisition of Resources domain in the organizational structure model are "relationship of the center to the subunits" (.0001) (free-standing), "the likelihood that the center will be permanent" (.0001) (for sure), "the length of time the center has been in its current position within the university" (.0249) (less than 5 years), and "the director's input into tenure and promotion" (-.0009) (never) The organizational structure model can explain $81 \%$ of the variance or the reason why the responses on the variables in the Resource Acquisition domain vary from the mean. The most important variables in the financial indicators model to the Resource Acquisition domain are "type of budget" (.0256) (permanent budget line) and "adequacy of funding" (.0043) (strongly agree). The financial indicator model explains $51 \%$ of the variance from the mean. These two models taken together seem to indicate that a center which is effective in resources acquistion will be a relatively new center, secure for the next five years, which is freestanding in the institution and is not strongly affiliated with an academic department so that the director has input into promotion and tenure. It has a fixed budget line and adequate funding.

The predictor model for the Career Goal Satisfaction domain is the financial indicators model. The most important variable to the Career Goal Satisfaction is the funding stability for five year variable (.0064) (strongly agree). Two other variables which are not statistically significant, but which approach significance are "type of budget" (-.1256) (dependent on continuous funding) and "adequacy of funding" (-.0884) (strongly disagree). The financial indicator model 
explains $28 \%$ of the variance. The significance of this model may indicate that a center effective in career goal satisfaction is an "adaptive" center, one that does not provide professional stability, but one which provides a stepping stone to professional growth.

The predictor model for the Quality of Faculty domain is the service activity model which includes five types of service activities in which a gerontology center might be involved. The three significant variables in this domain are "adult education" (-.0397) (no), "continuing education" (.0339) (yes), and "activities with state agencies" (.0114) (no). The service activity model explains $42 \%$ of the variance.

The predictor models for the Non-academic domain are organizational goals (.0644), the mission of the center (.0435), and demographics (.0024). The most important variable in the organizational goals model is the goal of professional development (.0302) (yes) and another variable which approaches significance is acquiring resources (-.0637) (no). This model explains $56 \%$ of the variance. The most important variable in the mission of the center model is the mission of instruction (.0461). Since the parameter estimate is positive, the center effective in the Non-academic domain will most likely not rate instruction high as its mission. This model explains $37 \%$ of the variance. The most important variable in the demographic model are "date of founding" (.0009), which means the center was founded at an earlier date, "type of facility" (-.0072), which means the center may have its own free-standing building, and "total operating budget" (which would probably be large) (.0149). The demographic model explains $80 \%$ of the variance. Centers effective in the Non-academic domain seem to be in many ways the opposite of centers effective in the Resource Acquisition domain, at least in their goals and mission. These centers are older and do not place a lot of importance on acquiring resources (however they have large budgets), their primary mission is not instruction, but they do have professional development a primary goal.

The predictor model for the Faculty and Staff Job Satisfaction is the organizational missions model, and the most significant variable is " mission of 
research" (-.0543), which means that a center effective in the Faculty and Staff Job Satisfaction would most likely chose research as its primary mission. The mission model explains $27 \%$ of the variance.

\section{4. $\quad$ Predictive Variables}

A second regression analysis was performed with all of the independent variables and the effectiveness domains. Significant predictor variables emerged for each domain. Table 4 shows each effectiveness domain with predictor models and variables. Regression analyzes can be found in Appendices XVI$X X I$. The R squares for individual variables are not large, and they explain only a small part of the variance from the mean, but they can be important indications of effectiveness. Further research can combine these variables into models to explain effectiveness in different ways. 
TABLE 6

\section{EFFECTIVENESS DOMAINS AND THEIR PREDICTORS Predictor Variables \\ Domains}

\begin{tabular}{|c|c|}
\hline Acquisition of Resources & 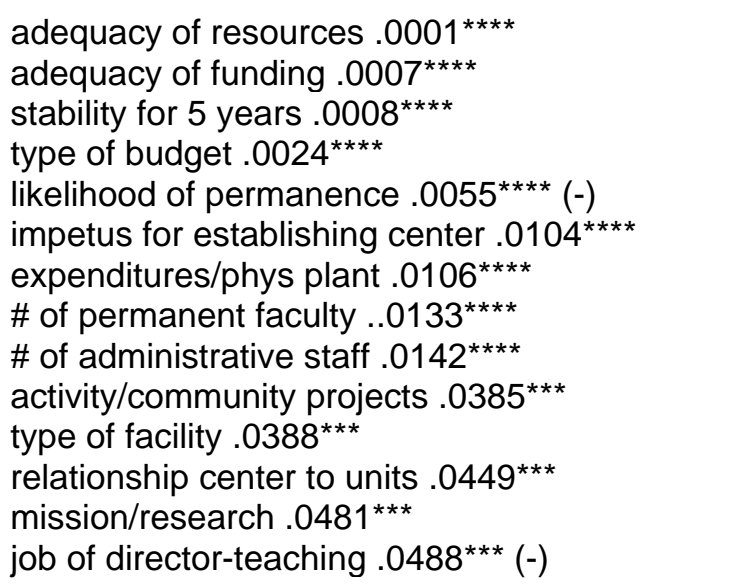 \\
\hline Career goal satisfaction & $\begin{array}{l}\text { likelihood of permanence } .0106^{\star * \star *}(-) \\
\text { job of director-budgeting } .0282^{* * \star *} \\
\text { \# of permanent faculty } .0552^{\star * \star} \\
\text { mission of center vs. institution } .0555^{\star *}\end{array}$ \\
\hline Organizational Health & $\begin{array}{l}\text { adequacy of space } .0192^{* * *} \\
\text { resources faculty use } .0529^{* * *} \\
\% \text { director's time--teaching } .0569^{* * *}\end{array}$ \\
\hline Quality of Faculty & $\begin{array}{l}\text { goal--student satisfaction } .0048^{\star * * *}(-) \\
\text { director's job--fundraising } .0134^{\star * \star *}(-) \\
\text { activities--state agencies } .0202^{* \star * *} \\
\% \text { of director's time--fundraising } .0324^{* \star *} \\
\text { goal--interdisciplinary collaboration } .0342^{\star * *}(-)\end{array}$ \\
\hline Non-academic & 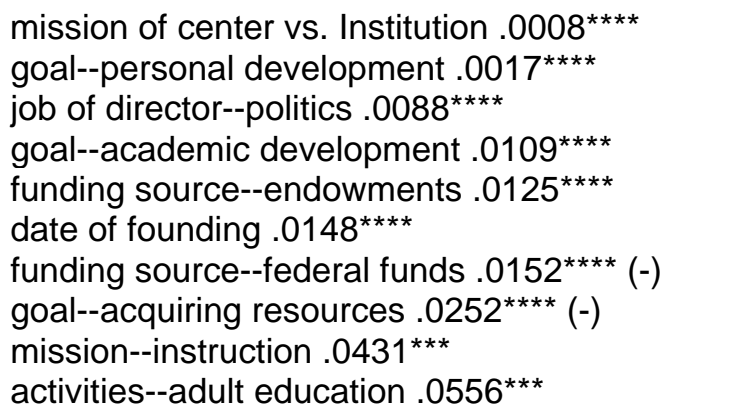 \\
\hline $\begin{array}{l}\text { Faculty and staff job } \\
\text { satisfaction }\end{array}$ & 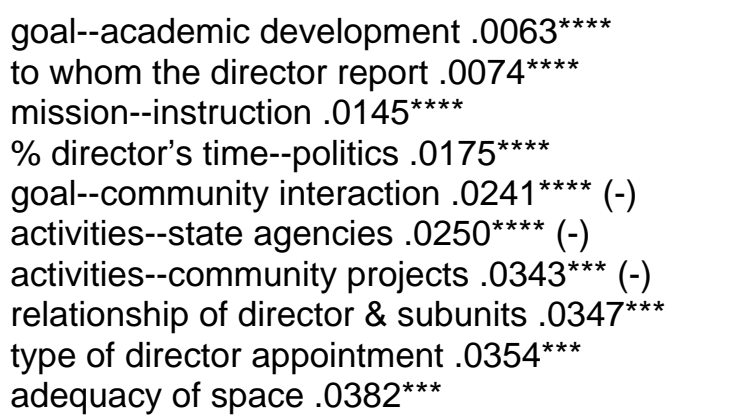 \\
\hline
\end{tabular}

${ }_{\star \star \star \star}<.03 ;{ }^{\star \star \star} .03-.0599 ;(-)$ negative parameter estimate, below the mean 


\section{CHAPTER 5}

\section{CONCLUSIONS AND RECOMMENDATIONS}

\section{A. Statement of the Problem}

Organizational effectiveness in gerontology centers and institutes in American universities and colleges has not been systematically studied. This exploratory study focuses on characteristics of gerontology institutes and centers at American universities and colleges and organizational effectiveness. It determines characteristics of gerontology institutes and centers that can explain differences in organizational effectiveness. Since this study is exploratory, no hypotheses is offered.

\section{B. Research Procedures}

Part A of the survey questionnaire (Appendix II) was designed to collect characteristics of each gerontology center/institute. This questionnaire was sent to directors of 96 gerontology centers and institutes listed in the National Directory of Gerontology and Geriatric Programs. Nine gerontology centers were eliminated because they no longer were in existence, leaving 87 for analysis. The characteristics of gerontology centers were gathered from literature on institutes and centers and literature on gerontology centers and organized under four factors: 1)organizational structure and external environment, 2) strategy of administrators, 3) organizational goal preferences, and 4) institutional demographics.

Part B of the survey questionnaire (Appendix III) was created from questions from the survey questionnaire used in a study by Kim Cameron (1981) to explore organizational effectiveness of higher education institutions, and was adapted for use in this project. Cameron's questionnaire was designed to focus on organizational effectiveness dimensions of colleges and universities and therefore minor word changes had to be made to adapt it to gerontology centers. The questionnaire asks respondents to rate the extent to which a gerontology 
center is typified by certain characteristics of effective centers. Part B was sent to the directors of gerontology centers as well as other administrators and faculty members associated with the center and recommended by the director.

A pilot study was done with interdisciplinary centers at West Virginia University. Adjustments to the questionnaire were made as a result of the pilot study.

Forty-two directors of gerontology centers returned Part A and Part B of the questionnaire (48\%) and $72(59 \%)$ other administrators and faculty members associated with the centers returned Part $B$ of the questionnaire.

The data were analyzed in the following way:

1. Factor analysis was used with data from Part $B$ of the questionnaire to determine domains of effectiveness of gerontology centers.

2. Cronbach Coefficient Alpha Correlations were run on each of the factors to determine if they should remain in the analysis.

3. A median analysis was performed to determine which gerontology centers were effective in each of the domains of organizational effectiveness. Centers whose mean scores on each of the domains were above the median were included in each domain group.

4. Multiple regression analysis was used to determine structural and functional models of institutions of higher education which may predict the domain of effectiveness of a gerontology center. Each of the models was analyzed separately.

5. Regression analysis was used to determine predictor variables for each of the domains of organizational effectiveness.

\section{Research Questions}

1. What are the domains of organizational effectiveness of gerontology centers?

2. What are the structural and functional models (i.e., organizational/external environment, strategic emphasis, 
organizational goal preferences, financial indicators, demographics) which may predict the domain in which a gerontology center will be effective?

3. What are the specific characteristics of gerontology centers that may predict the domain in which a gerontology center will be effective?

\section{Conclusions}

1. What are the domains of organizational effectiveness of gerontology centers?

Using a factor analysis of the ratings of organizational effectiveness in Part $B$ of the questionnaire, this study found six areas or domains of organizational effectiveness for gerontology centers. They are 1) non-academic and community openness, 2) career goal satisfaction, 3) resource acquisition, 4) organizational health, 5) quality of faculty, and 6) faculty and staff job satisfaction.

\section{a. Non-academic and Community Openness}

There were 18 gerontology centers that were found to be effective in this domain. Gerontology centers which are effective in the non-academic" domain excel in three areas: student personal development, alumni affairs, and community relationships. This domain corresponds to Cameron's dimensions of student personal development and systems openness and community interaction, and his domain of external adaptation which deals with student career development, system openness and community interaction. The literature supports the non-academic aspect of gerontology centers and it is the most important factor separating the more recent issue-related centers from earlier centers (1960s and 1970s) which were more research oriented. Gerontology centers are involved with community agencies, businesses, state agencies and elder advocacy groups ( Rueben \& Buck, 1994; Euster \& Reaves, 1995; Watt \& Meredith, 1995).

One recent effort to combine academics with its practical application is called service-learning. Service-learning has begun to make inroads into 
gerontology programs. For example, the Association of Gerontology in Higher Education and Generations Together, University of Pittsburgh offered grants in 1998 to gerontology programs interested in incorporating intergenerational service-learning into existing gerontology classes.

The most recent literature on centers in higher education focuses on the link they play between industry and higher education (Steiner, 1995; Bitting \& Spriggs, 1995). This link represents, for industry, an opportunity to train potential personnel in specific aspects or their operation and to be involved in state-of-the art research, and it gives institutions of higher education, applied settings and new funding opportunities. Gerontology centers can offer to industry innovative ideas in human resources, management and design of facilities for an aging workforce.

\section{b. Career Goal Satisfaction}

There were 14 gerontology centers found to be effective in this domain. Gerontology centers which are effective in the "career goal satisfaction" domain excel in successfully linking students with employment opportunities associated with their course of study and in enhancing the career opportunities of faculty members and administrators. Students often take gerontology courses to enhance their major and to make themselves more employable in their field. The career goal satisfaction domain, as it pertains to faculty and staff, may be an indication that gerontology centers are adaptive institutes as described by Norman (1971) because they are springboards to better academic careers. That is, as with adaptive institutes, gerontology centers were generally created in response to funding initiatives, are continually undergoing change; are redefining goals, are securing and releasing staff, and are initiating and terminating projects. Gerontology centers, like other adaptive centers and institutes in higher education, may be "jumping grounds" to higher positions in academia and administration. Therefore, a gerontology center which is able to enhance the career opportunities of its students and staff will be considered to be effective in the career goal satisfaction domain. 


\section{b. Resource Acquisition}

There were 16 gerontology centers found to be effective in this domain. Gerontology centers which are effective in the "resource acquisition" domain have the ability to obtain financial resources, can attract a leading faculty and students, and can obtain other needed resources. Cameron (1981b) included resource acquisition under the academic domain because acquiring resources, both financial and academic, is essential to providing a successful academic program. Gerontology centers are funded, to a large extent, with external funds, and their programs reflect the type of funding they receive, whether they are programmatic or research programs.

In Peterson's study (1994) only 50\% of the responding programs had a budget to administer and most of the budgets were modest. This study found a larger range of total operating budgets. Of the responding institutions, $8 \%$ had no funding, $22 \%$ had funding under $\$ 10,000$ a year, and $32 \%$ had a budget under $\$ 100,000$. The median was $\$ 175,000$ and the highest total operating budget was $\$ 2,700,000$. The range of the total operating budgets of the 15 gerontology centers which were found to be effective in resource acquisition in this study was $\$ 10,000$ a year to $\$ 2,700,000$. The median was $\$ 550,000$ and the average operating budget was $\$ 864,467$. It seems that most of the gerontology centers which scored high in resource acquisition were centers that were able to accrue large operating budgets, most likely from research grants.

\section{d. Organizational Health}

There were 17 gerontology centers found to be effective in this domain. A gerontology center which is effective in the "organizational health" domain is one in which members are able to work and plan across disciplines without friction and in which its members are rewarded equitably. In these centers, communication is open and authentic and the general social environment is cooperative, supportive and mutual, and disagreements are resolved face to face. The organization runs smoothly and the atmosphere is goal-directed. Since 
centers are more fluid and less secure than academic departments, faculty members who come to work there do so for reasons other an opportunity to rise within their discipline. Effectiveness in organizational health is important for gerontology centers, as well as other interdisciplinary centers, who for the most part, must attract faculty members away from academic departments or at least entice them to spend some of their teaching and research time at the center, often on a pro bono basis. This domain corresponds most closely to Cameron's morale domain in which he includes student and staff satisfaction and organizational health.

\section{e. Quality of Faculty}

There were 13 gerontology centers found to be effective in this domain. Gerontology centers which are effective in the "quality of faculty" domain have faculty members with national reputations, are publishing books or articles, are teaching at "the cutting edge" and are engaged in professional development activities. For most of the history of gerontology centers, faculty members have come to the centers from a variety of academic disciplines (e.g., sociology, psychology, political science, biology, medicine, nursing, social work, public administration) because there were no doctoral programs in gerontology. Today there are four Ph.D. programs in gerontology and gerontology centers are beginning to recruit from these programs. Still gerontology centers are for the most part, dependent on finding professors from other disciplines who are interested in teaching and doing research in gerontology. The Gerontological Society of America, the National Society of Aging and the Association for Gerontology in Higher Education are three organizations which give faculty members in gerontology a forum for presenting research.

\section{f. Faculty and Staff Job Satisfaction}

There were 15 gerontology centers found to be effective in this domain. 
A gerontology center which is effective in the "faculty and staff job satisfaction" domain is one in which good work is rewarded, employees feel informed about what is going on, faculty talents and expertise are used to the maximum, there is opportunity for development, and the administration is willing to change, adapt and move forward progressively. These faculty and staff job satisfaction characteristics found at gerontology centers are often lacking in academic departments. Interdisciplinary centers are able to move in directions not available to academic departments which must adhere to disciplinary standards. Faculty members who are not recognized for good work within their departments may have the opportunity to contribute a great deal in an interdisciplinary setting.

This study shows that gerontology centers are typified by unique patterns of organizational effectiveness and that the patterns represent effectiveness in both internal and external effectiveness. Internal effectiveness refers to effectiveness in internal procedures and operations such as bureaucratic expectations, informal groups, leadership decisions, communication processes, and individual needs. External effectiveness refers to effectiveness in the way the center deals with entities or relationships outside of the center such as other units at the university, associated faculty, and federal, state and community groups. Among the 42 gerontology centers in this study, there were 24 unique patterns of effectiveness across the six domains, including patterns in the internal domains only, the external domains only, and a mixture of the external and internal domains. The internal domains include "career goal satisfaction," "organizational health, and faculty and staff job satisfaction." The external domains include "resource acquisition," "quality of faculty and professional development," and "non-academic and community openness."

Several of the gerontology centers stood out in the number of domains in which they were effective. One institution was effective in six of the domains, one in five, and six in four domains. Among those centers that were highly effective were: Brandeis University, Penn State University, the University of Utah, Virginia Tech, the Scripps Center at the University of Miami, American River College, 
Boston University, and Utica College. The fact that a number of these are and have been leaders in gerontological education, is verification of the findings of this study.

\section{What are the structural and functional characteristics of} centers which may predict the domain in which a gerontology center will be effective?

Multiple regression analysis was used to determine which structural and functional characteristics can be used to predict the domain of effectiveness in which a gerontology center will be effective. The predictive variables were analyzed in models of structure and function and were analyzed separately. The structural and functional models which were analyzed in this study include:

- organizational/external environment

- $\quad$ strategic emphasis

- $\quad$ organizational goal preferences (goals, mission, activities)

- financial indicators

- $\quad$ organizational demographics

a. Organizational structure and the dimensions of the external environment

The predictive variables in this category include:

- $\quad$ relationship of the center to other units

- likelihood that the center will have permanency in the institution

- the length of time the center has held its current position in the institution

- $\quad$ type of faculty appointments

- input of the director into tenure and promotion

- $\quad$ whether or not the center has a permanent clerical staff

- $\quad$ strategic emphasis of administrators

- $\quad$ leadership style 
- $\quad$ emphasis placed on job functions of director

When all of these predictive variables were included in the model, there was no significant regression with any of the domains, but when strategic emphasis of administrators, leadership style, and emphasis placed on job functions of director were dropped from the model there was a significant regression (.0001, $\mathrm{R}^{2}=.8155$, Adj $\left.\mathrm{R}^{2}=.7540\right)$ between the domain of resource acquisition and organizational structure and the dimensions of the external environment. There were four significant variables in this model:

- $\quad$ relationship of the center to other units

- likelihood that the center would remain permanent

- the length of time the center had the same position within the university

- input of the director into tenure and promotion

The parameter estimate for "relationship of the center to other units" was negative ( 1 =free standing; $2=$ affiliated, but separate from the university; $3=$ within a college; $4=$ within a department; $5=$ subunits of a center), indicating that a center was more effective in resource acquisition the more independent it was from the institution.

The parameter estimate for "likelihood of the center being permanent ( $1=$ not likely; $5=$ for sure) was positive, indicating that the center would be more effective in the domain of resource acquisition if it was likely that the center would remain in the institution.

The parameter estimate for "length of time the center has had the same position in the institution" was positive (1=less than 5 years; $4=$ since its establishment), indicating that a center would be more effective in resource acquisition if it had maintained the same position for a longer period of time.

Finally, the parameter estimate for "input of the director into promotion and tenure" was negative (never $=1$; sometimes $=2$; always $=3$ ), indicating that for centers who are effective in resource acquisition, their directors do not have input 
into promotion and tenure. This further supports the likelihood that the center will be free standing or affiliated but not a part of the institution.

\section{b. Financial Indicators}

The predictive variables for the Financial Indicators category include:

- $\quad$ type of budget line

- $\quad$ adequacy of funding

- $\quad$ stability of funding for five years

There was a significant regression $\left(.0001, \mathrm{R}^{2}=.5080\right.$, Adj. $\left.\mathrm{R}^{2}=.4646\right)$ between the domain of resource acquisition and financial indicators. One of the variables which was significant within this model was: "type of budget" ( $1=$ permanent; $2=$ =renewable by funding source; $3=$ dependent on host; $4=0$ other). The parameter estimate was positive, indicating that a center which is effective in resource acquisition is more apt to be dependent on some non-permanent source of revenue.

The other variable within this model which was significant was "adequacy of funding" for which the parameter estimate was positive, indicating that a center which is effective in resource acquisition will have adequate funding.

There was also a significant regression between the domain of career goal satisfaction and financial indicators. The significant variables in the model were "type of budget" (permanent/institutional=1; reviewed by funding source=2; host unit=3; other=4), and "adequacy of funding" (strongly agree=1; strongly disagree $=5$ ). Both variables had positive parameter estimates indicating that as a center moves away from permanent, institutional funding toward some other form of funding, and as its constituencies view it as not having adequate funding, it becomes more effective in career goal satisfaction. This finding my indicate that centers that are not effective in career goal satisfaction are less stable financially and therfore faculty stay there only to meet career goals.

\section{b. Organizational Goal Preferences}

This category was divided for analysis into three parts: goals, mission, and activities. 
Goals

- $\quad$ student satisfaction

- $\quad$ academic development of students

- $\quad$ personal development of students

- faculty/staff satisfaction

- $\quad$ professional development of faculty and staff

- community interaction

- $\quad$ acquiring resources

There was a regression that approached significance with the goals of gerontology centers and the domain of non-academics $\left(.0644, \mathrm{R}^{2}=5606\right.$, Adj $R^{2}=3408$ ). The significant variable within the model was "the goal of professional development of faculty and staff" (.0302) and a near significant variable (.0637) "the goal of acquiring resources." The professional development goal had a positive parameter estimate indicating that if a center was effective in the nonacademic domain, it would rank professional development of faculty and staff high on its list of goals. However, the parameter estimate of the "acquiring resource" variable was negative, indicating that centers effective in nonacademics and community involvement would not rank acquiring resources high on a list of goals.

Mission

- $\quad$ instruction

- $\quad$ service

- research

There was a significant regression between the non-academic domain and the mission of the gerontology center $\left(.0435, \mathrm{R}^{2}=.0435\right.$, Adj $\left.\mathrm{R}^{2}=.2610\right)$. The significant variable in this model is "the mission of instruction" and the parameter estimate is positive, indicating that a center which is effective in non-academics and community involvement will rank instruction high on its list of missions

There was also a near significant regression between the domain of faculty and staff job satisfaction and the mission of the gerontology center (.0649, 
$\mathrm{R}^{2}=.2651$, Adj $\left.\mathrm{R}^{2}=.1692\right)$. The significant variable in this model is the director's job function of research (.0543) and the parameter estimate is negative, indicating that if a center is effective in faculty and staff job satisfaction, the director will not rank research high on his/her list of job functions.

Activities

- $\quad$ adult education

- continuing education

- $\quad$ activities with state agencies

There was a significant regression between activities of gerontology centers and the domain of quality of faculty $\left(.0241, \mathrm{R}^{2}=.4245\right.$, Adj $\left.\mathrm{R}^{2}=.2937\right)$. There were three significant variables: "adult education," "continuing education," and "activities with state agencies." Continuing education and activities with state agencies had positive parameter estimates, indicating that centers which are effective in the "quality of faculty" domain will rank continuing education and activities with state agencies high on their list of activities. However the parameter estimates with "adult education" were negative, indicating that the same centers would rank adult education low on their list of activities.

c. Organization Demographics

- date of founding

- $\quad$ type of faculty

- $\quad$ total operating budget

There was a significant regression with the domain of Non-Academics and Community Involvement and the demographics of the gerontology centers (.0024, $\mathrm{R}^{2}=.7994$, Adj. $\mathrm{R}^{2}=6900$ ). The significant variables in this model were: "date of founding," "type of facility," and "total operating budget." The variables of date of founding and the total operating budget, had positive parameter estimates and therefore indicated that centers who were effective in non-academics and community involvement were founded more recently and had a large operating budget. These results agree with the literature on centers which indicates that earlier centers emphasize research, while centers created recently emphasize 
activities outside the academic institution, such as alliances with industry and state organizations.

\section{What are the specific characteristics of gerontology centers that} may predict the domain in which a gerontology center will be effective?

Single regressions were done with each domain of organizational effectiveness and each of the predictor variables found in Part A of the survey. These variables with their corresponding domains and predictor variables are listed in Table 6

\section{a. Acquisition of Resources}

Predictor variables for the domain of "acquisition of resources" are ones which deal with the adequacy of resources and funding, stability and permanence of the center, size of the center measured in the number of faculty and administrative staff, the independence of the center as measured by the type of facility and the relationship of the center to other units, the mission of research and the percentage of the director's time not spent on teaching.

\section{b. Career Goal Satisfaction}

Predictor variables for the "career goal satisfaction" domain are ones that deal with the likelihood of the center's permanence (not permanent), the percentage of the director's job spent in budgeting activities, the number of faculty, and the synergy between the mission of the center and the mission of the institution.

\section{c. Organizational Health}

Predictor variables for the "organizational health" variable include the adequacy of the physical space of the center, the ability of faculty to use the resources of the center for their education and research pursuits, and the percentage of time the director spends teaching.

\section{d. Quality of Faculty}


Predictor variables for the "quality of faculty" domain include the goal of student satisfaction not being a top priority and the director not wanting to make fundraising a priority but finding s/he has to do a lot of fundraising.

\section{e. Non-academic and Community Openness}

Predictor variable for the "non-academic and community openness" domain include goals of personal and academic development, but not a goal of acquiring resources, funding from endowments, not from federal funds, a mission of instruction, synergy between the goals of the center and the goals of the institution, involvement in adult education activities, and a less recent date of founding of the center.

This study showed gerontology centers typified by success in one effectiveness domain may have different organizational characteristics than gerontology centers with success in another organizational effectiveness domain. Using each of the predictor models and individual variables or organizational characteristics, it is possible to describe a gerontology center which is likely to be effective in each of the domains. It should be noted that some of the characteristics that relate to overall effectiveness in each domain seem contradictory or incompatible with each other making it difficult at best and at worst inappropriate to construct organizational models. The following vignettes are attempts to describe a gerontology center that is effective in each of the domains based on the significant variables.

\section{Acquisition of Resources}

A gerontology center that is effective in the domain of acquisition of resources is one which began, not by the impetus of faculty members, but by the impetus of forces outside of an academic unit, either from central administration or from the state. These centers tend to be free standing and occupy their own facility. The center is perceived by its constituency to have adequate funding and resources and to be stable within the institution; that is, constituents believe it is likely to continue to exist for at least the next five years. The center's operating budget comes from nonpermanent, non-institutional sources. Resources include 
a large group of permanent faculty members associated with the center and a large administrative staff. These gerontology centers are governed from the top down; administrators, not committees decide on the activities of the center. The director does not see him/herself as a teacher. The center also has a service component.

\section{Career Goal Satisfaction}

Gerontology centers which are effective in the domain of career goal satisfaction are centers which are not perceived by their constituents as having permanence within the institution. However, they do have a large number of permanent faculty members associated with, but not permanently employed at, the center. The director sees a large portion of his/her job as budgeting. The unstable character of these centers seems to be what enables them to enhance the careers of faculty, administrators, and students because individuals are able to use the resources of the center (research projects, networks, facilities) for their personal projects and then move on in their careers.

\section{Organizational Health}

Gerontology centers which are effective in the domain of organizational health are centers have adequate space and resources for faculty associates to use for their gerontology pursuits, rather than having to use space and resources in their own academic departments. The directors of these centers spend a large portion of their time teaching.

\section{Quality of Faculty}

Gerontology centers which are able to attract quality faculty members are centers that have the mission of research and do not rank student satisfaction or interdisciplinary collaboration high on their list of goals. The directors of these centers do not see their job as being a fund raiser, but they do spend a large portion of their time fund raising.

\section{Non-Academic and Community Openness}

These gerontology centers were founded earlier than other centers and therefore are probably better established in the institution. They have low 
federal funding and high funding from endowments. They spend little of their budget on research and acquiring resources is low on their list of goals. The top mission of these centers is instruction and a major activity is adult education. High on their list of goal priorities are personal development of the director and academic development.

\section{Faculty and Staff Job Satisfaction}

Gerontology centers which are effective in faculty and staff job satisfaction are centers that are independent of academic departments and report to a provost rather than to an academic dean or chairperson. The director has direct supervision over the subunits of the center. However, the director is likely to have a tenured appointment from an academic department. There is adequate space in the center's facility for faculty to do their work. The directors of these centers spend a lot of time in political activities. The number one mission of these centers is instruction and an important goal of these centers is academic development. Community interaction does not rank high on a list of goals and these centers tend not to be involved in activities with the community or with state agencies.

\section{Implications}

\section{Implications}

This study has implications for:

a. Identifying the type of evaluative methodology that should be used to study effectiveness of centers in higher education.

This study supports the assumption that organizational effectiveness in gerontology centers is multi-domain construct and should be evaluated using a integrated approach. The use of only one model to measure effectiveness would limit the evaluation and create the possibility of missing important factors. By using an integrated approach, this study identified six domains of effectiveness of gerontology centers in 24 different patterns. Each of the four major approaches to effectiveness evaluation are satisfied by at least one of the domains of 
effectiveness found in this study: the goal approach would have identified effectiveness in the "quality of faculty" domain; the systems approach would have identified effectiveness in the "resource acquisition" domain; the process approach would have identified effectiveness in the "organizational health" domain, "faculty and staff job satisfaction" domain, and the "career goal satisfaction" domain; and the ecological or participant satisfaction approach would have identified centers effective in the "non-academic and community openness" domain, the "faculty and staff job satisfaction" domain, and the career goal satisfaction" domain. If we had taken a single approach to studying effectiveness in gerontology centers, for instance, the goal approach, we might have concluded that the center was effective in attracting quality faculty, but would have missed that the center was also effective in the "non-academic and community openness" and the "faculty and staff job satisfaction" domains. Similarly, if we had taken a systems approach, and effectiveness was measured only on the basis of the center's ability to acquire resources, centers effective in the "organizational health" and "career goal satisfaction" domains would not have been identified.

b. Studying the evolution of centers in higher education.

Demographic information, specifically the date of founding, was helpful in predicting effectiveness of gerontology centers in the "non-academic and community openness" domain, a finding that supports studies that have found that the new breed of social science, issue-related centers, founded in the 1970s and later, are more apt to be involved in activities outside the university with industry and community groups then are centers which were founded earlier.

Recent literature indicates that academic research centers have been looked upon as vital links between industry and higher education (Steiner, 1995; Bitting, \& Spriggs, 1995). In addition, federal and state government initiatives have been sponsoring research that is based upon "real world" problems and are encouraging industry-academic collaboration. This study confirms that the more recent a center has been founded, the more likely it is that it is connecting with 
industry and community groups in research, technology transfer, education and evaluation.

c. Understanding the similarities and dissimilarities between centers and other units in higher education.

This study showed that centers in higher education combine characteristics of academic and administrative units. This is illustrated by the fact that the six domains found in this study correspond to, but are not identical to, the dimensions or domains found in Cameron's studies of organizational effectiveness in institutions of higher education (Cameron, 1978 \& 1981b) and those found in other studies of organizational effectiveness in higher education that reproduced Cameron's study in other countries and with non-academic, administrative units. Using an integrated approach in his 1981 study, Cameron identified four domains of organizational effectiveness including external adaptation, which deals with student career development, system openness, and community interaction; morale, which is concerned with student educational satisfaction, administrator satisfaction, and organizational health; academic orientation, which deals with student academic development, professional development, quality of faculty, and ability to acquire resources; and extracurricular, which deals with student personal development. This study identified six domains of organizational effectiveness, including the quality of faculty and resource acquisition domains that correspond with the academic orientation domain; faculty and staff job satisfaction and career goal satisfaction domains, which correspond to the morale domain; organizational health and non-academic and community involvement domains which correspond to the external adaptation domain.

In addition, Cameron and other scholars of organizational effectiveness have noted that in most cases, a higher education institution will be effective in either internal or external domains, but not both. This study shows that gerontology centers can be effective in both internal and external domains. Perhaps successful involvement in internal and external areas is one way in which centers differ from other units in higher education. Although seven centers 
in this study had an effectiveness pattern that represented only external effectiveness and nine centers had effectiveness patterns that included internal effectiveness domains only, nineteen centers had domain patterns which contained both external and internal effectiveness domains. For the most part, organizational structure and financial indicators predicted organizational effectiveness in the internal domains: "acquisition of resources," "career goal satisfaction," and "organizational health." Organizational goals, activities, and mission and demographics predict the external domains: "quality of faculty," and "non-academic and community involvement." An exception to this pattern is that organizational goals, activities, and mission predict "faculty and staff job satisfaction", an internal domain.

Centers are fluid organizations that have the potential to meet the changing needs of universities in ways that academic departments can not. It is important to understanding the place of centers within the institution and their relationship with community, state, and national organizations.

d. Understanding the role of negative organizational characteristics in organizational effectiveness.

Most evaluations of organizational effectiveness look at positive outcomes and determinants of success. This study illustrates that such an approach might miss important areas of effectiveness because the characteristics of centers which predict effectiveness in a domain are not necessarily positive characteristics. It seems that at times unstableness and uncertainty breed positive results. For instance, this study found that financial indicators can be used to predict effectiveness in both acquisition of resources and career goal satisfaction. However, effectiveness in the acquisition of resources domain is predicted with positive financial indicators, while career goal satisfaction is predicted with negative financial indicators. Centers that are effective in acquisition of resources have adequate funding and a permanent budget line while centers that are effective in career goal satisfaction do not have adequate funding and are dependent on their host organizations to continue their funding. 
What is it about financial instability that aids a center in being effective in career goal satisfaction? Is it unstableness that gives professionals permission to stay only as long as they need to enhance their own careers through research, directorship, or an entrepreneurial pursuit and then leave? This is a question for future study.

This study also illustrates the fact that if we measure effectiveness by assessing a center's ability to reach its goals, but don't examine why a center chooses or does not choose a particular goal, we may miss the importance of not selecting a particular goal in determining a center's effectiveness. For instance, gerontology centers which are effective in the "non-academic" domain are centers that do not place the goal of acquiring resources high on their list of goals. Why? Perhaps it is because they tend to be older centers with high operating budgets, funded by endowments rather than renewable grants, more established in the institution, and free to pursue non-academic, community activities, without the pressure of bringing in outside funds.

\section{E. Recommendations}

\section{Recommendations for Further Studies}

Further studies should be designed to answer the following questions:

a. Which domains of organizational effectiveness are unique to centers in higher education?

This study looked at the domains of organizational effectiveness of gerontology centers. There are many other types of centers at academic institutions ranging from social science/issue related centers such as women's studies, African American studies, and American studies to business related centers, health science centers, and high technology centers. Further research should look at other types of centers to determine if the domains identified in this study can be extended to the population of centers in higher education.

b. Can gerontology centers be divided into groups of centers that differ significantly with regard to the domains of 
effectiveness in which they excel?

In Cameron's research into organizational effectiveness of institutions of higher education, he used discriminant analysis to divide institutions into four types (scholarly-high morale, scholarly-medium morale, externally oriented, mediocre) that differed significantly in the domains of effectiveness in which they excel. This procedure was beyond the scope and expertise of this study, but organizational groups of gerontology centers, and other types of centers, might be pursued by other researchers.

c. Can centers be effective in both internal and external domains?

According to a hypothesis presented by Dubin (1976) organizations will be effective in either internal domains or external domains, but not both. Cameron's research (1981b) supports this hypothesis. However, this study of gerontology centers cannot confirm this hypothesis. Instead, it appears that most gerontology centers excel in both internal and external domains. The number one domain for gerontology centers is "non-academic and community openness" (external) and the number two domain is "organizational health" (internal). Further research is required to see if this might be a characteristic of centers which distinguished them from other university units.

\section{Recommendations for Gerontology Centers}

a. Centers that wish to increase their effectiveness in organizational health and faculty and staff satisfaction should concentrate their efforts on activities which focus internally rather than out into the community. Teaching (rather than research or service) seems to be the activity and mission of choice.

Centers which are effective in organizational health and faculty and staff satisfaction have one characteristic in common - they are not involved in activities with state agencies and do not place community interaction high on their 
list of goals. It seems that focusing internally, preferably on teaching, is the key to a good work environment at gerontology centers.

b. Centers that wish to increase their effectiveness in acquiring resources and attracting quality faculty members, should emphasize research as a mission of their center.

Centers which are effective in acquiring resources, including quality faculties, are centers which have research as their number one mission and which spend a large portion of their budget on research. This seems like a circular effect; quality faculty members do research and attract research dollars. However, changing a center's focus from instruction or service to research could increase revenues which could then fund additional instruction and service.

\section{c. Centers that wish to increase their effectiveness in}

- $\quad$ acquiring a quality faculty and enhancing the career goals of both faculty and staff might consider implementing a looser form of administration which includes nominal supervision by the director.

Centers which scored high on the domains of Quality Faculty and Career goal satisfaction were centers which were less structured organizationally and which had directors which did not employ a top-down administrative style. Faculty members, who tend to be independent, seem to prefer an environment where they are free to pursue their own interests without interference from administration. 


\section{BIBLIOGRAPHY}

Abbott, M. (1965) Hierarchical impediments to innovation in educational organizations. In Change Perspectives in Educational Administration. M.

Abbot \& J. Lovell (Eds.). Auburn, AL: Auburn University, 40-53.

Adelman, R. C. (1986). The dilemma of research training in gerontology. Educational Gerontology, 12(6), 579-584.

Ashton, S. J., et. al. (1988, Fall). Optometric gerontology: State of the art in schools and colleges of optometry. Jn. of Optometric Education, 14(1), 812.

Bader, J. E., et. al. (1988). The first 20 years of the University of Oregon Center for Gerontology. Educational Gerontology, 14(6), 471-480.

Bass, S. A. \& Caro, F. G. (1995, July-August). Older people as researchers: Benefits to research and the community. Educational Gerontology, 21(5), 467-78.

Bass, S. A. (1986). The elderly as surplus people: Is there a role for higher education? The Gerontologist, 26(1), 12-18.

Batsche, C. N. \& Monoson, P. (1993, September). A four-phase multidisciplinary faculty development model in aging. Educational Gerontology 19(6), 551567.

Beckhard, R. (1969). Organizational Development. Reading, MA: AddisonWesley.

Bell, W. G. (1986). Endowed positions in gerontology and geriatrics in higher education:Results from a preliminary survey. Educational Gerontology, 12(6), 507-508.

Bennis, W. (1966). Changing Organizations. New York: McGraw-Hill. Bluedorn, AC. Bitting, R. K. \& Spriggs, R. M. (1994). The evaluation of New York state's centers for advanced technology program: One center's perspective. SRA Journal of the Society of Research Administrators, 25(2), 5-16. 
Blumberg, P., Deveau, E., \& Clark, P. (1997). Describing the structure and content of interdisciplinary collaboration in an educational center on aging and health. Educational Gerontology, 27(7), 609-629.

Bolton, C. (1989). Program standards and faculty development in gerontology instruction: A role for professional organizations. Educational Gerontology 14(6), 497-507.

Brower, H. T. \& Yurchuck, E. R. (1993, April). Teaching gerontological nursing in southern states. Nursing and Health Care, 14(4), 198-205.

Callender, W. D. (1984, November). Gerontology training for adult educators: The experience of the University of Maine. Paper presented at the National Adult Education Conference, Louisville, KY.

Campbell, J. P. (1977). On the nature of organizational effectiveness. In P. S. Goodman and J. M. Pennings (Eds.), New Perspectives on Organizational Effectiveness, 13-55. San Francisco: Jossey-Bass.

Cameron, K.S. (1996). Organizational effectiveness and quality. In John C. Smart (Ed.), Higher Education Handbook of Theory and Research. Vol. XI.

Cameron, K.S. (1986). A study of organizational effectiveness and its predictors. Management Science, 32, 87-112.

Cameron, K.S. (1983, March 25-26). A study of organizational effectiveness and its predictors. Paper presented at the annual meeting of the Association for the Study of Higher Education, Washington, D.C.

Cameron, K.S. (1981a, Sept.). The enigma of organizational effectiveness. New Directions for Program Evaluation: Measuring Effectiveness, 11.

Cameron, K.S. (1981b) Domains of organizational effectiveness in colleges and universities. Academy of Management Journal, 24(1), 25-47.

Cameron, K.S. (1978, December). Measuring organizational effectiveness in institutions of higher education. Admin. Science Quarterly, 23: 604-632.

Cameron, K.S. \& Smart, J.C. (1997). Maintaining effectiveness amid downsizing and decline in institutions of higher education. Paper presented at the Annual Forum of the Association for Institutional Research. 
Cameron, K.S. \& Whetten, D. A. (1983). Organizational Effectiveness: A

Comparison of Multiple Models. New York: Academic.

Camp, C.J. \& Brookover, C. (1997). Learning about older learners: Training undergraduates as researchers. Educational Gerontology, 23(8), Dec. 80913.

Cavallaro, M. L. (1992, September). A master's degree specialization in gerontological counseling. Counseling Education and Supervision, 32(1), 70-78.

Clark, P.G. (1994). Learning on interdisciplinary gerontological teams: Instructional concepts and methods. Educational Gerontology, 20(4), June, 349-64.

Clott, C. B. (1995, November 2-5)). The effects of environment, strategy, culture, and resource dependency on perceptions of organizational effectiveness of schools of business. Paper presented at the Annual Meeting of the Asssociation for the Study of Higher Education, 320th, Orlando, FL.

Coccaro, E.F., et.al. (1983, July-August). Gerontologic/geriatric training in medical school: Preferences of students, educators, and practitioners of medicine in regard to curricular content. Ed. Gerontology, 9(4), 293-306.

Connelly, J. R. \& Rich, T. A. (Eds.). (1989). AGHE Standards and Guidelines for Gerontology Programs. Washington, DC: Association for Gerontology in Higher Education.

Connolly, T., Conlon, E. M. \& Deutsch, S. J. Organizational effectiveness: A multiple constituency approach. Academy of Management Review, 5, 211218.

Craig, B. (1981, November, 9). An analysis of characteristics of education institutions supported by AoA for planning and development of instructional programs in aging. Paper presented at the Joint Annual Meeting of the Canadian Association of Gerontology and the Gerontological Society of American, Toronto, Ontario.

Donahue, W. (1960). Training in social gerontology. Geriatrics, 15, 801-809.

Dubin, R. (1976). Organizational effectiveness: Same dilemmas of perspective. 
Organization and Administrative Sciences, 7, 7-14.

Duthie, E. H., et.al. (1988, April). Determining geriatric content in a medical school curriculum. Jn. of Medical Education, 63(4), 301-308.

Ernst, M., Ernst, N. S., \& Wilson, L. B. (1982). Developing an empirically grounded applied gerontology program. Gerontology and Geriatrics Education, 2, 183-189.

Etzioni, A. (1964). Modern Organizations. Englewood Cliffs, NJ: Prentice-Hall. Euster, G.L. \& Reaves, E. W. (1995, April/May). Reassessment of the quality of gerontology certificate program: A second follow-up survey of graduates. Educational Gerontology, 21(3), 191-207.

Ewald, PD. (1993, March-April). In consideration of an integrated knowledge base in gerontology. Educational Gerontology, 19(2), 173-180.

Everhart, D.E., et.al. (1996). Doctoral training in the psychology of adult development and aging: 1993-1994 survey results. Educational Gerontology, 22(5), July-Aug, 451-66.

Fairchild, T. J. (1988). It is difficult to make predictions, especially about the future. In Gerontology: The Next Generation, Atlanta, GA: Southern Regional Education Board.

Fjortoft, N. \& Smart, J.C. (1994). Enhancing organizational effectiveness: The importance of culture type and mission agreement. Higher Education, 27(4), June, 429-47.

Fortune, A. E. \& Rathbone, M. E. (1981, Fall). Education in gerontological social work: Application of the task-centered mode. Jn. of Education for Social

Work, 17(3), 98-105.

Friedlander, F. \& Pickle, H. (1968). Components of effectiveness in small organizations. Admin. Science Quarterly, 13, 289-304.

Filinson, R. (1993, April-May). Assessing outcomes of a gerontology certificate program. Educational Gerontology, 19(3), 251-264.

Friedman, R. C. (1977). The continuing saga of institutes and centers. (Report No.28). Pennsylvania State University: Center for the Study of Higher Education. 
Friedsam, H. J. (1995, summer). Professional education and the invention of social gerontology. Generations, $\underline{19}$ (2), 23-32.

Friedsam, H. J. (1986). Recurrent issues in gerontological education for service. Educational Gerontology, 12(6), 563-578.

Geiger, R. L. (1990, January/February). Organized research units--their role in the development of university research. The Journal of Higher Education, 61, 1-19.

Georgopolous, B. S. \& Tannenbaum, A. S. (1957). The study of organizational effectiveness. American Sociological Review, 22, 534-544.

Getzels, J. W. \& Guba, E. G. (1957). Social behavior and the administrative process. $\underline{\text { School Review, }} \underline{65}, 423-441$.

Getzels, J. W. , Lipham, J. M., \& Campbell, R. F. Educational Administration as a Social Process: Theory, Research and Practice. New York: Harper \& Row. Goodman, P.S \& Pennings, J.M. (Eds.). (1977). New Perspectives on Organizational Effectiveness. San Francisco: Jossey-Bass.

Greaves, G. et.al. (1995). Collaboration of seniors and faculty in an undergraduate program. Educational Gerontology, 21(1), Jan-Feb, 69-79.

Hall, R. P. (1972). Organizations: Structures and Process. Englewood Cliffs, NJ: Prentice-Hall.

Hoffman, W. M. \& Petry, E. (1991). Business ethics at Bently College. Moral Education Forum, 18(3), 1-8.

Hoy, W. K. \& Miskel, C. G. (1991). Educational Administration: Theory, Research, Practice. New York: McGraw-Hill, Inc.

Ikenberry, S.O. (1970). A profile of proliferating institutes. A study of selected characteristics of institutes and centers in 51 land grant institutes. Pennsylvania State University. University Park: Center for the Study of Higher Education. ED046325.

Ikenberry, S. O. \& Friedman, R. C. (1972). Beyond academic departments: The story of institutes and centers. ED196398. 
John, R., et.al. (1992). Faculty development in gerontology for faculty of American Indian colleges. Final report. American Indian Higher Education Consortium, Kansas State University, University of Kansas.

Johnson, M.E. \& Rosich, R.M. (1997). Gerontological training in APA accredited clinical and counseling psychology programs. Educational Gerontology, 23(1), Jan-Feb, 29-35.

Jones, C. J. \& Rikli, R. E. (1993, January). The gerontology movement--is it passing us by? Jn. of Physical Education, Recreation \& Dance, 64 (1), 17-26.

Johnson, H., Britton, J., Lang, C., Seltzer, M., Stanford, E., Yancik, R., Maklan, C., \& Middleswarth, A. (1980). Foundations for gerontological education. The Gerontologist, 20, 1-61.

Kahn, R. L. (1977). Organizational effectiveness: An overview. In P. S. Goodman and J. M. Pennings (Eds.). New Perspectives on Organizational Effectiveness, San Francisco: Jossey-Boss.

Katz, D. \& Kahn, R. L. (1978). The Social Psychology of Organizations, NY: Wiley.

Keeley, M. (1980). Organizational analysis: A comparison of organismic and social contract models. Administrative Science Quarterly, 25, 337-362.

Keyser-Jones, J. (1986). Institute of gerontology: A comprehensive approach to the care of the elderly. Educational Gerontology, 12(1), 43-55.

Kropf, N.P. et.al. (1993). The status of gerontology in baccalaureate social work education. Educational Gerontology, 19(7), Oct-Nov, 623-34.

Lawson, I. R. (1986). The development of geriatrics/gerontology at the UCONN health center: The model for care. Educational Gerontology, 12(1), 107113.

Leavitt, H. J. (1965). Applied organizational change in industry: Structural, technological, and humanistic approaches. In Handbook of Organizations, J. G. Marsh (Ed.). Chicago: Rand McNally, 1144-1170.

Leavitt, H. J. (1965). Applied organizational change in industry: Structural 
technological and humanistic approaches. In Handbook of Organizations, J. C. March (Ed). Chicago: Rand McNally, 1144-1170.

Leavitt, H. J., Dill, W. R., \& Eyring, H. B. (1973). The Organizational World. New York: Harcourt Brace Jovanovich.

Likert, R. (1967). The Human Organization. New York: McGraw Hill.

Lipham, J. A. (1988). Getzel's model in educational administration. In Handbook of Research on Educational Administration, N. J. Boyan (Ed.). New York: Longman, 101-109.

Luckie, J.C. (1996). Principles and practices in the gerontology instruction leading to the Texas basic certificate in gerontology. Educational Gerontology, 22(2), March, 183-92.

Lysons, A. (1996). Predicting a taxonomy of organizational effectiveness in U.K. higher educational institutions. Higher Education 32(1), July, 23-29.

Lysons, A. (1993, August). The typology of organizational effectiveness in Australian higher education. Research in Higher Education, 34(4), 36588.

Lysons, A. \& Hatherly, D. (1992, April). Cameron's dimensions of effectiveness in higher education in the UK: A cross cultural comparison. Higher Education, 23(3), 221-230.

Maddox, GL. (1988). The future of gerontology in higher education: Continuing to open the American mind about aging. The Gerontologist. 28(6), December, 748-752.

Madison, A. M. (1992). Faculty development in gerontology: Minority/majority institutional collaboration. Journal of Aging for the Southwest, 8, 39-55.

Malone-Beach, E.E., et.al. (1992, October - November). Building a partnership of university resources and rural service providers: A case study. Educational Gerontology, 18(7), 691-699.

Mann, J., et.al. (1987, December). Current status of geriatric dentistry educational activities in U.S. dental schools. Jn. of Dental Education, $\underline{51}(12), 705-708$.

Martin, C. A., et.al. (1991, October). Twenty years of gerontological education. A 
report on the experience of one program. The Gerontologist, 31(5), 679685.

Masunaga, H., Peterson, D.A., \& Seymour, R. (1998). Effect of gerontology education. Educational Gerontology, 24(1), Jan-Feb, 78-89.

Mazzoni, D.S. et. al. (1997). Perspectives on the instruction of biological aging courses. Educational Gerontology 23(6), September, 549-65.

Meyer, M. W. (1978). Introduction: Recent developments in organizational research and theory. In Environments and Organizations, M. W. Meyer (Ed.), San Francisco: Jossey-Bass, 233-263.

Meyer, J. W. \& Rowan, B. (1977). Institutionalized organizations: Formal structure as myth and ceremony. American Journal of Sociology, 83, 440463.

Miles, R. H. \& Cameron, K. S. (1982). Coffin nails and corporate strategies. Englewood Cliffs, NJ: Prentice-Hall.

Mintzberg, H. (1979). The Structuring of Organizations, Englewood Cliffs, NJ: Prentice Hall.

Mullins, L. C. (1988). Reflections on gerontological education into the twenty-first century. In Gerontology: The Next Generation, Atlanta, GA: Southern Regional Educational Board.

Nadler, D.A. \& Tuchman, M. L. (1989). A congruence model for organizational assessment. In E. E. Lawler, D. A. Nadler, \& Cammann, P. (Eds.), Organizational assessment: Perspectives on measurement of organizational behavior and the quality of working life. New York: Wiley, 261-278.

Netting, F. E. \& Wilson, C. C. (1988). The student-faculty gerontological research team. Educational Gerontology. 14(3), 221-228.

Newborn, V. B., et.al. (1994, July-August). Required clinical course in gerontology: The key to providing competent nurse caregivers for the elderly. Nursing Outlook, 42(4), 170-174. 
Newborn, V. B. \& Kennedy (1994, May-June). In support of gerontological nursing program: A resource exchange model. Journal of Professional Nursing, 10(3), 186-190.

Nichols, A. (1995, February). A historical perspective on institutes and centers: A comparison of gerontology with other fields of study. Paper presented at the Association for Gerontology in Higher Education Annual Meetings, Fort Worth Texas.

Norman, MM. (1971). Centers and institutes and the Pennsylvania State University. A case study. Pennsylvania State University, University Park: Center for the Study of Higher Education. ED051774.

Olson, E. A. (1994, June). Methodological issues in evaluation of a faculty development in gerontology program. Educational Gerontology, 20(4), 379-394.

Olsen, M. E. (1968). The Process of Social Organization. New York: Holt, Rinehart \& Winston.

Orton, J. D. \& Weick, K. E. (1990). Loosely coupled systems: A reconceptualization. Academy of Management Review, 15, 203-223.

Parson, T. (1960). Structure and Process in Modern Societies. Glencoe, IL: Free Press.

Perrow, C. (1970). Organizational Analysis: A Sociological View. Belmont, CA: Wadsworth.

Peterson, DA (1984). Are master's degrees in gerontology comparable? The Gerontologist, 24(6), 646-65.

Peterson, DA. (1986, December). Extent of gerontology instruction in American institutions of higher education. Educational Gerontology, 12(6), 519-529.

Peterson, D. A. (1987, February). Job placement and career advancement of gerontology? Master's degree graduates. The Gerontologists, 27(1), February, 34-38.

Peterson, D. A., \& Bolton, C. (1980). Gerontolgy instruction in higher education. New York: Springer.

Peterson, D. A., Kerin, P. B., \& Douglas, E. P. (1991). Critical variables for 
gerontology program development and stability: A naturalistic inquiry.

Gerontology \& Geriatrics Education, 12(1), 33-45.

Peterson, D. A., Wendt, P. F., \& Douglass, E. B. (1994). Development of

Gerontology, Geriatrics, and Aging Studies Programs in Institutions of

Higher Education. Washington, D.C.: Association for Gerontology in

Higher Education.

Pfeffer, J. \& Salancik, G. R. (1978). The External Control of Organizations New York: Harper and Row.

Pfiffner, J. M. \& Sherwood, F. P. (1960). Administrative Organization. Englewood Cliffs, NJ: Prentice-Hall.

Phillipose, V., et.al. (1991). Review of nursing literature: Evolution of gerontology education in nursing. Nursing and Health Care, 12(10), December, 524530.

Price, J. L. (1972). The study of organizational effectiveness. Sociological Quarterly, 14, 115-126.

Puglisi, J. T. (1987). An Undergraduate, Interdisciplinary Program in Gerontology, Washington, DC: American Association of State Colleges and Universities.

Pullen, C. H. (1989). Geriatric education centers: An analysis of policy implementation. ED341297.

Quinn, R. E. \& Cameron, K. (1983). Organizational life cycles and shifting criteria of effectiveness: some preliminary evidence. Management Science, 29, 33-51.

Rachal, J.R., et.al. (1996). Institutional publication productivity in selected gerontology journals. Educational Gerontology, 22(3), April-May, 281-91.

Reed, C. C., et.al. (1992, September). Gerontological education for students in nursing and social work: knowledge, attitudes and perceived barriers. Educational Gerontology, 18(6.), 625-636.

Reuben, D. B. \& Beck, J. C. (1994). Training Physicians to Care for Older Americans: Progress, Obstacles, and Future Directions. Washington, D.C.: Institute of Medicine.

Rice, C. E. (1961). A model for empirical study of large social organizations. 
General Systems Yearbook, 6: 101-106.

Rich, T. A., Connelly, J. R., \& Douglass, E. B. (Eds.). (1990). Standards and Guidelines for Gerontology Programs. Washington, D.C.: Association for Gerontology in Higher Education.

Rosin, A.J. \& Abramovitz, L. (1997). Formal and informal frameworks for teaching geriatrics. Educational Gerontology, 23(2), March, 91-103.

Rothman, M. B. (1989). Southeast Florida Center on Aging. Washington, DC: American Association of State Colleges and Universities.

Romaniuk, J. G. \& Arling, G. (1984, November, 16-20). Developing gerontological curriculum and competencies: A statewide perspective. Paper presented at the Annual Scientific Meeting of the Gerontological Society 37th, San Antonio, TX.

Scott, W. R. (1981). Organizations: Rational Natural, and Open System, 1st ed., Englewood Cliffs, NJ: Prentice-Hall.

Scott, W. R. (1977). Effectiveness of organizational effectiveness studies. In P. S. Goodman \& J Pennings (Eds.), New Perspectives on Organizational Effectiveness, San Francisco: Jossey-Bass, 63-95.

Seltzer, M.M. (1985). Issues of accreditation of academic gerontology programs and credentialing of workers in the field of aging. Gerontology and Geriatrics Education, 5, 7-18.

Seashore, S. E. (1976). Defining and measuring the quality of work life. In L. E Davis, A. B. Cherns \& Associates (Eds.) The Quality of Working Life. New York: Free Press, 39-83.

Simonson, W. \& Pratt, C. C. (1982, Fall). Geriatric pharmacy curriculum in U.S. pharmacy schools: a nationwide survey. Amer. Jn. of Pharmacy Educ., $\underline{46}(3), 249-252$.

Simson, S. \& Wilson, L. B. (1981, September - October). The performance of administration on aging multidisciplinary gerontology centers for education and training. Educational Gerontology, 7(2-3), 215-229.

Smart, J. C. \& Hamm, R. E. (1993, August). Organizational effectiveness and mission orientation of two-year colleges. Research in Higher Education, 
34, 4, 489-502.

Smart, J. et.al. (1996). The roles of institutional cultures and decision approaches in promoting organizational effectiveness in two-year colleges. Paper presented at the Annual Forum of the Association for Institutional Research, Albuquerque, N.M., May 5-8, 1996)

Stahler, G. J., Tash, WR (1994, Sept./Oct.). Centers and institutes in the research university: issues, problems, prospects. Jn. of Higher Education, 65, 540554.

Steers, R. M. (1975). Problems in measurement of organizational effectiveness. Admin.Science Quarterly, 7, 109-121.

Steiner, K. V. \& Kukich, d. S. (1995, June). The academic research centre; A vital link between industry and higher education. Industry and Higher Education, $\underline{9}(3), 135-39$.

Taylor, B.E. \& Massy, W.F. (1996). Strategic indicators for higher education, 1996. New Jersey: Peterson's Guides, Inc.

Teicher, M. I. \& Corcoran, E. H. (1984, Summer). Bringing gerontology to the university. Educational Recreation, 65(3), 36-39.

Totman, TL. (1976). A social science research institute in the quality American university. Final technical report. ED137156.

Thomas, A. M. \& Shipp, I. I. (1981, September). Current status of geriatric education in American dental schools. Jn. of Dental Education, 45(9), 589691.

Thornton, J. E. (1992, July-August). Educational gerontology in Canada. Educational Gerontology, 18(5), 415-431.

Van Orman, R. (1984, March). Bachelor's degree curricula in gerontology. Paper presented at the meeting of the Western Gerontological Society, Anaheim, CA.Watt, S \& Meredith, S. (1995, January-February). Integrating gerontology into socialwork education programs. Educational Gerontology, 21(1), 55-58. 
Weber, Max. The Theory of Social and Economic Organizations. Talcott Parsons (ed.), A.M. Henderson and Talcott Parsons (trans.). New York: Free Press, 1947.

Weick, K. E. (1976). Educational organizations as loosely coupled systems. Administrative Science Quarterly, 21, 1-19.

Wendt, P. F \& Peterson, D. A. (1993a, Winter). A case study in the evolution of professional education. Review of Higher Education, 16(2), 181-198.

Wendt, PF \& Peterson, DA (1993b, January - February). Developing gerontological expertise among higher education faculty. Educational Gerontology, 19(1), 59-70.

Wilber, KH \& Zarit, SH (1987). Practicum training in gerontological counseling. Educational Gerontology. 13(1), 15-32.

Yee, D. \& Barley, L. R. (1987). Gerontology and health education at the baccalaureate level. Paper presented at the Annual Northeastern Gerontological Society Conference 7th. Hartford, CT, May 27-30.

Yuchtman, E. \& Seashore, S. E. (1967). A system resource approach to organizational effectiveness. American Sociological Review, 32, 891-903.

Zammuto, R. F. (1982). Assessing Organizational Effectiveness. Albany: State University of New York Press.

\section{APPENDIX A \\ LIST OF GERONTOLOGY CENTERS AND INSTITUTES AT COLLEGES AND UNIVERSITIES IN THE UNITED STATES}

1. University of Alabama

2. University of Alabama, Birmingham

3. University of Arizona

4. University of Arkansas, Little Rock

5. American River College

6. California State University, Los Angeles
Center for the Study of Aging

Center for Aging

Arizona Center on Aging

Center on Gerontology

Gerontology Center

Roybal Institute for Applied 
Gerontology

7. California State University, Sacramento

8. University of California, Berkeley

9. University of California, Davis

10. San Diego State University

11. University of Santa Clara

12. University of Southern California

13. University of Connecticut

14. University of Colorado, Colorado Springs

15. University of Denver

16. Saint Joseph College

17. University of the District of Columbia

18. Bethune Cookman College

19. Florida International University

20. Florida State University

21. University of Florida

22. University of Miami

23. Emory University

24. Georgia State University

25 . University of Georgia

26. University of Hawaii, Manoa

27. Illinois State University

28. Northwestern University

29. Ball State University

30. University of Evansville

31. Indiana University at Bloomington

32. University of lowa, College of Medicine

33. Kansas State University
Gerontology Program and Center

Center on Aging

Center for Aging and Health

University Center on Aging

Center on Aging

Andrus Gerontology Center

Travelers Center on Aging

Center on Aging

Institute of Gerontology

Institute in Gerontology

Institute for Gerontology

Center for Aging

Southeast Florida Center on

Aging

Pepper Institute on Aging and

Public Policy

Center for Gerontological Studies

Center for Adult Development and

Aging

Center for Geriatrics

Gerontology Center

Gerontology Center

Center on Aging

Center for the Study of Aging

Buehler Center on Aging

Center for Gerontology

Center for Gerontology

Center on Aging and Aged

Center on Aging

Center on Aging 
34. University of Kansas

35. University of Kansas, Medical Center

36. University of Kentucky

37. University of Louisville

38. Boston University

39. Brandeis University

40. University of Massachusetts, Boston

41. University of Michigan, Ann Arbor

42. Wayne State University

43. University of Missouri, Kansas City

44. University of Nevada, Reno

45. Rutgers, New Brunswick

46. University of New Mexico

47. City University of New York, Hunter College

48. Columbia University

49. Fordham University

50. Long Island University--CW Post

51. New York Medical College

52. State University of NY at Albany

53. State University of NY at Buffalo

54. Syracuse University

55. Utica College of Syracuse

56. Duke University

57. Wake Forest University, Bowman Gray School of Medicine

58. University of North Dakota
Gerontology Center

Center on Aging

Sanders-Brown Center on Aging

Urban Center on Aging

Gerontology Center

Policy Center on Aging

Gerontology Institute and Center

Institute of Gerontology

Institute of Gerontology

Center on Aging

Graham \& Jean Stanford Center

on Aging

Institute for Health/Health Care

Policy/Aging Research

Center on Aging

Brookdale Center on Aging

Center for Geriatrics/Gerontology

Third Age Center

Center on Aging

Center for the Study of Aging

Ringel Institute of Gerontology

Multidisciplinary Center on Aging

Policy Center on Aging

Institute of Gerontology

Center for the Study of Aging and

Human Development

J. Paul Sticht Center on Aging

Resource Center on Gerontology 
59. University of Akron

60. Case Western Reserve University

61. Miami University of Ohio

62. Portland State University

63. Pennsylvania State University

64. University of Pennsylvania

65. Temple University

66. West Chester University of PA

67. Brown University

68. Rhode Island College

69. Meharry Medical College

70. Abilene Christian University

71. Baylor University

72. Baylor College of Medicine

73. University of North Texas, Hlth Sc. Ctr.

74. University of North Texas

75. University of Texas Hlth Sc. Center

76. University of Texas--Galveston

77. University of Utah

78. University of Vermont

79. Virginia Commonwealth University

80. Virginia Polytechnic Institute \&

State University

81. University of Washington

82. West Virginia University

83. University of Wisconsin

84. University of Wisconsin, Milwaukee
Institute for Life-Span

Development and Gerontology University Center on Aging and Health

Scripps Gerontology Center

Institute on Aging

Gerontology Center

Institute on Aging

Institute on Aging

Gerontology Center

Center for Gerontology and

Health Care Research

Gerontology Center

Center on Aging

Center for the Study of Aging Institute of Gerontological Studies Huffington Center on Aging

Texas Institute for Research and Education on Aging

Center for Studies in Aging

Center on Aging

Center on Aging

Gerontology Center

Center for the Study of Aging

Virginia Center on Aging

Center for Gerontology

Institute on Aging

Center on Aging

Institute on Aging

Institute on Aging \& Environment 
85. Incarnate Word College

86. University of South Florida

87. University of Illinois, at Urbana-Champaign Office of Gerontology and Aging
Institute on Aging Suncoast Gerontology Center 


\section{APPENDIX B}

PART A

\section{CHARACTERISTICS OF CENTERS AND INSTITUTES}

\section{Please answer the following questions about your gerontology center.}

1.Name of institute/center

2. Address

3. Director (name and title)

4. If not director, name and title of person completing this survey

5. Date of founding of the center

6. Degrees offered and number of students enrolled in each degree program

$\begin{array}{ll}\text { Associate Degree } & \text { Baccalaureate Degree } \\ \text { Masters Degree } & \text { Doctoral Degree } \\ \text { Professional Certification } & \text { Other }\end{array}$

(specify)

7. Certificates offered and number of students enrolled in each certificate program Undergraduate Certificate Graduate Certificate Practitioner Certificate Other (specify)

8. Subunits of the center (for example: research unit; education unit; outreach unit)

9. Number of permanent faculty members

10. Number of affiliated faculty members

11. Number of permanent administrative staff

12. Number of permanent clerical staff

13. Type of facility

Free-standing building

Offices in building belonging to a college or department

Building/offices off-campus

No permanent space except director's office

14. Total operating budget for the center

15. Total amount of sponsored research

\section{CHARACTERISTICS OF THE PARENT INSTITUTION}

Please answer the following questions about the university or college in which your gerontology center or institute is located. 
16, Name of parent institution

17. Affiliation

PRIVATE (junior/2-yr)

PRIVATE (4-year college)

PRIVATE (university)

PUBLIC (community/2-year)

PUBLIC (4-year college)

PUBLIC (land-grant university)

PUBLIC (university)

18. Total university/college enrollment

19. Highest degree offered

20. Number of doctoral degrees offered last year

21. Library holdings

22. Number of colleges

23. Number of professional schools

24. Total number of faculty

25 . Total number of faculty with doctoral degrees

26. Total general expenditure

\section{ORGANIZATIONAL STRUCTURE AND DIMENSIONS OF EXTERNAL ENVIRONMENT}

\section{Please answer these questions with regard to your gerontology center or institute.}

27. Choose the description which best describes the relationship of your institute or center to other units in your institution:

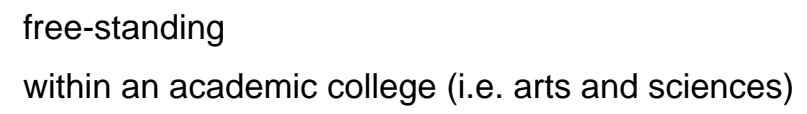

State which one

within an academic department

State which one

affiliated, but separate from university

or college

subunit of a center or institute (i.e. Center on Aging within the Center for Social Policy)

state which one

other

28. The director reports to:

a provost or vice president 


a dean
a chairperson
_ a director of another institute or center
the funding agency
$\quad$ Other

29. The center has had the same position in the institution:

since its establishment
not since its establishment, but for 10 years or more
between $5-9$ years
_ less than 5 years

30. The likelihood that the center will remain a permanent part of your institution in the next five years is:

$$
\text { _for sure _ very likely _ likely__somewhat likely _ not likely }
$$

31. The impetus for establishing the center came from:

central administration

_ a department or college
_ an individual faculty member or group of faculty members
__ funding agency initiative community groups state legislature other, please state:

32. The center's building and/or office space is adequate to meet its goals and mission. __strongly agree _ agree _ somewhat agree _ disagree _ strongly disagree

33. Which disciplines do permanent center faculty represent?

$\begin{array}{ll}\text { Sociology } & \text { Psychology } \\ \text { Political Science } & \text { Public Administration } \\ \text { Social Work } & \text { Nursing } \\ \text { Allied Health } & \text { Medicine } \\ \text { Other } & \end{array}$

(specify)

34. Which disciplines do affiliated faculty represent?

$\begin{array}{ll}\text { Sociology } & \text { Psychology } \\ \text { Political Science } & \text { Public Administration } \\ \text { Social Work } & \text { Nursing } \\ \text { Allied Health } & \text { _ Medicine }\end{array}$


Other

(specify)

35. Check appropriate statements about permanent faculty academic appointments:

Faculty have permanent positions at the center, but receive tenure through academic departments.

Faculty have permanent positions at the center and receive tenure from the center.

Faculty have permanent positions at the center, but are not eligible for

tenure at the

university/college.

36. Check appropriate statements about the director's academic appointment:

Director has tenured-faculty position with the university through an academic department.

Director has tenured-faculty position through center.

Director does not have a tenured-faculty position.

37. Director gives input into decisions of hiring, tenure and promotion to the academic departments of the staff.

_ sometimes_ always_ never

38. Affiliated faculty prepare for their center activities at their:

_ center office

academic department office

off campus

other

specify)

39. For center activities, affiliated faculty usually use resources (phone, computer, etc.) belonging to:

the center/institute

academic department

the faculty member

other

(specify)

40. Does the center/institute employ a permanent clerical staff?

yes no

41. If no, from where does the center get clerical assistance?

the departments of affiliated faculty department in which the center resides director or other administrative staff do their own clerical work 
other

(specify)

\section{STRATEGIC EMPHASES OF ADMINISTRATOR}

\section{Please answer these questions with regard to the gerontology center director's} perspective on administrating the center.

42. Which term best describes the relationship between the director and the sub-divisions? direct supervision indirect supervision nominal supervision other (specify)

43. I would describe my leadership behavior as: directive (clarifies expectations, gives specific directions, asks subordinates to follow rules and procedures). achievement-oriented (sets goals, seeks improvements, emphasizes excellence). supportive (shows consideration, displays concern for the well-being of subordinates, creates friendly organizational health). participative (calls for consultation with subordinates, uses others ideas in making decisions. other (specify)

44. Rank, in order of importance, your job responsibilities as director of the center or institute. fund raising managing teaching research/academic scholarship politics and public relations external professional involvement budgeting public service other (specify)

45. Rank, in order of time spent over the course of an academic year, your job responsibilities as the director of the center or institute: fund raising managing teaching 
research/academic scholarship

politics and public relations

external professional involvement

budgeting

public service

other (specify)

46. Activities for the center/institute are selected by:

central administration

director

associate/assistant directors

faculty

funding agency

advisory committee

other (specify)

\section{ORGANIZATIONAL GOAL PREFERENCE}

47. Rank order the primary mission/s of your center/institute.

_ research

__ university/college instruction

service (i.e. continuing education, community programs)

other (specify)

48. If you included research as one of the center's missions, does your center conduct research in any of these areas? (Check as many as apply.)

$\begin{array}{lll}\text { sociological } & \text { Yes } & \text { No } \\ \text { educational } & \text { Yes } & \text { No } \\ \text { biological } & \text { Yes } & \text { No } \\ \text { psychological } & \text { Yes } & \text { No } \\ \text { medical } & \text { Yes } & \text { No } \\ \text { other } & \text { Yes } & \text { No (if yes,specify) }\end{array}$

49. If you selected service, please indicate types of service projects. (Check as many as apply.)

\begin{tabular}{|c|c|c|}
\hline adult education programs & -Yes & No \\
\hline professional continuing education programs & YYes & No \\
\hline consultation services & _Yes & $\mathrm{Nc}$ \\
\hline support groups & _Yes & No \\
\hline community groups projects & Y Yes & No \\
\hline
\end{tabular}


other

Yes No

(if yes, specify)

50. Rank in order of importance to the center, the following list of goals:

student satisfaction

academic development of students

career development of students

personal development of students

faculty/staff satisfaction

professional development of faculty and staff

community interaction

interdisciplinary collaboration

acquiring resources

other (specify)

51. The mission of the center and the mission of the parent institution are:

__identical _ very close _ close _ somewhat close _ far apart

\section{FINANCIAL FACTORS}

52. Funding for this center comes from:

(please write in an approximate percentage of funding from each source)

$\begin{aligned} \% & \text { central administration (tuition and fees) } \\ \% & \text { public funds other than university funding } \\ \% & \text { private donations } \\ \% & \text { federal or state grants } \\ \% & \text { industry } \\ \% & \text { endowments }\end{aligned}$

53. Give the percent of the center's expenditures in each of the following areas:

$\begin{aligned} \% & \text { research } \\ \% & \text { student aid and services } \\ \% & \text { public service } \\ \% & \text { academic support } \\ \% & \text { library books } \\ \% & \text { auxiliary enterprises } \\ \% & \text { physical plant }\end{aligned}$

54. Check the statement which is true for your center. The center has a permanent budget line. 
The center is reviewed periodically by funding source to determine continuation of funding.

The center is dependent on the continued funding its host unit. other

55. Funding for the center is adequate to meet its objectives and activities.

__strongly agree _ _ agree _ somewhat agree _ disagree _ strongly disagree

56. Funding for the center is stable for the next five years.

__strongly agree __agree __somewhat agree _ disagree _ strongly disagree

57. The center has adequate resources (equipment, facilities, staff) to meet its goals.

_ strongly agree __agree _ _somewhat agree _ disagree__strongly disagree

In order to continue this study of centers and institutes, we need the opinions of others associated with your center. These individuals will be sent only Part B of the questionnaire. Please list the name and title and address of individuals at your institution who fall under the following categories:

I would like to send this questionnaire to at least five individuals from your institution, if possible.

I. Central administrator responsible for the center/institute

II. Directors of the subunits of the center

III. Program/project directors/administrators

IV. Faculty with major responsibility in the center 


\section{APPENDIX C \\ PART B \\ ASSESSMENT OF ORGANIZATIONAL CHARACTERISTICS OF CENTERS AND INSTITUTES}

This questionnaire was used by permission from Kim Cameron, Brigham Young University. Contact Dr. Cameron for further details. 


\section{APPENDIX D}

\section{(Shortened Version)}

PART A

\section{CHARACTERISTICS OF GERONTOLOGY CENTERS AND INSTITUTES}

1.Name of institute/center

2. Address

3. Director (name and title)

4. If not director, name and title of person completing this survey

5. Date of founding of the center

6. Number of permanent faculty members

7. Number of permanent administrative staff

8. Type of facility

Free-standing building

Offices in building belonging to a college or department

Building/offices off-campus

No permanent space except director's office

9. Total operating budget for the center

10. Total amount of sponsored research

11. Choose the description which best describes the relationship of your institute or center to other units in your institution:

_ free-standing

_ within an academic college (i.e. arts and sciences)

_ within an academic department

_ affiliated, but separate from university or college

_ subunit of a center or institute (i.e. within the Center for Social Policy)

other

12. The director reports to:
a provost or vice president
a dean
a chairperson
a director of another institute or center
the funding agency 
other

(state)

13. The impetus for establishing the center came from:

central administration

_ a department or college

an individual faculty member or group of faculty members

funding agency initiative

community groups

state legislature

other or combination of above

14. Which disciplines do permanent and affiliated center faculty represent?

$\begin{array}{lll}\text { Sociology } & \text { Psychology } & \text { Biology } \\ \text { Political Science } & \text { Public Administration } & \text { Other _ _ Nursing _ Allied Health }\end{array}$

15. Check appropriate statements about permanent faculty academic appointments:

Faculty have permanent positions at the center, but receive tenure through academic

\section{departments.}

Faculty have permanent positions at the center and receive tenure from the center.

Faculty have permanent positions at the center, but are not eligible for tenure at the university/college.

16. Check appropriate statements about the director's academic appointment:

Director has tenured-faculty position with the university through an academic

department.

Director has tenured-faculty position through center.

Director does not have a tenured-faculty position.

17. Director gives input into decisions of hiring, tenure and promotion to academic departments.

sometimes always never

18. Does the center/institute employ a permanent clerical staff? yes no

19. Which term best describes the relationship between the director and the sub-divisions? direct supervision indirect supervision nominal supervision other

(specify) 
20. I would describe my leadership behavior as: (Choose one)

directive (clarifies expectations, gives specific directions, asks subordinates to follow rules and procedures).

achievement-oriented (sets goals, seeks improvements, emphasizes

excellence).

supportive (shows consideration, displays concern for the well-being of subordinates, creates friendly organizational health).

participative (calls for consultation with subordinates, uses others ideas in making decisions.

other

(specify)

21. Rank, in order of importance, your job responsibilities as director of the center or institute. fund raising managing teaching research/academic scholarship politics and public relations external professional involvement budgeting public service other

(specify)

22. Rank, in order of time spent over the course of an academic year, your job responsibilities as the director of the center or institute:

fund raising managing

teaching research/academic scholarship politics and public relations external professional involvement budgeting public service other

(specify)

23. Rank order the primary mission/s of your center /institute. 
research

university/college instruction

service (i.e. continuing education, community programs)

other

(specify)

24. If you selected service, please indicate types of service projects. (Check as many as apply.)

adult education programs
professional continuing education programs
consultation services
support groups
community groups projects
coordinated projects with state agencies
other
(if yes, specify)

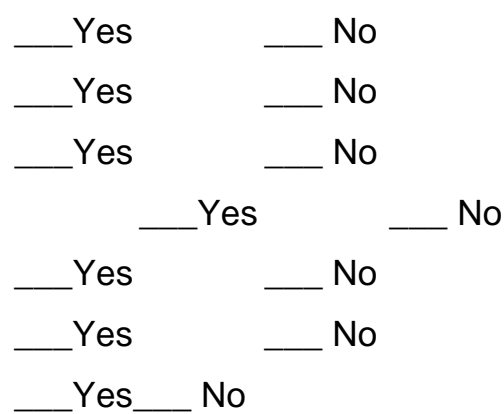

25. Rank in order of importance to the center, the following list of goals:

student satisfaction

academic development of students

career development of students

personal development of students

faculty/staff satisfaction

professional development of faculty and staff

community interaction

interdisciplinary collaboration

acquiring resources

other (specify)

26. The mission of the center and the mission of the parent institution are:

__identical _ very close _ close _ somewhat close _ far apart

27. Funding for this center comes from: (please write in an approximate percentage of funding from each source)

$\begin{aligned} \% & \text { central administration (tuition and fees) } \\ \% & \text { public funds other than university funding } \\ \% & \text { private donations } \\ \% & \text { federal or state grants } \\ \% & \text { industry } \\ \% & \text { endowments }\end{aligned}$

28. Give the percent of the center's expenditures in each of the following areas:

$\% \quad$ research 


$\begin{aligned} \% & \text { student aid and services } \\ \% & \text { public service } \\ \% & \text { academic support } \\ \% & \text { library books } \\ \% & \text { auxiliary enterprises } \\ \% & \text { physical plant }\end{aligned}$

29. Check the statement which is true for your center.

The center has a permanent budget line.

The center is reviewed periodically by funding source to determine continuation of funding.

The center is dependent on the continued funding its host unit. other

30. Funding for the center is adequate to meet its objectives and activities.

__strongly agree _ agree _ somewhat agree _ disagree _ strongly disagree

31. Funding for the center is stable for the next five years.

_strongly agree _agree __somewhat agree _ disagree__strongly disagree

32. The center has adequate resources (equipment, facilities, staff) to meet its goals.

__strongly agree __agree__somewhat agree _ disagree__strongly disagree

In order to continue this study of centers and institutes, we need the opinions of others associated with your center. These individuals will be sent only Part $B$ of the questionnaire. Please list the name and title and address of individuals at your institution who fall under the following categories:

I would like to send this questionnaire to at least five individuals from your institution, if possible.

I. Central administrator responsible for the center/institute

II. Directors of the subunits of the center 
III. Program/project directors/administrators

IV. Faculty with major responsibility in the center 


\section{APPENDIX E}

\section{Rotated Factor Pattern}

FACTOR1 FACTOR2 FACTOR3 FACTOR4 FACTOR5 FACTOR6 FACTOR7 FACTOR8

\begin{tabular}{|c|c|c|c|c|c|c|c|c|}
\hline JTEL & 0.26563 & 0.11199 & 0.5075 & -0.1926 & 0.2799 & 0.18120 & -0.01147 & 0.29380 \\
\hline RDIV & 0.72533 & 0.12979 & 0.2695 & 0.0222 & 0.03057 & 0.02734 & -0.00306 & 0.13009 \\
\hline COMNE & 0.76406 & -0.00095 & 0.0518 & -0.2103 & -0.0396 & -0.01368 & -0.06152 & 0.16816 \\
\hline HIFIN & 0.15245 & 0.08151 & 0.8505 & 0.0323 & $0.2367 \mathrm{~s}$ & $0.0593 c$ & -0.13771 & -.04530 \\
\hline LEFAC & 0.12439 & .05584 & 0.9394 & 0.0069 & $0.0011 \mathrm{C}$ & 0.00860 & -0.02610 & 0.08857 \\
\hline LESTU & 0.08907 & $0.0915 \mathrm{~s}$ & 0.6689 & 0.126 & $0.1425 \varepsilon$ & -0.11320 & 0.16379 & 0.28854 \\
\hline HIRES & 0.24001 & -0.12603 & 0.7832 & 0.0551 & $510 \quad 0.31943$ & 0.06638 & -0.20102 & -0.05528 \\
\hline STUCON & И 0.68680 & 0.29686 & 0.4331 & -0.075 & $566 \quad 0.04928$ & -0.0890 & -0.01078 & 0.19451 \\
\hline ALUMSU & 0.50103 & 0.1384 & 0.314 & 0.023 & 3960.0261 & -0.1997 & -0.02644 & 0.13128 \\
\hline STUDIS & 0.14141 & 0.1928 & 0.084 & -0.011 & 1170.0006 & 0.29690 & -0.14053 & 0.79183 \\
\hline STUDRO & JP 0.00275 & 0.0622 & 0.011 & -0.17 & $7518-0.0512$ & 0.8698 & -0.0606 & $69 \quad 0.21635$ \\
\hline STUCON & UP-0.24898 & 0.2506 & 0.009 & 0.0296 & $69-0.0625$ & $0.6564 \varepsilon$ & $-0.3154 C$ & 0.29704 \\
\hline STUACA & AD 0.11903 & 0.0185 & -0.1675 & 0.3764 & -0.1569 & -0.0100 & 0.09055 & 0.72152 \\
\hline STUDEC & G 0.14077 & -0.14507 & -0.4172 & 0.0927 & $71-0.14177$ & -0.12614 & -0.01543 & 0.00961 \\
\hline DEVOPP & -0.58390 & 0.18112 & -0.2229 & 0.26975 & $5-0.03362$ & -0.04168 & 0.48620 & 0.18679 \\
\hline OUTACA & AD 0.27098 & 0.0021 & $-0.077 \subseteq$ & $795-0.1114$ & $40 \quad 0.28122$ & -0.0345 & -0.22988 & 0.02714 \\
\hline OUTPER & RS 0.62455 & -0.05196 & 0.1048 & $82-0.20446$ & 0.03508 & -0.06006 & -0.36657 & -0.15173 \\
\hline OUTFAC & 0.06630 & 0.21415 & 0.0035 & -0.25470 & 0.14929 & 0.04878 & -0.04447 & 0.06415 \\
\hline OUTCEN & V $0.70506-$ & 0.07356 & -0.0941 & -0.20904 & -0.13865 & -0.15286 & -0.19402 & 0.07227 \\
\hline STUCAR & 0.10385 & 0.17187 & 0.44297 & 0.10492 & 0.28615 & 0.15067 & -0.01369 & 0.23215 \\
\hline STUMAT & 0.86486 & 0.00729 & 0.10000 & 0.10919 & -0.15288 & 0.11069 & 0.00554 & -0.19996 \\
\hline COMFAC & C 0.11692 & 0.10017 & -0.0681 & 180.07077 & 0.20588 & 0.01156 & 0.16394 & 0.32123 \\
\hline COMCTF & R 0.32478 & 0.01387 & 0.24556 & $6-0.19273$ & 0.18486 & 0.14152 & -0.21400 & 0.00428 \\
\hline FACREF & P 0.02208 & -0.13896 & 0.45411 & 0.01331 & 0.66092 & -0.05690 & 0.17616 & -0.02891 \\
\hline STUMOT & T -0.06679 & 0.21516 & 0.46707 & -0.13895 & 0.33312 & 0.11905 & -0.01850 & -0.00205 \\
\hline STUEMP & 0.23865 & 0.73183 & $-0.1151<$ & $\begin{array}{ll}4 & 0.06565\end{array}$ & .18301 & 0.01739 & -0.01817 & -0.28772 \\
\hline STUINT & -0.28450 & 0.72470 & 0.04939 & -0.06943 & -0.20011 & 0.12773 & 0.12590 & 0.06910 \\
\hline CARCOI & 0.07989 & 0.00256 & -0.03479 & 0.04384 & -0.06490 & -0.03995 & -0.15643 & -0.06031 \\
\hline CARFIR & 0.01539 & 0.48151 & 0.16236 & -0.05109 & 0.07403 & 0.50473 & -0.15709 & -0.21093 \\
\hline CARHEL & 0.03914 & 0.38088 & 0.09938 & -0.36144 & 0.13819 & 0.54709 & 0.26085 & 0.07158 \\
\hline FACLEA & A 0.13292 & 0.28807 & -0.00082 & -0.35175 & -0.14376 & 0.26939 & 0.02854 & 0.44408 \\
\hline ADMLEA & A 0.26999 & 0.71658 & 0.20420 & -0.09044 & 0.19913 & -0.15825 & -0.23054 & 0.18246 \\
\hline FACSAT & 0.03859 & 0.72541 & 0.08434 & -0.20020 & -0.00812 & 0.44288 & -0.30431 & 0.17446 \\
\hline ADMSAT & $\Gamma-0.00453$ & 0.90076 & 0.03059 & -0.08459 & -0.00168 & 0.17203 & -0.10443 & 0.18699 \\
\hline FACSCH & H 0.01448 & & 0.18303 & -0.07710 & 0.05782 & 0.36286 & -0.23921 & 0.34429 \\
\hline FACCON & VF- 0.20446 & 0.07029 & 0.12833 & -0.10707 & 0.32842 & 0.07674 & -0.08875 & 0.22533 \\
\hline & B $=000544$ & -0.00466 & 0.32277 & -0.08434 & 0.83539 & -0.06391 & 0.04320 & -0.11308 \\
\hline FACCUT & 0.0757 & 0.44676 & -0.07337 & -0.09583 & 0.63716 & 0.28295 & 0.08871 & 0.36691 \\
\hline FACAW/ & A - $-0.025 \&$ & 30.03985 & 0.11009 & 0.11337 & 0.68863 & -0.05638 & -0.02593 & -0.00499 \\
\hline FACPRO & & & & -0.11652 & 0.89863 & 0.04034 & -0.11084 & 0.11329 \\
\hline STUTO & 0.0205 & 0.01942 & 0.15412 & -0.14657 & 0.11791 & -0.25646 & 0.00509 & 0.14075 \\
\hline & & & & 0.19464 & -0.10467 & 0.26216 & -0.10967 & -0.29191 \\
\hline & $1 T 00030-1$ & 011077 & & & -0.10365 & 0.01241 & 0.05340 & -0.10598 \\
\hline
\end{tabular}

FACTOR1 FACTOR2 FACTOR3 FACTOR4 FACTOR5 FACTOR6 FACTOR7 FACTOR8

$\begin{array}{llllllll}\text { SUPERV }-0.01091 & -0.02826 & 0.00433 & 0.14742 & -0.04028 & 0.02658 & -0.01273 & 0.08609\end{array}$

$\begin{array}{lllllll}\text { TREREW - } 0.17112-0.19547 & 0.09244 & 0.52099 & 0.25606 & 0.07428 & 0.40651 & 0.14354\end{array}$

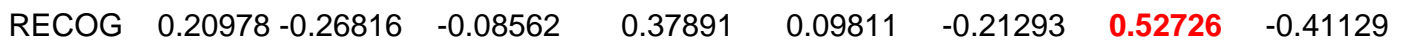

$\begin{array}{llllllll}\text { FEEDBAC-0.32839 } & 0.13014 & -0.14529 & 0.35462 & -0.02727 & -0.15683 & 0.55281 & -0.17303\end{array}$

$\begin{array}{llllllll}\text { COMMUN } 0.06394 & 0.08565 & 0.13897 & 0.61386 & -0.25360 & -0.07831 & 0.11237 & -0.04170\end{array}$

$\begin{array}{llllllll}\text { ENVIRON-0.28286 } & -0.17087 & -0.06060 & 0.53718 & -0.24811 & -0.12748 & 0.27220 & -0.22875\end{array}$

$\begin{array}{llllllll}\text { FLEXAD -0.13443 } & -0.32573 & -0.09722 & 0.11036 & -0.07688 & -0.08256 & 0.82261 & -0.07413\end{array}$

$\begin{array}{llllllll}\text { TRUST }-0.09789 & -0.16055 & 0.03135 & -0.01448 & -0.14032 & -0.62991 & 0.06023 & 0.02244\end{array}$

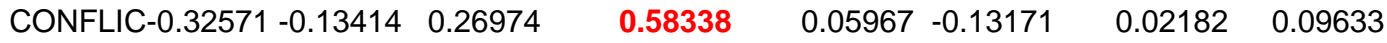

$\begin{array}{llllllll}\text { DISAGRE } 0.05822 & 0.32910 & 0.05690 & -0.71592 & -0.18843 & 0.33517 & -0.01285 & -0.05128\end{array}$

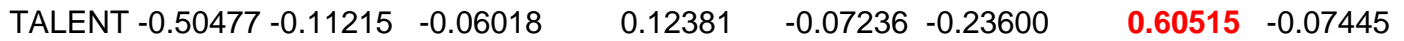

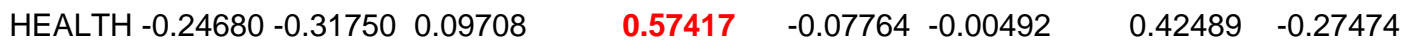

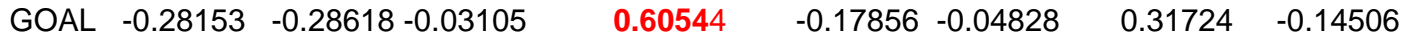

Final Communality Estimates: Total $=49.05880$ 


$\begin{array}{llllllllll}\text { INTEL } & \text { PERDIV } & \text { COMNE } & \text { HIFIN } & \text { LEFAC } & \text { LESTU } & \text { HIRES } & \text { STUCOM } \\ 0.816096 & 0.901780 & 0.875786 & 0.919038 & 0.960817 & 0.876686 & 0.913679 & 0.878441 \\ \text { ALUMSU } & \text { STUDIS } & \text { STUDROP } & \text { STUCOMP } & \text { STUACAD } & \text { STUDEG } & \text { DEVOPP } & \text { OUTACAD } \\ 0.758115 & 0.871860 & 0.930663 & 0.871615 & 0.895324 & 0.846458 & 0.881720 & 0.912530 \\ \text { OUTPERS } & \text { OUTFAC } & \text { OUTCEN } & \text { STUCAR } & \text { STUMAT } & \text { COMFAC } & \text { COMCTR } & \text { FACREP } \\ 0.865712 & 0.831164 & 0.870740 & 0.830165 & 0.919900 & 0.832705 & 0.874672 & .923055 \\ \text { STUMOT } & \text { STUEMP } & \text { STUINT } & \text { CARCOU } & \text { CARFIR } & \text { CARHEL } & \text { FACLEA } & \text { ADMLEA } \\ 0.769401 & 0.874603 & 0.841070 & 0.929615 & 0.814075 & 0.934562 & 0.862712 & 0.901736 \\ \text { FACSAT } & \text { ADMSAT } & \text { FACSCH } & \text { FACCONF } & \text { FACPUB } & \text { FACCUT } & \text { FACAWA } & \text { FACPRO } \\ 0.957872 & 0.937853 & 0.918733 & 0.876447 & 0.921938 & 0.910005 & 0.861965 & 0.835770 \\ \text { STUTOP } & \text { STUFAC } & \text { INTDEPT } & \text { SUPERV } & \text { TREREW } & \text { RECOG } & \text { FEEDBAC } & \text { COMMUN } \\ 0.872048 & 0.928013 & 0.696673 & 0.900926 & 0.774550 & 0.897887 & 0.884286 & 0.797203 \\ \text { ENVIRON } & \text { FLEXAD } & \text { TRUST } & \text { CONFLIC } & \text { DISAGRE } & \text { TALENT } & \text { HEALTH } & \text { GOAL } \\ 0.882020 & 0.926667 & 0.853927 & 0.824622 & 0.901375 & 0.883410 & 0.923215 & 0.904904\end{array}$




\section{APPENDIX F \\ ALPHA CORRELATIONS OF DOMAIN VARIABLES Non-Academic}

8 'VAR' Variables: PERDIV COMNE STUCOM ALUMSU DEVOPP OUTPERS OUTCEN STUMAT

Cronbach Coefficient Alpha

for RAW variables : 0.620124

for STANDARDIZED variables: 0.651188

Raw Variables

Deleted

Variable

Correlation

with Total

PERDIV $\quad 0.495461$

COMNE $\quad 0.532545$

STUCOM 0.629888

ALUMSU $\quad 0.610876$

DEVOPP $\quad-0.568350$

OUTPERS 0.418808

OUTCEN 0.335066

STUMAT 0.526326
Std. Variables

Correlation

Alpha with Total Alpha

$$
0.535575
$$

0.533879

0.497478

0.489905

0.810222

0.555258

0.583316

0.531540

0.498990

0.541145

0.618463

0.622748

$-0.558362$

0.436331

0.350811

0.517398
0.578196

0.566341

0.544014

0.542754

0.810739

0.595412

0.618138

0.573047

\section{Career goal satisfaction}

5 'VAR' Variables: STUEMP STUINT ADMLEA FACSAT CARFIR

Correlation Analysis

Cronbach Coefficient Alpha

for RAW variables : 0.626049

for STANDARDIZED variables: 0.646692

Raw Variables

Deleted

Std. Variables

Variable

Correlation

Correlation

with Total Alpha with Total Alpha

STUEMP

0.542950

\subsection{5}

0.555087

0.515831

STUINT

0.264907

0.632248

0.302561

ADMLEA

0.341232

0.590585

0.335814

0.374300

0.579200

0.389879

0.639100

FACSAT

0.417098

0.555358

0.424946

0.623926

0.598585

0.581698 


\section{Resource Acquistion \\ 4 'VAR' Variables: HIFIN LEFAC LESTU HIRES \\ Cronbach Coefficient Alpha}

for RAW variables $\quad: 0.862089$

for STANDARDIZED variables: 0.859148

\begin{tabular}{lcccc}
$\begin{array}{l}\text { Raw Variables } \\
\text { Deleted } \\
\text { Variable }\end{array}$ & $\begin{array}{c}\text { Correlation } \\
\text { with Total }\end{array}$ & \multicolumn{2}{l}{$\begin{array}{c}\text { Std. Variables } \\
\text { Correlation } \\
\text { with Total }\end{array}$} & Alpha \\
& & & & \\
HIFIN & 0.762275 & 0.801467 & 0.756372 & 0.798596 \\
LEFAC & 0.782315 & 0.792927 & 0.784712 & 0.786418 \\
LESTU & 0.539454 & 0.885658 & 0.534382 & 0.887745 \\
HIRES & 0.768699 & 0.799583 & 0.754517 & 0.799387
\end{tabular}

\section{ORGANIZATIONAL HEALTH}

8 'VAR' Variables:TREREW COMMUN ENVIRON CONFLIC DISAGRE HEALTH GOAL Cronbach Coefficient Alpha

for RAW variables : 0.616582

for STANDARDIZED variables: 0.595799

$\begin{array}{lcccc}\begin{array}{l}\text { Deleted } \\ \text { Variable }\end{array} & \begin{array}{l}\text { Raw Variables } \\ \text { Correlation } \\ \text { with Total }\end{array} & \text { Alpha } & \begin{array}{c}\text { Std. Variables } \\ \text { Correlation } \\ \text { with Total }\end{array} & \text { Alpha } \\ \text { TREREW } & 0.460924 & 0.538070 & 0.463021 & 0.510489 \\ \text { COMMUN } & 0.320316 & 0.583183 & 0.315898 & 0.557215 \\ \text { ENVIRON } & 0.542675 & 0.519041 & 0.537116 & 0.485694 \\ \text { CONFLIC } & 0.399813 & 0.556162 & 0.390463 & 0.533943 \\ \text { DISAGRE } & -0.704024 & 0.788937 & -0.699244 & 0.800772 \\ \text { HEALTH } & 0.714012 & 0.479878 & 0.700403 & 0.427948 \\ \text { GOAL } & 0.532095 & 0.514012 & 0.546593 & 0.482461 \\ \text { INTDEPT } & 0.502482 & 0.539839 & 0.499572 & 0.498366\end{array}$


Quality of Faculty

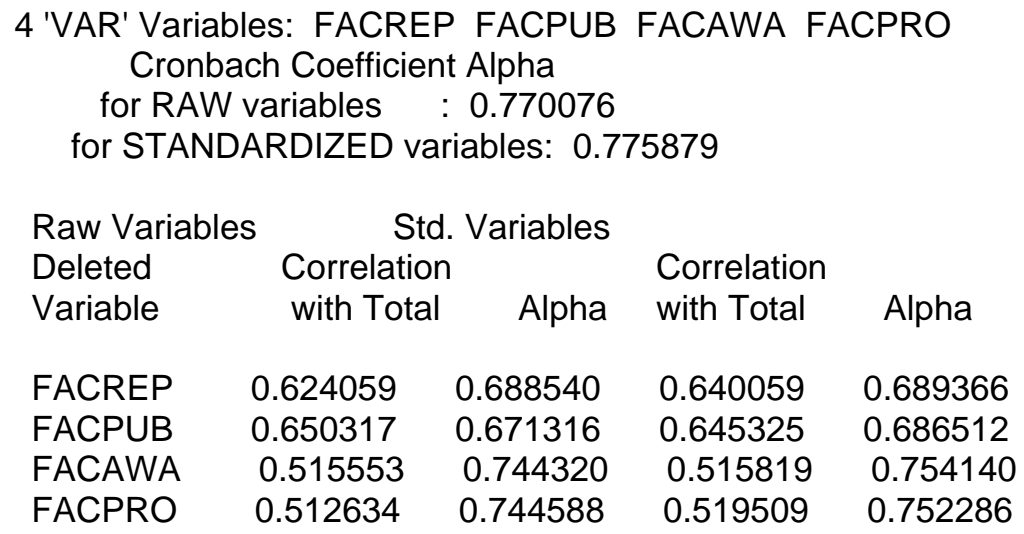

Student Satisfaction

4 'VAR' Variables: STUDROP STUCOMP CARHEL TRUST

Cronbach Coefficient Alpha

for RAW variables : -.096875

for STANDARDIZED variables: 0.344933

$\begin{array}{lrrrr}\begin{array}{l}\text { Raw Variables } \\ \text { Deleted } \\ \text { Variable }\end{array} & \begin{array}{l}\text { Std. Variables } \\ \text { Correlation } \\ \text { with Total }\end{array} & \text { Alpha } & \begin{array}{c}\text { Correlation } \\ \text { with Total }\end{array} & \text { Alpha } \\ \text { STUDROP } & 0.225515 & -0.331815 & 0.504191 & -0.148441 \\ \text { STUCOMP } & 0.167094 & -0.269321 & 0.430113 & -0.038582 \\ \text { CARHEL } & -0.019251 & -0.110627 & 0.192371 & 0.270453 \\ \text { TRUST } & -0.240853 & 0.565732 & -0.231036 & 0.678434\end{array}$




\title{
Faculty and Staff Job Satisfaction
}

\author{
4 'VAR' Variables: RECOG FEEDBAC FLEXAD TALENT \\ Cronbach Coefficient Alpha \\ for RAW variables : 0.761650 \\ for STANDARDIZED variables: 0.767104
}

\begin{tabular}{|c|c|c|c|c|}
\hline \multirow{3}{*}{$\begin{array}{l}\text { Deleted } \\
\text { Variable }\end{array}$} & \multicolumn{2}{|c|}{ Raw Variables } & \multicolumn{2}{|c|}{ Std. Variables } \\
\hline & Correlation & & Correlation & \\
\hline & with Total & Alpha & with Total & Alpha \\
\hline RECOG & 0.465806 & 0.756165 & 0.481086 & 0.756446 \\
\hline FEEDBAC & 0.609412 & 0.686221 & 0.616855 & 0.684838 \\
\hline FLEXAD & 0.600676 & 0.683989 & 0.600942 & 0.693543 \\
\hline TALENT & 0.584985 & 0.692137 & 0.573147 & 0.708545 \\
\hline
\end{tabular}




\section{APPENDIX G \\ MEDIAN ANALYSIS}

NPAR 1 W A Y PROCEDURE

Median Scores (Number of Points Above Median) for Variable WORK Classified by Variable NAMECT

\begin{tabular}{|c|c|c|c|c|c|}
\hline & & Sum of & Expected & Std Dev & Mean \\
\hline NAMECT & $\mathrm{N}$ & Scores & Under HO & Under HO & Score \\
\hline & 2 & 2.0 & 1.00000000 & 0.70366585 & 1.00000000 \\
\hline 34 & 1 & 1.0 & 0.50000000 & 0.50000000 & 1.00000000 \\
\hline 8 & 3 & 2.0 & 1.50000000 & 0.85757617 & 0.66666667 \\
\hline 19 & 1 & 0.0 & 0.50000000 & 0.50000000 & 0.00000000 \\
\hline 21 & 5 & 2.0 & 2.50000000 & 1.09610963 & 0.40000000 \\
\hline 4 & 3 & 0.0 & 1.50000000 & 0.85757617 & 0.00000000 \\
\hline 26 & 2 & 1.0 & 1.00000000 & 0.70366585 & 0.50000000 \\
\hline 5 & 3 & 1.0 & 1.50000000 & 0.85757617 & 0.33333333 \\
\hline 10 & 4 & 1.0 & 2.00000000 & 0.98532928 & 0.25000000 \\
\hline 2 & 2 & 1.0 & 1.00000000 & 0.70366585 & 0.50000000 \\
\hline 9 & 2 & 0.0 & 1.00000000 & 0.70366585 & 0.00000000 \\
\hline 42 & 1 & 0.0 & 0.50000000 & 0.50000000 & 0.00000000 \\
\hline 13 & 1 & 0.0 & 0.50000000 & 0.50000000 & 0.00000000 \\
\hline 39 & 5 & 2.0 & 2.50000000 & 0963 & 0.40000000 \\
\hline 30 & 2 & 1.0 & 1.00000000 & 0.70366585 & 0.50000000 \\
\hline 20 & 2 & 1.0 & 1.00000000 & 0.70366585 & 0.50000000 \\
\hline 3 & 3 & 3.0 & 1.50000000 & 0.85757617 & 1.00000000 \\
\hline 7 & 2 & 0.0 & 1.00000000 & 0.70366585 & 0.00000000 \\
\hline 6 & 2 & 0.0 & 1.00000000 & 0.70366585 & 0.00000000 \\
\hline 1 & 2 & 2.0 & 1.00000000 & 0.70366585 & 1.00000000 \\
\hline 32 & 3 & 3.0 & 1.5000 & 7617 & 1.00000000 \\
\hline 12 & 3 & 1.0 & 1.50000000 & 0.85757617 & 0.33333333 \\
\hline 14 & 5 & 3.0 & 2.50000000 & 1.09610963 & 0.60000000 \\
\hline 29 & 3 & 1.0 & 1.5000 & 0.85 & 0.33333333 \\
\hline 28 & 3 & 2.0 & 1.50000000 & 0.85757617 & 0.66666667 \\
\hline 15 & 3 & 2.0 & 1.50000000 & 0.85757617 & 0.66666667 \\
\hline 27 & 2 & 0.0 & 1.00000000 & 0.70366585 & 0.00000000 \\
\hline 33 & 1 & 1.0 & 0.50000000 & 0.50000000 & 1.00000000 \\
\hline 35 & 3 & 1.0 & 1.00000000 & 0.70366585 & 0.50000000 \\
\hline 22 & 2 & 1.0 & 1.00000000 & 0.70366585 & 0.50000000 \\
\hline 37 & 6 & 6.0 & 3.000000 & 1.19464826 & 1.00000000 \\
\hline 16 & 3 & 0.0 & 1.50000000 & 0.85757617 & 0.00000000 \\
\hline 23 & 2 & 1.0 & 1.00000000 & 0.70366585 & 0.50000000 \\
\hline 25 & 3 & 3.0 & 1.500000 & 0.85757617 & 1.00000000 \\
\hline 40 & 1 & 1.0 & 0.50000000 & 0.50000000 & 1.00000000 \\
\hline 17 & 4 & 1.0 & 2.00000000 & 0.98532928 & 0.25000000 \\
\hline 36 & 3 & 2.0 & 1.50000000 & 0.85757617 & 0.66666667 \\
\hline 24 & 2 & 2.0 & 1.00000000 & 0.70366585 & 1.00000000 \\
\hline \multirow[t]{2}{*}{31} & 2 & 0.0 & 1.00000000 & 0.70366585 & 0.00000000 \\
\hline & & 7.803 & $\mathrm{DF}=39$ & \multicolumn{2}{|c|}{ Prob $>$ CHISQ $=0.1576$} \\
\hline
\end{tabular}


Median Scores (Number of Points Above Median) for Variable NOACAD Classified by Variable NAMECT

\begin{tabular}{|c|c|c|c|c|c|}
\hline NAMECT & $\mathrm{N}$ & $\begin{array}{l}\text { Sum of } \\
\text { Scores }\end{array}$ & $\begin{array}{l}\text { Expected } \\
\text { Under HO }\end{array}$ & $\begin{array}{l}\text { Std Dev } \\
\text { Jnder HO }\end{array}$ & $\begin{array}{l}\text { Mean } \\
\text { Score }\end{array}$ \\
\hline 18 & 1 & 0.00000000 & 0.49367089 & 0.49037360 & 0.00000000 \\
\hline 8 & 2 & 0.00000000 & 0.98734177 & 0.68903319 & 0.00000000 \\
\hline 19 & 1 & 0.00000000 & 0.49367089 & 0.49037360 & 0.00000000 \\
\hline 21 & 4 & 3.00000000 & 1.97468354 & 0.96170176 & 0.75000000 \\
\hline 4 & 3 & 3.00000000 & 1.48101266 & 0.83839216 & 1.00000000 \\
\hline 26 & 2 & 2.00000000 & 0.98734177 & 0.68903319 & 1.00000000 \\
\hline \multirow[t]{2}{*}{5} & 3 & 2.00000000 & 1.48101266 & 0.83839216 & 0.66666667 \\
\hline & 2 & 2.00000000 & 0.98734177 & 0.68903319 & 1.00000000 \\
\hline & 1 & 1.00000000 & 0.49367089 & 0.49037360 & 1.00000000 \\
\hline & 1 & 1.00000000 & 0.49367089 & 0.49037360 & 1.00000000 \\
\hline 42 & 1 & 1.00000000 & 0.49367089 & 0.49037360 & 1.00000000 \\
\hline 13 & 1 & 0.00000000 & 0.49367089 & 0.49037360 & 0.00000000 \\
\hline 39 & 2 & 00000 & 0.98734177 & 0.68903319 & 0.00000000 \\
\hline 30 & 2 & 000000 & 3734177 & 0.68903319 & 00000 \\
\hline 20 & 2 & 00000 & 34177 & 0.6 & 000 \\
\hline 3 & 2 & 0.25 & 34177 & 0.68903 & 0000 \\
\hline 7 & 2 & 2.00000000 & 0.98734177 & 03319 & 0000 \\
\hline & 1 & 0.00 & 57089 & 0.4 & 0.0 \\
\hline 1 & 2 & 2.00000000 & 0.98734177 & 0.68903319 & 1.00000000 \\
\hline 32 & 3 & 2.00000000 & 1.48101266 & 0.83839216 & 0.66666667 \\
\hline 12 & 1 & 0.00000000 & 0.49367089 & 0.49037360 & 0.00000000 \\
\hline 14 & 2 & 2.00000000 & 0.98734177 & 0.68903319 & 1.00000000 \\
\hline 29 & 3 & 0000 & 01266 & 0.8 & 0.6 \\
\hline 28 & 3 & 0.2 & 1266 & & \\
\hline 15 & 2 & 000 & 34177 & 0.6 & 000 \\
\hline 27 & 1 & 1.0 & 67089 & 0.4 & 000 \\
\hline 35 & 3 & 1.00 & 1266 & 0.8 & 0.3 \\
\hline 41 & 2 & 0.00 & 34177 & 0.6 & \\
\hline 22 & 1 & 1.00 & 0.49367089 & 37360 & 1.00000000 \\
\hline 37 & 6 & 2.25000000 & 2.96202532 & 21.16202866 & 0.37500000 \\
\hline 16 & 2 & 1.00000000 & 0.98734177 & $\begin{array}{ll}7 & 0.68903319\end{array}$ & 0.50000000 \\
\hline 23 & 2 & 2.00000000 & 0.98734177 & 0.68903319 & 1.00000000 \\
\hline 25 & 2 & 0.00000000 & 0.98734177 & 0.68903319 & 0.00000000 \\
\hline 40 & 1 & 1.00000000 & 0.49367089 & 0.49037360 & 1.00000000 \\
\hline 17 & 3 & 3.00000000 & 1.48101266 & 0.83839216 & 1.00000000 \\
\hline 36 & 3 & 0.00000000 & 1.48101266 & 0.83839216 & 0.00000000 \\
\hline 24 & 2 & 0.25000000 & 0.98734177 & 0.68903319 & 0.12500000 \\
\hline 31 & 2 & 0.00000000 & 0.98734177 & 0.68903319 & 0.00000000 \\
\hline & & & & & \\
\hline
\end{tabular}


N PAR 1 W A Y PROCEDURE

Median Scores (Number of Points Above Median)for Variable RESOURC classified by Variable NAMECT

\begin{tabular}{|c|c|c|c|c|c|}
\hline & \multicolumn{2}{|c|}{ Sum of } & Expected & \multicolumn{2}{|c|}{ Dev Mean } \\
\hline NAMECT & $\mathrm{N}$ & Scores & Under HO & Under HO & Score \\
\hline 18 & 2 & 0.00000000 & 1.00000000 & 0.69172399 & 0.00000000 \\
\hline 34 & 1 & 0.00000000 & 0.50000000 & 0.49151454 & 0.00000000 \\
\hline 11 & 1 & 0.00000000 & 0.50000000 & 0.49151454 & 0.00000000 \\
\hline 8 & 4 & 2.00000000 & 2.00000000 & 0.96860732 & 0.50000000 \\
\hline 19 & 2 & 1.00000000 & 1.00000000 & 0.69172399 & 0.50000000 \\
\hline & 3 & 1.87500000 & 1.50000000 & 0.84302231 & 0.62500000 \\
\hline 21 & 4 & 4.00000000 & 2.00000000 & 0.96860732 & 1.00000000 \\
\hline 26 & 2 & 0.87500000 & 1.00000000 & 0.69172399 & 0.43750000 \\
\hline & 3 & 1.00000000 & 1.50000000 & 0.84302231 & 0.33333333 \\
\hline 10 & 4 & 2.00000000 & 2.00000000 & 0.96860732 & 0.50000000 \\
\hline & 2 & 2.00000000 & 1.00000000 & 0.69172399 & 1.00000000 \\
\hline 42 & 1 & 0.00000000 & 0.50000000 & 0.49151454 & 0000 \\
\hline 13 & 1 & 0.00000000 & 0.50000000 & 9151454 & 000 \\
\hline 39 & 5 & 000000 & 00000 & 750763 & 000 \\
\hline 30 & 2 & 0.8 & & 172399 & 00 \\
\hline 20 & 2 & 0.0 & & 172399 & \\
\hline & 3 & 00000 & 1.50 & 0.84302231 & 000 \\
\hline & 2 & 2.00000000 & 1.00000000 & 0.69172399 & 1.00000000 \\
\hline & 2 & 0.00000000 & 1.00000000 & 0.69172399 & 0.00000000 \\
\hline & 2 & 2.00000000 & 1.00000000 & 0.69172399 & 1.00000000 \\
\hline 32 & 3 & 00000 & 1.50000000 & 0.84302231 & 66667 \\
\hline 12 & 3 & $2.0 c$ & 0000 & 0.84302231 & 667 \\
\hline 14 & 6 & 5.0 & & 437397 & \\
\hline 29 & 3 & 3.0 & & 302231 & 000 \\
\hline 28 & 3 & 0.0 & & 02231 & 00 \\
\hline 15 & 3 & 0.0 & 1.5 & 302231 & 000 \\
\hline 27 & 2 & 1.000 & 1.0 & 0.69172399 & 0.5 \\
\hline 33 & 1 & 500000 & 0.50000000 & 0.49151454 & 00000 \\
\hline 35 & 3 & 2.00000000 & 1.50000000 & 0.84302231 & 0.66666667 \\
\hline 41 & 2 & 0.00 & 1.00 & 0.69172399 & 0000 \\
\hline 22 & 2 & 0.87 & 1.00000000 & 0.69172399 & 0000 \\
\hline 37 & 6 & 6.00000000 & 3.00000000 & 1.17437397 & 1.00000000 \\
\hline 16 & 3 & 0.000 & 1.500 & 0.84302231 & 0.0 \\
\hline 23 & 2 & 500000 & 1.00000000 & 0.69172399 & 750000 \\
\hline 25 & 3 & 1.00000000 & 1.50000000 & 0.84302231 & 0.33333333 \\
\hline 40 & 1 & 1.00000000 & 0.50000000 & 0.49151454 & \\
\hline 17 & 4 & 1.000 & 2.00 & 0.96860732 & \\
\hline 36 & 3 & 0.00000000 & 1.500000 & 0.84302231 & 0.00000000 \\
\hline 24 & 1 & 0.00000000 & 0.50000000 & 0.49151454 & 0.00000000 \\
\hline & & & & 0.69172399 & 0.87500000 \\
\hline & & & & & \\
\hline
\end{tabular}


Median Scores (Number of Points Above Median)for Variable STUD Classified by Variable NAMECT

\begin{tabular}{|c|c|c|c|c|c|}
\hline $\begin{array}{l}\text { Sum of } \\
\text { AMECT }\end{array}$ & $\mathrm{N}$ & $\begin{array}{l}\text { Expected } \\
\text { Scores }\end{array}$ & $\begin{array}{l}\text { Std Dev } \\
\text { Under H0 }\end{array}$ & $\begin{array}{l}\text { Mean } \\
\text { Under Ho }\end{array}$ & Score \\
\hline 18 & 2 & 1.13043478 & 0.98823529 & 0.65827721 & 0.56521739 \\
\hline 8 & 3 & 1.13043478 & 1.48235294 & 0.80135017 & 0.37681159 \\
\hline 21 & 5 & 2.13043478 & 2.47058824 & 1.02184441 & 0.42608696 \\
\hline 1 & 3 & 1.26086957 & 1.48235294 & 0.80135017 & 0.42028986 \\
\hline 26 & 2 & 1.13043478 & 0.98823529 & 0.65827721 & 0.56521739 \\
\hline 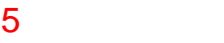 & 1 & 1.00000000 & 0.49411765 & 0.46826794 & 1.00000000 \\
\hline 10 & 3 & 2.13043478 & 1.48235294 & 0.80135017 & 0.71014493 \\
\hline 2 & 2 & 2.00000000 & 0.98823529 & 0.65827721 & 1.00000000 \\
\hline 9 & 2 & 2.00000000 & 0.98823529 & 0.65827721 & 1.00000000 \\
\hline 42 & 1 & 1.00000000 & 0.49411765 & 0.46826794 & 1.00000000 \\
\hline 13 & 1 & 0.13043478 & 0.49411765 & 0.46826794 & 0.13043478 \\
\hline 39 & 2 & 0.13043478 & 0.98823529 & 0.65827721 & 0.06521739 \\
\hline 30 & 2 & 0.13043478 & 0.98823529 & 0.65827721 & 0.06521739 \\
\hline 20 & 2 & 1.13043478 & 0.98823529 & 0.65827721 & 0.56521739 \\
\hline 3 & 2 & 2.00000000 & 0.98823529 & 0.65827721 & 1.00000000 \\
\hline 7 & 2 & 1.13043478 & 0.98823529 & 0.65827721 & 0.56521739 \\
\hline 6 & 2 & 0.00000000 & 0.98823529 & 0.65827721 & 0.00000000 \\
\hline 1 & 2 & 1.13043478 & 0.98823529 & 0.65827721 & 0.56521739 \\
\hline 32 & 2 & 0.00000000 & 0.98823529 & 0.65827721 & 0.00000000 \\
\hline 12 & 2 & 0.13043478 & 0.98823529 & 0.65827721 & 0.06521739 \\
\hline 14 & 3 & 0.00000000 & 35294 & 0.80135017 & 0.00000000 \\
\hline 29 & 3 & 3.00000000 & 294 & 35017 & 0000000 \\
\hline 28 & 3 & 1.13043478 & 1.48235294 & | 35017 & \\
\hline 15 & 3 & 3.00000000 & 35294 & | 35017 & 0000000 \\
\hline 27 & 2 & 0.13043478 & 3529 & 827721 & 0.06521739 \\
\hline 33 & 1 & 0.13043478 & 11765 & 0.46826794 & 0.13043478 \\
\hline 35 & 2 & 0.13043478 & 0.98823529 & 0.65827721 & 0.06521739 \\
\hline 41 & 2 & 1.00000000 & 0.98823529 & 0.65827721 & 0.50000000 \\
\hline 22 & 1 & 1.00000000 & 0.49411765 & 0.46826794 & 1.00000000 \\
\hline 37 & 5 & 2.00000000 & 2.47058824 & 1.02184441 & 0.40000000 \\
\hline 16 & 2 & 0.13043478 & 0.98823529 & 0.65827721 & 0.06521739 \\
\hline 23 & 2 & 1.13043478 & 0.98823529 & 0.65827721 & 0.56521739 \\
\hline 25 & 3 & 1.26086957 & 1.48235294 & 0.80135017 & 0.42028986 \\
\hline 40 & 1 & 0.00000000 & 0.49411765 & 0.46826794 & 0.00000000 \\
\hline 17 & 4 & 4.00000000 & 1.97647059 & 0.91965997 & 1.00000000 \\
\hline 36 & 3 & 1.13043478 & 1.48235294 & 0.80135017 & 0.37681159 \\
\hline 31 & 2 & 2.00000000 & 0.98823529 & 0.65827721 & 1.0000000 \\
\hline
\end{tabular}

$\mathrm{CHISQ}=46.079 \quad \mathrm{DF}=36 \quad$ Prob $>\mathrm{CHISQ}=0.1212$ 
Median Scores (Number of Points Above Median) for Variable CAREER Classified by Variable NAMECT

\begin{tabular}{|c|c|c|c|c|c|}
\hline $\begin{array}{l}\text { Sum of } \\
\text { NAMECT }\end{array}$ & $\mathrm{N}$ & $\begin{array}{l}\text { Expected } \\
\text { Scores }\end{array}$ & $\begin{array}{l}\text { Std Dev } \\
\text { Under H0 }\end{array}$ & $\begin{array}{l}\text { Mean } \\
\text { Under HO }\end{array}$ & core \\
\hline 18 & 2 & 0.00000000 & 1.00000000 & 0.68509787 & 0.00000000 \\
\hline 34 & 1 & 0.00000000 & 0.50000000 & 0.48809353 & 0.00000000 \\
\hline 8 & 1 & 0.00000000 & 0.50000000 & 0.48809353 & 0.00000000 \\
\hline 21 & 4 & 3.20000000 & 2.00000000 & 0.95408185 & 0.80000000 \\
\hline 4 & 3 & 3.00000000 & 1.50000000 & 0.83268924 & 1.00000000 \\
\hline 26 & 1 & 0.00000000 & 0.50000000 & 0.48809353 & 0.00000000 \\
\hline 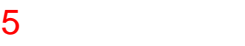 & 1 & 1.00000000 & 0.50000000 & 0.48809353 & 1.00000000 \\
\hline 10 & 3 & 2.00000000 & 1.50000000 & 0.83268924 & 0.66666667 \\
\hline 2 & 1 & 0.00000000 & 0.50000000 & 0.48809353 & 0.00000000 \\
\hline 9 & 1 & 1.00000000 & 0.50000000 & 0.48809353 & 1.00000000 \\
\hline 42 & 1 & 1.00000000 & 0.50000000 & 0.48809353 & 1.00000000 \\
\hline 13 & 1 & 0.00000000 & 0.50000000 & 0.488 & 000 \\
\hline 39 & 2 & 2.00000000 & 1.00000000 & 0.685 & 0000 \\
\hline 30 & 2 & 0.00000000 & 1.00000000 & 0.68509787 & 000 \\
\hline 20 & 2 & 2.00000000 & 1.00000000 & 0.68509787 & 0000 \\
\hline 3 & 2 & 1.00000000 & 1.00000000 & 0.68509787 & 0.50000000 \\
\hline 7 & 2 & 2.00000000 & 1.00000000 & 0.68509787 & 1.00000000 \\
\hline 6 & 1 & 0.00000000 & 0.50000000 & 0.48809353 & 0.00000000 \\
\hline 1 & 2 & 1.00000000 & 1.00000000 & 0.68509787 & 0.50000000 \\
\hline 32 & 2 & 0.20000000 & 1.00000000 & 0.68509787 & 0000 \\
\hline 12 & 2 & 1.00000000 & 000000 & 9787 & 000 \\
\hline 14 & 2 & 0.000 & 1.00000000 & 9787 & 000 \\
\hline 29 & 2 & 2.00000000 & 1.00000 & 9787 & 00000 \\
\hline 28 & 1 & 0.00000000 & 0.50000000 & 0.4880 & 000 \\
\hline 15 & 1 & 1.00000000 & 0.50000000 & 0.48809353 & 00000 \\
\hline 33 & 1 & 0.00000000 & 0.50000000 & 0.48809353 & 0.00000000 \\
\hline 35 & 1 & 1.00000000 & 0.50000000 & 0.48809353 & 1.00000000 \\
\hline 41 & 1 & 0.00000000 & 0.50000000 & 0.48809353 & 0.00000000 \\
\hline 22 & 1 & 0.20000000 & 0.50000000 & 0.48809353 & 0.20000000 \\
\hline 37 & 6 & 2.20000000 & 3.00000000 & 1.15010401 & 0.36666667 \\
\hline 16 & 2 & 0.00000000 & 1.00000000 & 0.68509787 & 0.00000000 \\
\hline 23 & 2 & 2.00000000 & 1.00000000 & 0.68509787 & 1.00000000 \\
\hline 25 & 1 & 0.20000000 & 0.50000000 & 0.48809353 & 0.20000000 \\
\hline 40 & 1 & 1.00000000 & 0.50000000 & 0.48809353 & 1.00000000 \\
\hline 17 & 4 & 1.00000000 & 2.00000000 & 0.95408185 & 0.25000000 \\
\hline 36 & 3 & 1.00000000 & 1.50000000 & 0.83268924 & 0.33333333 \\
\hline 31 & 2 & 2.00000000 & 1.00000000 & 0.68509787 & 1.00000000 \\
\hline
\end{tabular}


Median Scores (Number of Points Above Median)for Variable FACULTY Classified by Variable NAMECT

\begin{tabular}{|c|c|c|c|c|c|}
\hline NAMECT & $\mathrm{N}$ & $\begin{array}{l}\text { Sum of } \\
\text { Scores }\end{array}$ & $\begin{array}{l}\text { Expected } \\
\text { Under HO }\end{array}$ & $\begin{array}{lr}\text { Std Dev } & \text { Mean } \\
\text { Under HO } & \text { Sco }\end{array}$ & \\
\hline 18 & 2 & 1.00000000 & 0.98969072 & 0.68977729 & 0.50000000 \\
\hline 34 & 1 & 0.00000000 & 0.49484536 & 0.49030657 & 0.00000000 \\
\hline 8 & 3 & 0.92857143 & 1.48453608 & 0.84034312 & 0.30952381 \\
\hline 19 & 1 & 0.00000000 & 0.49484536 & 0.49030657 & 0.00000000 \\
\hline 21 & 6 & 3.92857143 & 2.96907216 & 1.16930663 & 0.65476190 \\
\hline 4 & 3 & 2.00000000 & 1.48453608 & 0.84034312 & 0.66666667 \\
\hline 26 & 2 & 1.92857143 & 0.98969072 & 0.68977729 & 0.96428571 \\
\hline 5 & 3 & 0.00000000 & 1.48453608 & 0.84034312 & 0.00000000 \\
\hline 10 & 3 & 3.00000000 & 1.48453608 & 0.84034312 & 1.00000000 \\
\hline 2 & 2 & 1.00000000 & 0.98969072 & 0.68977729 & 0.50000000 \\
\hline 9 & 2 & 2.00000000 & 0.98969072 & 0.68977729 & 1.00000000 \\
\hline 42 & 1 & 0.00000000 & 0.49484536 & 0.49030657 & 0.00000000 \\
\hline 13 & 1 & 0.00000000 & 0.49484536 & 0.49030657 & 0.00000000 \\
\hline 39 & 5 & 4.78571429 & 2.47422680 & 1.07327499 & 0.95714286 \\
\hline 30 & 2 & 1.92857143 & 0.98969072 & 0.68977729 & 0.96428571 \\
\hline 20 & 2 & 0.92857143 & 0.98969072 & 0.68977729 & 0.46428571 \\
\hline 3 & 3 & 1.00000000 & 1.48453608 & 0.84034312 & 0.33333333 \\
\hline 7 & 2 & 0.00000000 & 0.98969072 & 0.68977729 & 0.00000000 \\
\hline 6 & 2 & 0.00000000 & 0.98969072 & 0.68977729 & 0.00000000 \\
\hline 1 & 2 & 0.00000000 & 0.98969072 & 0.68977729 & 0.00000000 \\
\hline 32 & 3 & 0.00000000 & 1.48453608 & 0.84034312 & 0.00000000 \\
\hline 12 & 4 & 0.92857143 & 1.97938144 & 0.96516944 & 0.23214286 \\
\hline 14 & 4 & 0.92857143 & 1.97938144 & 0.96516944 & 0.23214286 \\
\hline 29 & 3 & 2.00000000 & 1.48453608 & 0.84034312 & 0.66666667 \\
\hline 28 & 3 & 1.92857143 & 1.48453608 & 0.84034312 & 0.64285714 \\
\hline 15 & 3 & 3.00000000 & 1.48453608 & 0.84034312 & 1.00000000 \\
\hline 33 & 1 & 0.00000000 & 0.49484536 & 0.49030657 & 0.00000000 \\
\hline 35 & 2 & 1.00000000 & 0.98969072 & 0.68977729 & 0.50000000 \\
\hline 41 & 2 & 0.00000000 & 0.98969072 & 0.68977729 & 0.00000000 \\
\hline 22 & 1 & 0.00000000 & 0.49484536 & 0.49030657 & 0.00000000 \\
\hline 37 & 6 & 4.92857143 & 2.96907216 & 1.16930663 & 0.82142857 \\
\hline 16 & 2 & 0.00000000 & 0.98969072 & 0.68977729 & 0.00000000 \\
\hline 23 & 2 & 0.00000000 & 0.98969072 & 0.68977729 & 0.00000000 \\
\hline 25 & 3 & 1.00000000 & 1.48453608 & 0.84034312 & 0.33333333 \\
\hline 40 & 1 & 1.00000000 & 0.49484536 & 0.49030657 & 1.00000000 \\
\hline 17 & 4 & 3.85714286 & 1.97938144 & 0.96516944 & 0.96428571 \\
\hline 36 & 3 & 1.00000000 & 1.48453608 & 0.84034312 & 0.33333333 \\
\hline 31 & 2 & 2.00000000 & 0.98969072 & 0.68977729 & 1.00000000 \\
\hline & & $51-0$ & & J & \\
\hline
\end{tabular}


Median Scores (Number of Points Above Median) for Variable JOB

\begin{tabular}{|c|c|c|c|c|c|}
\hline & Sum o & & Expected St & ev Mean & \\
\hline NAMECT & $\mathrm{N}$ & Scores & Under HO & Under $\mathrm{H} 0$ & Score \\
\hline 18 & 2 & 1.0 & 1.00000000 & 0.70366585 & 0.50000000 \\
\hline 34 & 1 & 1.0 & 0.50000000 & 0.50000000 & 1.00000000 \\
\hline 8 & 3 & 2.0 & 1.50000000 & 0.85757617 & 0.66666667 \\
\hline 19 & 1 & 1.0 & 0.50000000 & 0.50000000 & 1.00000000 \\
\hline 21 & 5 & 0.0 & 2.50000000 & 1.09610963 & 0.00000000 \\
\hline 4 & 2 & 0.0 & 1.00000000 & 0.70366585 & 0.00000000 \\
\hline 26 & 1 & 0.0 & 0.50000000 & 0.50000000 & 0.00000000 \\
\hline 5 & 3 & 1.0 & 1.50000000 & 0.85757617 & 0.33333333 \\
\hline 10 & 4 & 1.0 & 2.00000000 & 0.98532928 & 0.25000000 \\
\hline 2 & 2 & 1.0 & 1.00000000 & 0.70366585 & 0.50000000 \\
\hline 9 & 2 & 0.0 & 1.00000000 & 0.70366585 & 0.00000000 \\
\hline 42 & 1 & 0.0 & 0.50000000 & 0.50000000 & 0.00000000 \\
\hline 13 & 1 & 0.0 & 0.50000000 & 0.50000000 & 0.00000000 \\
\hline 39 & 5 & 1.0 & 2.50000000 & 1.09610963 & 0.20000000 \\
\hline 30 & 2 & 1.0 & 1.00000000 & 0.70366585 & 0.50000000 \\
\hline 20 & 2 & 1.0 & 1.00000000 & 0.70366585 & 0.50000000 \\
\hline 3 & 3 & 2.0 & 1.50000000 & 0.85757617 & 0.66666667 \\
\hline 7 & 2 & 1.0 & 1.00000000 & 0.70366585 & 0.50000000 \\
\hline 6 & 2 & 1.0 & 1.00000000 & 0.70366585 & 0.50000000 \\
\hline 1 & 2 & 0.0 & 1.00000000 & 0.70366585 & 0.00000000 \\
\hline 32 & 3 & 2.0 & 1.50000000 & 0.85757617 & 0.66666667 \\
\hline 12 & 4 & 1.0 & 2.00000000 & 0.98532928 & 0.25000000 \\
\hline 14 & 6 & 2.0 & 3.00000000 & 1.19464826 & 0.33333333 \\
\hline 29 & 3 & 2.0 & 1.50000000 & 0.85757617 & 0.66666667 \\
\hline 28 & 3 & 2.0 & 1.50000000 & 0.85757617 & 0.66666667 \\
\hline 15 & 3 & 1.0 & 1.50000000 & 0.85757617 & 0.33333333 \\
\hline 27 & 2 & 0.0 & 1.00000000 & 0.70366585 & 0.00000000 \\
\hline 33 & 1 & 0.0 & 0.50000000 & 0.50000000 & 0.00000000 \\
\hline 35 & 3 & 1.0 & 1.50000000 & 0.85757617 & 0.33333333 \\
\hline 41 & 2 & 0.0 & 1.00000000 & 0.70366585 & 0.00000000 \\
\hline 22 & 2 & 1.0 & 1.00000000 & 0.70366585 & 0.50000000 \\
\hline 37 & 6 & 5.0 & 3.00000000 & 1.19464826 & 0.83333333 \\
\hline 16 & 3 & 3.0 & 1.50000000 & 0.85757617 & 1.00000000 \\
\hline 23 & 2 & 2.0 & 1.00000000 & 0.70366585 & 1.00000000 \\
\hline 25 & 3 & 3.0 & 1.50000000 & 0.85757617 & 1.00000000 \\
\hline 40 & 1 & 1.0 & 0.50000000 & 0.50000000 & 1.00000000 \\
\hline 17 & 4 & 4.0 & 2.00000000 & 0.98532928 & 1.00000000 \\
\hline 36 & 3 & 3.0 & 1.50000000 & 0.85757617 & 1.00000000 \\
\hline 24 & 2 & 2.0 & 1.00000000 & 0.70366585 & 1.00000000 \\
\hline 31 & 2 & 2.0 & 1.00000000 & 0.70366585 & 1.00000000 \\
\hline
\end{tabular}




\title{
APPENDIX H \\ REGRESSION ANALYSIS OF ORGANIZATIONAL STRUCTURE AND DOMAINS OF ORGANIZATIONAL EFFECTIVENESS
}

\author{
Domain: Resource Acquisition
}

Model: MODEL1

Dependent Variable: RESOURC

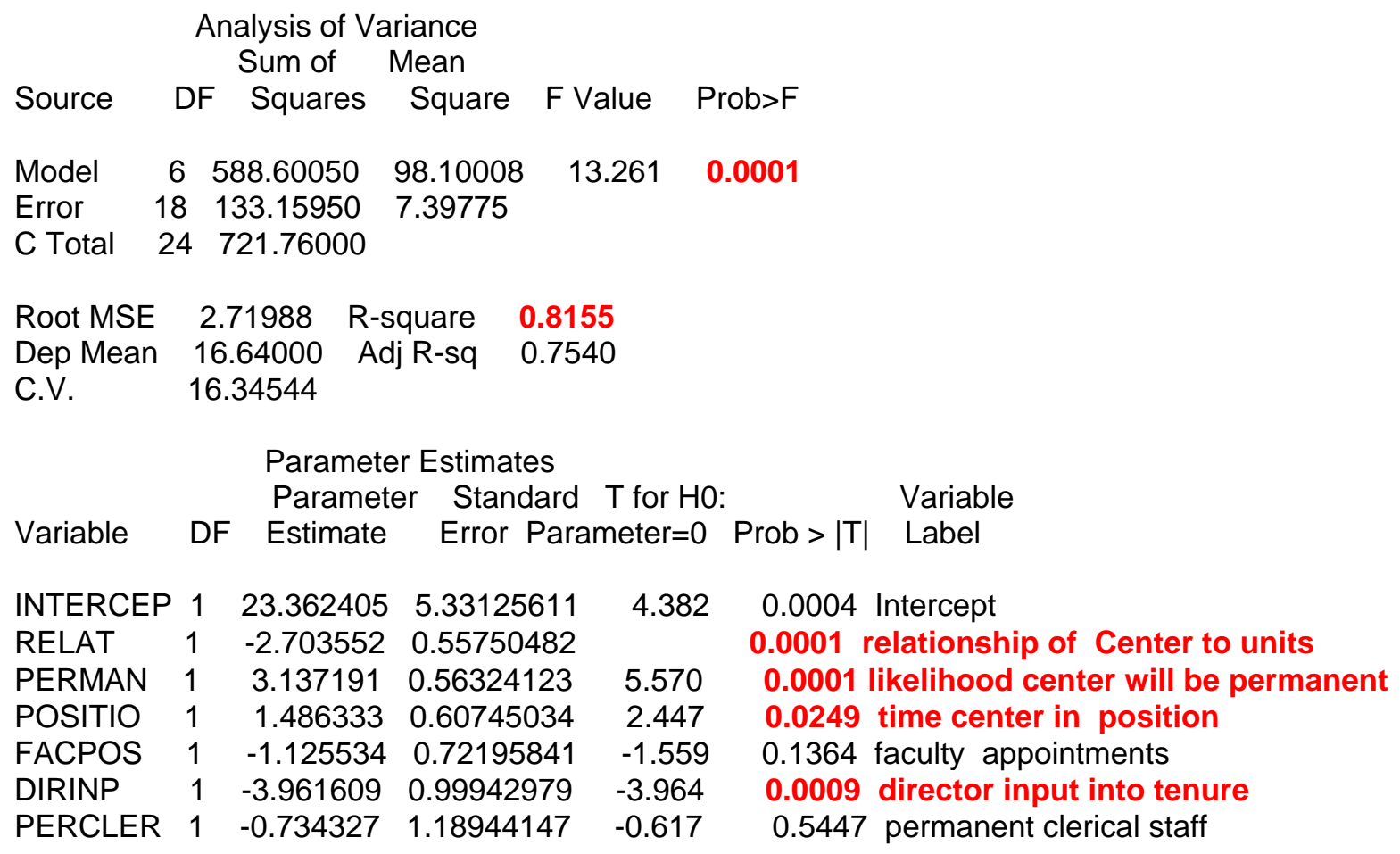




\section{APPENDIX I \\ REGRESSION ANALYSIS OF FINANCIAL ISSUES AND DOMAINS OF ORGANIZATIONAL EFFECTIVENESS}

Domain: Acquisition of Resources

Model: MODEL1

Dependent Variable: RESOURC

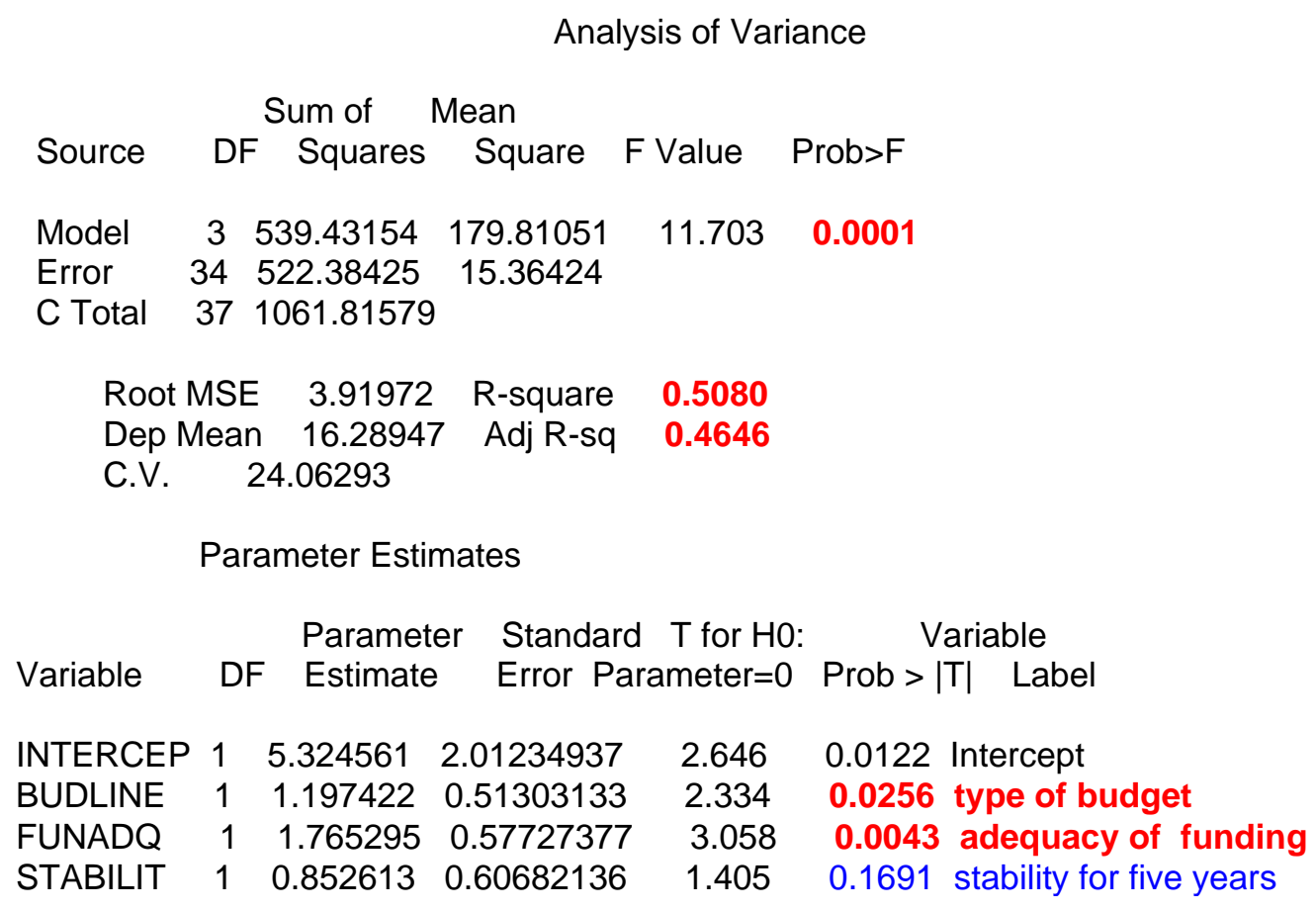




\title{
APPENDIX J \\ REGRESSION ANALYSIS OF FINANCIAL ISSUES AND DOMAINS OF ORGANIZATIONAL EFFECTIVENESS
}

\author{
Domain: Career Goal Satisfaction
}

Model: MODEL1

Dependent Variable: CAREER

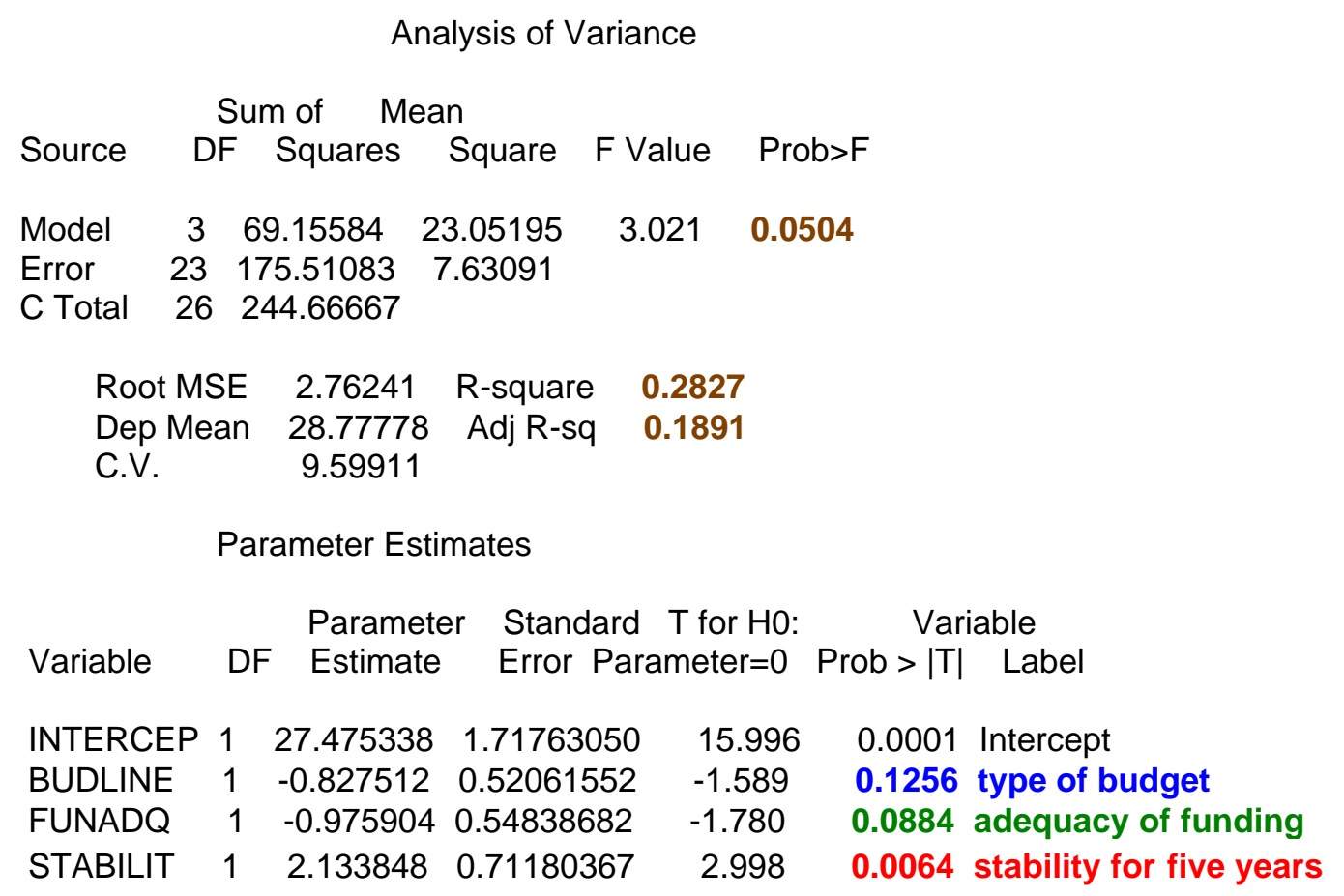




\title{
APPENDIX K \\ REGRESSION ANALYSIS OF ORGANIZATIONAL ACTIVITIES AND DOMAINS OF ORGANIZATIONAL EFFECTIVENESS
}

\author{
Domain: Quality of Faculty
}

Model: MODEL1

Dependent Variable: FACULTY

Analysis of Variance

\begin{tabular}{|c|c|c|c|c|c|}
\hline \multirow[b]{2}{*}{ Source } & \multicolumn{5}{|c|}{ Sum of Mean } \\
\hline & DF & Squares & s Square & F Value & Prob $>F$ \\
\hline $\begin{array}{l}\text { Model } \\
\text { Error } \\
\text { C Total }\end{array}$ & $\begin{array}{r}5 \\
22 \\
27\end{array}$ & $\begin{array}{c}345.84460 \\
468.83398 \\
814.67857\end{array}$ & $\begin{array}{c}69.1689 \\
21.31064\end{array}$ & 3.246 & 0.0241 \\
\hline oot MSE & & 4.61634 & R-square & 0.4245 & \\
\hline Dep Mear & & 20.10714 & Adj R-sq & 0.2937 & \\
\hline C.V. & & 2.95873 & & & \\
\hline
\end{tabular}

Parameter Estimates

Parameter Standard T for H0: Variable

Variable DF Estimate Error Parameter $=0$ Prob $>|T|$ Label

$\begin{array}{lrrrrr}\text { INTERCEP } & 1 & -0.668227 & 8.71944173 & -0.077 & 0.9396 \text { Intercept } \\ \text { ADLED } & 1 & -4.384637 & 2.00577307 & -2.186 & 0.0397 \text { adult education } \\ \text { CE } & 1 & 5.312225 & 2.34849265 & 2.262 & 0.0339 \text { continuing education } \\ \text { CONSUL } & 1 & 4.133811 & 3.59174069 & 1.151 & 0.2621 \text { consultation } \\ \text { SUPPOR } & 1 & -1.244769 & 2.27617490 & -0.547 & 0.5900 \text { support groups } \\ \text { STATE } & 1 & 6.347742 & 2.30010830 & 2.760 & 0.0114 \text { state agencies }\end{array}$




\title{
APPENDIX L \\ REGRESSION ANALYSIS OF ORGANIZATIONAL GOALS AND DOMAINS OF ORGANIZATIONAL EFFECTIVENESS
}

\author{
Domain: Non-Academic
}

Model: MODEL1

Dependent Variable: NOACAD

Analysis of Variance

\begin{tabular}{lrlllll}
\multicolumn{9}{c}{ Sum of } & \multicolumn{1}{c}{ Mean } & & \\
Source & DF & Squares & Square & F Value & Prob>F \\
& & & & & \\
Model & 7 & 619.47362 & 88.49623 & 2.551 & 0.0644 \\
Error & 14 & 485.61729 & 34.68695 & & \\
C Total & 21 & 1105.09091 & & &
\end{tabular}

Root MSE $5.88956 \quad$ R-square 0.5606

Dep Mean 36.63636 Adj R-sq 0.3408

C.V. $\quad 16.07573$

Parameter Estimates

\begin{tabular}{|c|c|c|c|c|c|}
\hline Variable & DF & $\begin{array}{l}\text { Paramete } \\
\text { Estimate }\end{array}$ & $\begin{array}{l}\text { er Standard } \\
\text { Error }\end{array}$ & $\begin{array}{l}\text { T for } \mathrm{H} 0: \\
\text { Paramete }\end{array}$ & $\begin{aligned} \text { Variable } & \text { Pab }=0 \quad \text { Prob }>|T| \text { Label }\end{aligned}$ \\
\hline INTERCEP & 1 & 17.845466 & 9.80686891 & 1.820 & 0.0903 Intercept \\
\hline $\mathrm{GO}$ & 1 & 1.176522 & 0.71787063 & 1.639 & 0.1235 goals:student satisfaction \\
\hline CAR & 1 & -0.942722 & 0.78406498 & -1.202 & 0.2492 goal:career development \\
\hline FAC & 1 & -0.230118 & 1.00703122 & -0.229 & 0.8226 goal: faculty/staff development \\
\hline GOAPRO & 1 & 2.189352 & 0.90791629 & 2.411 & $0.0302 \mathrm{goal}$ :professional development \\
\hline ACOM & 1 & 0.81 & 0.633 & 1.285 & 0.2196 goal:community interaction \\
\hline GOAINT & 1 & 0.730265 & 0.58594945 & 1.246 & 0.2331 goal:interdisciplinary collaboration \\
\hline GOARES & 1 & -0.938233 & 0.46592504 & -2.014 & 0.0637 acquiring resources \\
\hline
\end{tabular}




\section{APPENDIX M \\ REGRESSION ANALYSIS OF DEMOGRAPHICS AND DOMAINS OF ORGANIZATIONAL EFFECTIVENESS \\ Domain: Non-Academic}

Model: MODEL1

ependent Variable: NOACAD

Analysis of Variance

\begin{tabular}{lrrllll} 
Source & Sum of & \multicolumn{2}{c}{ Mean } & & & \\
& DF & Squares & Square & F Value & Prob>F \\
Model & 6 & 701.85621 & 116.97604 & 7.305 & 0.0024 \\
Error & 11 & 176.14379 & 16.01307 & & \\
C Total & 17 & 878.00000 & & &
\end{tabular}

$\begin{array}{lccc}\text { Root MSE } & 4.00163 & \text { R-square } & \mathbf{0 . 7 9 9 4} \\ \text { Dep Mean } & 35.33333 & \text { Adj R-sq } & \mathbf{0 . 6 9 0 0} \\ \text { C.V. } & 11.32538 & & \end{array}$

Parameter Estimates

\begin{tabular}{|c|c|c|c|c|c|}
\hline \multicolumn{6}{|c|}{ Parameter Standard $\mathrm{T}$ for $\mathrm{HO}$ : } \\
\hline Variable & DF & Estimate & Error Par & ameter $=0$ & Prob $>|\mathrm{T}| \quad$ Label \\
\hline INTERCEP & $1-$ & -1788.780442 & 411.60908620 & -4.346 & 0.0012 Intercept \\
\hline FOUND & & 0.932509 & 0.20867977 & 4.469 & 0.0009 date of founding \\
\hline FACPER & 1 & 0.993441 & 0.95089489 & 1.045 & 0.3186 permanent faculty \\
\hline FACAFF & 1 & 0.083766 & 0.04667982 & 1.794 & 0.1002 affiliated faculty \\
\hline FACILITY & 1 & 6.257302 & 1.90136560 & -3.291 & 0.0072 type of facility \\
\hline OPBUDG & 1 & 0.000006057 & 0.00000210 & 2.882 & $\begin{array}{l}0.0149 \text { total operating } \\
\text { budget }\end{array}$ \\
\hline NSTIT & $1-($ & 0.000005651 & 0.00000479 & -1.180 & 0.2629 name of institution \\
\hline
\end{tabular}




\section{APPENDIX N \\ REGRESSION ANALYSIS OF ORGANIZATIONAL MISSION AND DOMAINS OF ORGANIZATIONAL EFFECTIVENESS \\ Domain: Non-Academic}

Model: MODEL1

Dependent Variable: NOACAD

Analysis of Variance

$\begin{array}{lrrrrrr}\text { Source } & \text { DF } & \begin{array}{l}\text { Sum of } \\ \text { Squares }\end{array} & \begin{array}{l}\text { Mean } \\ \text { Square }\end{array} & \text { F Value } & \text { Prob>F } \\ \text { Model } & 3 & 352.46378 & 117.48793 & 3.355 & 0.0435 \\ \text { Error } & 17 & 595.34574 & 35.02034 & & \\ \text { C Total } & 20 & 947.80952 & & & \end{array}$

$\begin{array}{lccc}\text { Root MSE } & 5.91780 & \text { R-square } & 0.3700 \\ \text { Dep Mean } & 35.23810 & \text { Adj R-sq } & \mathbf{0 . 2 6 1 0} \\ \text { C.V. } & 16.79375 & & \end{array}$

\begin{tabular}{|c|c|c|c|c|c|c|}
\hline \multirow[b]{2}{*}{ Variable } & \multicolumn{4}{|c|}{ Parameter Estimates } & & \multirow[b]{2}{*}{$\begin{array}{l}\text { Variable } \\
\text { Label }\end{array}$} \\
\hline & DF & $\begin{array}{l}\text { Paramete } \\
\text { Estimate }\end{array}$ & $\begin{array}{l}\text { Standard } \\
\text { Error Para }\end{array}$ & $\begin{array}{l}\text { T for } \mathrm{H0} \text { : } \\
\text { ameter }=0\end{array}$ & Prob > $|\mathrm{T}|$ & \\
\hline INTERCEP & 12 & 22.249233 & 13.09567502 & 1.699 & 0.1075 & Intercept \\
\hline MISSRES & 1 & -1.185193 & 1.86924081 & -0.634 & 0.5345 & mission:research \\
\hline MISSIN & 1 & 5.827081 & 2.70795537 & 2.152 & 0.0461 & mission:instruction \\
\hline MISSSER & 1 & 0.560032 & 2.47977225 & 0.226 & 0.8240 & mission:service \\
\hline
\end{tabular}




\section{APPENDIX $O$ \\ REGRESSION ANALYSIS OF ORGANIZATIONAL MISSION AND DOMAINS OF ORGANIZATIONAL EFFECTIVENESS}

Domain: Faculty and Staff Job Satisfaction

Model: MODEL1

Dependent Variable: JOB

Analysis of Variance

\begin{tabular}{lrrrrr} 
& \multicolumn{1}{c}{$\begin{array}{c}\text { Sum of } \\
\text { Source }\end{array}$} & DF & Mean & & \\
Squares & Square & F Value & Prob>F \\
Model & 3 & 74.11645 & 24.70548 & 2.765 & 0.0649 \\
Error & 23 & 205.51318 & 8.93536 & & \\
Total & 26 & 279.62963 & & &
\end{tabular}

$\begin{array}{lccc}\text { Root MSE } & 2.98921 & \text { R-square } & \mathbf{0 . 2 6 5 1} \\ \text { Dep Mean } & 10.70370 & \text { Adj R-sq } & \mathbf{0 . 1 6 9 2} \\ \text { C.V. } & 27.92684 & & \end{array}$

\begin{tabular}{lcccccc}
\multicolumn{7}{c}{ Parameter Estimate } \\
Variable & DF $\begin{array}{c}\text { Parameter } \\
\text { Estimate }\end{array}$ & $\begin{array}{c}\text { Standard T for H0: } \\
\text { Error Parameter=0 }\end{array}$ & Prob $>|\mathrm{T}|$ Lariable \\
& & & & & \\
INTERCEP & 1 & 14.272356 & 4.03129318 & 3.540 & 0.0017 & Intercept \\
MISSRES & 1 & -1.106416 & 0.54546304 & -2.028 & 0.0543 mission:research \\
MISSIN & 1 & 0.754271 & 0.91771315 & 0.822 & 0.4196 mission:instruction \\
MISSSER & 1 & -1.512541 & 0.88808801 & -1.703 & $\mathbf{0 . 1 0 2 0}$ mission:service
\end{tabular}




\section{APPENDIX P \\ Predictor Variables for Resource Acquisition}

Adequacy of Funding

Model: MODEL1

Dependent Variable: Resource Acquisition

Analysis of Variance

\begin{tabular}{|c|c|c|c|c|c|}
\hline \multirow[b]{2}{*}{ Source } & \multicolumn{2}{|c|}{ Sum of Mean } & & \multirow[b]{2}{*}{ F Value } & \multirow[b]{2}{*}{ Prob $>F$} \\
\hline & DF & Squares & Square & & \\
\hline $\begin{array}{l}\text { Model } \\
\text { Error } \\
\text { C Total }\end{array}$ & $\begin{array}{c}1 \\
36 \\
37\end{array}$ & $\begin{array}{c}388.55268 \\
673.26311 \\
1061.81579\end{array}$ & $\begin{array}{l}388.55268 \\
18.70175\end{array}$ & 20.776 & $6 \quad 0.0001$ \\
\hline $\begin{array}{l}\text { Roo } \\
\text { Dep } \\
\text { C.V }\end{array}$ & $\begin{array}{l}\text { MSE } \\
\text { Mean }\end{array}$ & $\begin{array}{c}4.32455 \\
16.28947 \\
26.54814\end{array}$ & $\begin{array}{r}\text { R-square } \\
\text { Adj R-sq }\end{array}$ & $\begin{array}{l}0.3659 \\
0.3483\end{array}$ & \\
\hline
\end{tabular}

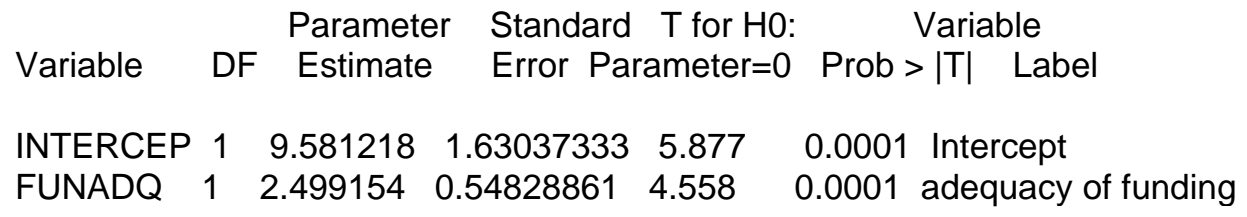


Adequacy of Resources

Model: MODEL1

Dependent Variable: Resource Acquisition

Analysis of Variance

$\begin{array}{ll}\text { Sum of Mean } \\ \text { Source } & \text { DF Squares Square F Value Prob }>F\end{array}$

$\begin{array}{llllll}\text { Model } & 1 & 297.76951 & 297.76951 & 13.694 & 0.0007\end{array}$

Error $\quad 35 \quad 761.04130 \quad 21.74404$

C Total 361058.81081

Root MSE $\quad 4.66305 \quad$ R-square $\quad 0.2812$

Dep Mean 16.24324 Adj R-sq $\mathbf{0 . 2 6 0 7}$

C.V. $\quad 28.70763$

Parameter Estimates

$\begin{array}{cccc} & \text { Parameter Standard T for H0: } & \text { Variable } \\ \text { Variable } & \text { DF Estimate Error Parameter }=0 & \text { Prob }>|\mathrm{T}| & \text { Label }\end{array}$

$\begin{array}{llllll}\text { INTERCEP } 1 & 9.919053 & 1.87303537 & 5.296 & 0.0001 & \text { Intercept }\end{array}$

$\begin{array}{llllll}\text { ADEGRE } & 1 & 2.463106 & 0.66559957 & 3.701 & 0.0007\end{array}$ adequacy of resources 


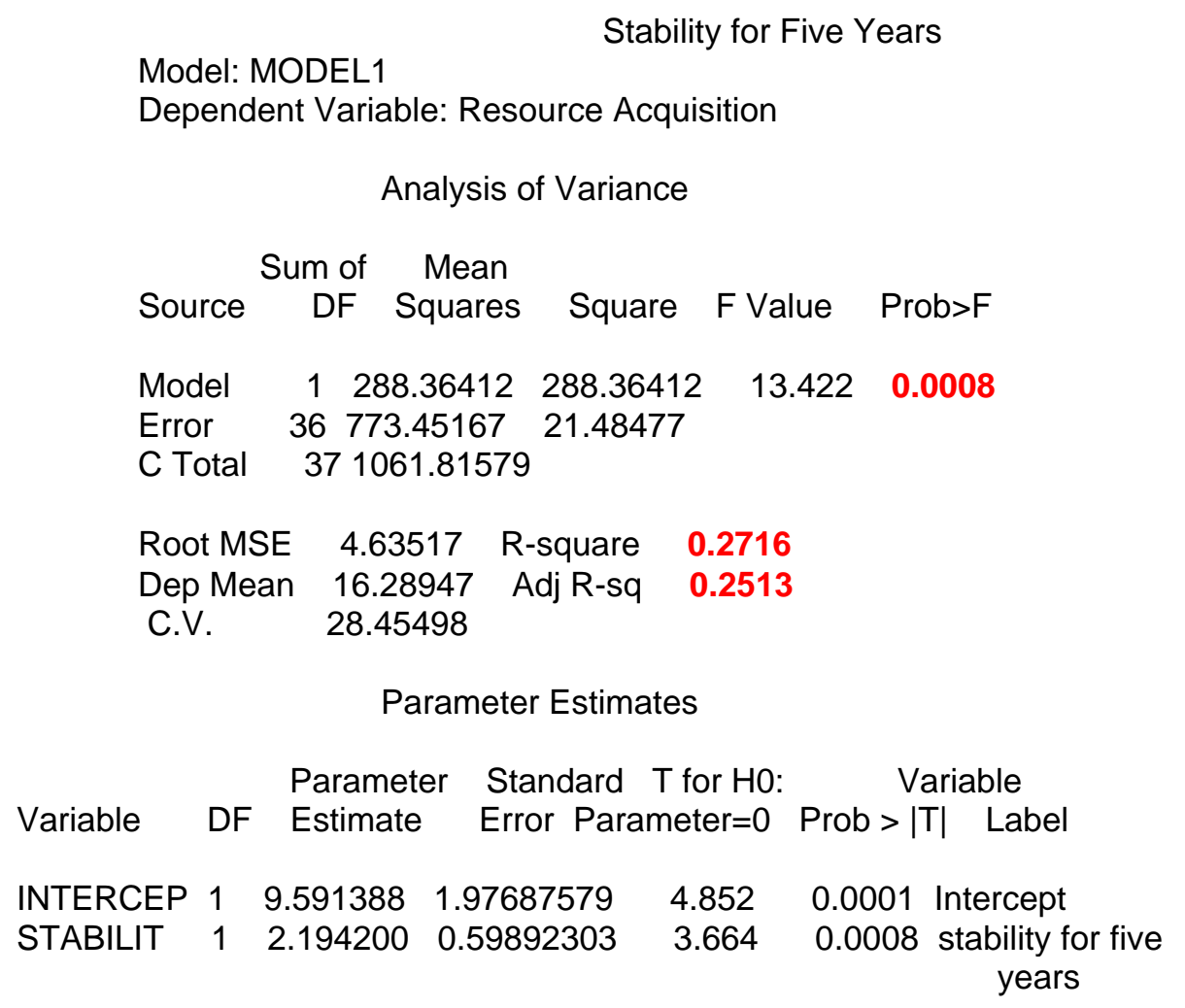


Model: MODEL1

Type of Budget

Dependent Variable: Resource Acquisition

Analysis of Variance

\begin{tabular}{|c|c|c|c|c|}
\hline \multicolumn{5}{|c|}{ Sum of Mean } \\
\hline Source & DF Squares & Square & F Value & Prob $>F$ \\
\hline Model & 1243.52817 & 243.52817 & 10.714 & 0.0024 \\
\hline $\begin{array}{l}\text { Error } \\
\text { C Total }\end{array}$ & $\begin{array}{c}36818.28762 \\
371061.81579\end{array}$ & 22.73021 & & \\
\hline
\end{tabular}

Root MSE 4.76762 R-square 0.2294

Dep Mean 16.28947 Adj R-sq 0.2079

C.V. $\quad 29.26811$

\begin{tabular}{|c|c|c|c|c|c|c|c|}
\hline \multicolumn{8}{|c|}{ Parameter Estimates } \\
\hline \multirow[b]{2}{*}{ Variable } & & ameter Star & ndard & $\mathrm{T}$ for $\mathrm{HC}$ & & Variable & \multirow[b]{2}{*}{ Label } \\
\hline & DF & Estimate & Error & Parame & $e r=0$ & Prob $>|\mathrm{T}|$ & \\
\hline INTERCE & $P 1$ & 10.518664 & 1.92 & 522679 & 5.46 & 0.0001 & Intercept \\
\hline BUDLINE & 1 & 1.906876 & 0.582 & 257205 & 3.273 & 0.0024 & type of budget \\
\hline
\end{tabular}


Likelihood Center will be Permanent

\author{
Model: MODEL1 \\ Dependent Variable: Resource Acquisition \\ Analysis of Variance \\ Source DF $\begin{aligned} & \text { Sum of } \\ & \text { Squares }\end{aligned} \quad \begin{array}{lll}\text { Mean } \\ \text { Square }\end{array}$ F Value Prob $>F$ \\ $\begin{array}{llllll}\text { Model } & 1 & 196.79816 & 196.79816 & 8.892 & 0.0055\end{array}$ \\ Error $\quad 31 \quad 686.11094 \quad 22.13261$ \\ C Total 32882.90909 \\ Root MSE $\quad 4.70453 \quad$ R-square $\quad 0.2229$ \\ Dep Mean 15.81818 Adj R-sq 0.1978 \\ C.V. $\quad 29.74129$ \\ Parameter Estimates \\ $\begin{array}{lll}\text { Variable DF } & \begin{array}{l}\text { Parameter } \\ \text { Estimate }\end{array} & \begin{array}{l}\text { Standard T for } \mathrm{HO}: \\ \text { Error Parameter }=0 \text { Prob }>|\mathrm{T}|\end{array} \text { Label }\end{array}$ \\ $\begin{array}{llllll}\text { INTERCEP } 1 & 20.029393 & 1.63252776 & 12.269 & 0.0001 & \text { Intercept }\end{array}$ \\ $\begin{array}{llllll}\text { PERMAN } & 1 & -1.432680 & 0.48045759 & -2.982 & 0.0055\end{array}$ likelihood center \\ will be permanent
}




\section{Impetus for Starting Center}

Model: MODEL1

Dependent Variable: Resource Acquisition

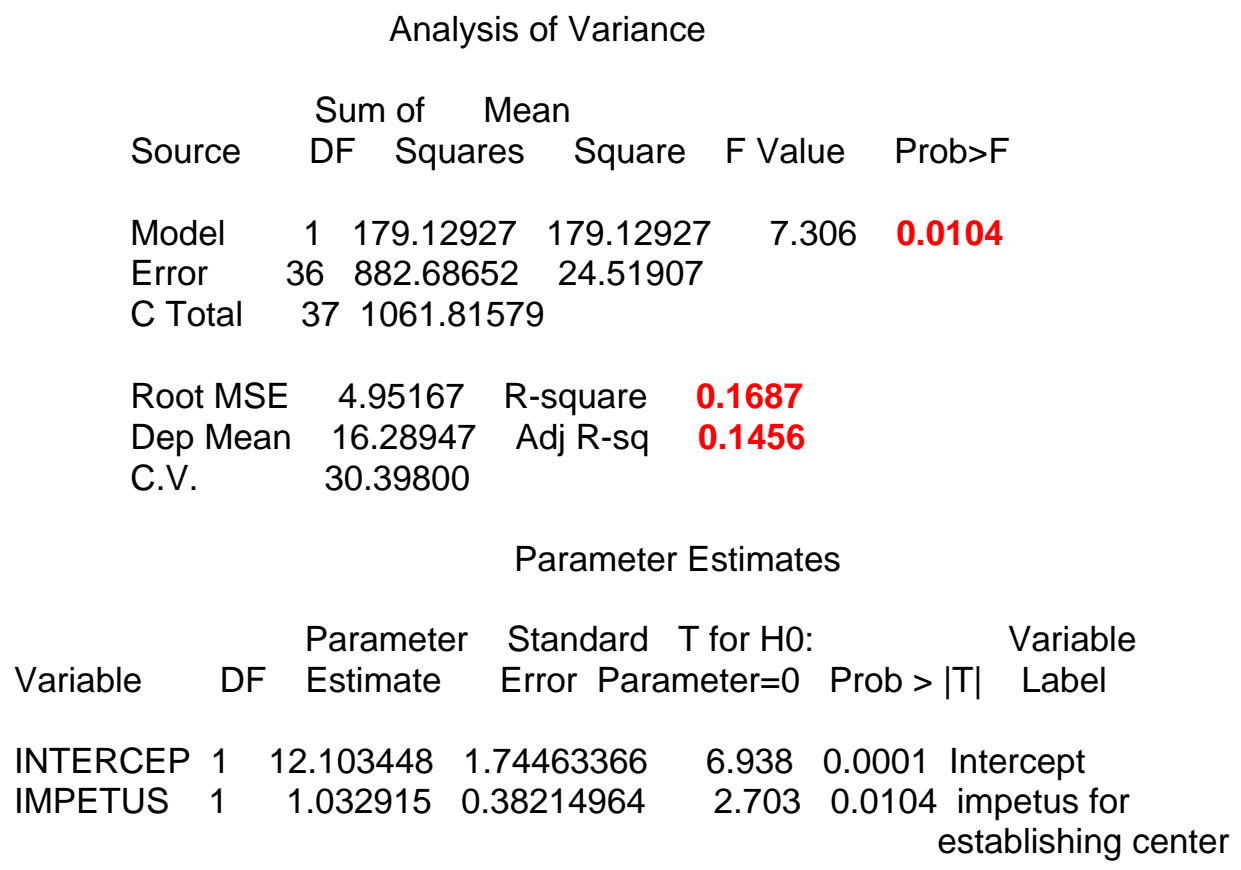




\section{Expenditures on the Physical Plant}

Model: MODEL1

Dependent Variable: Resource Acquisition

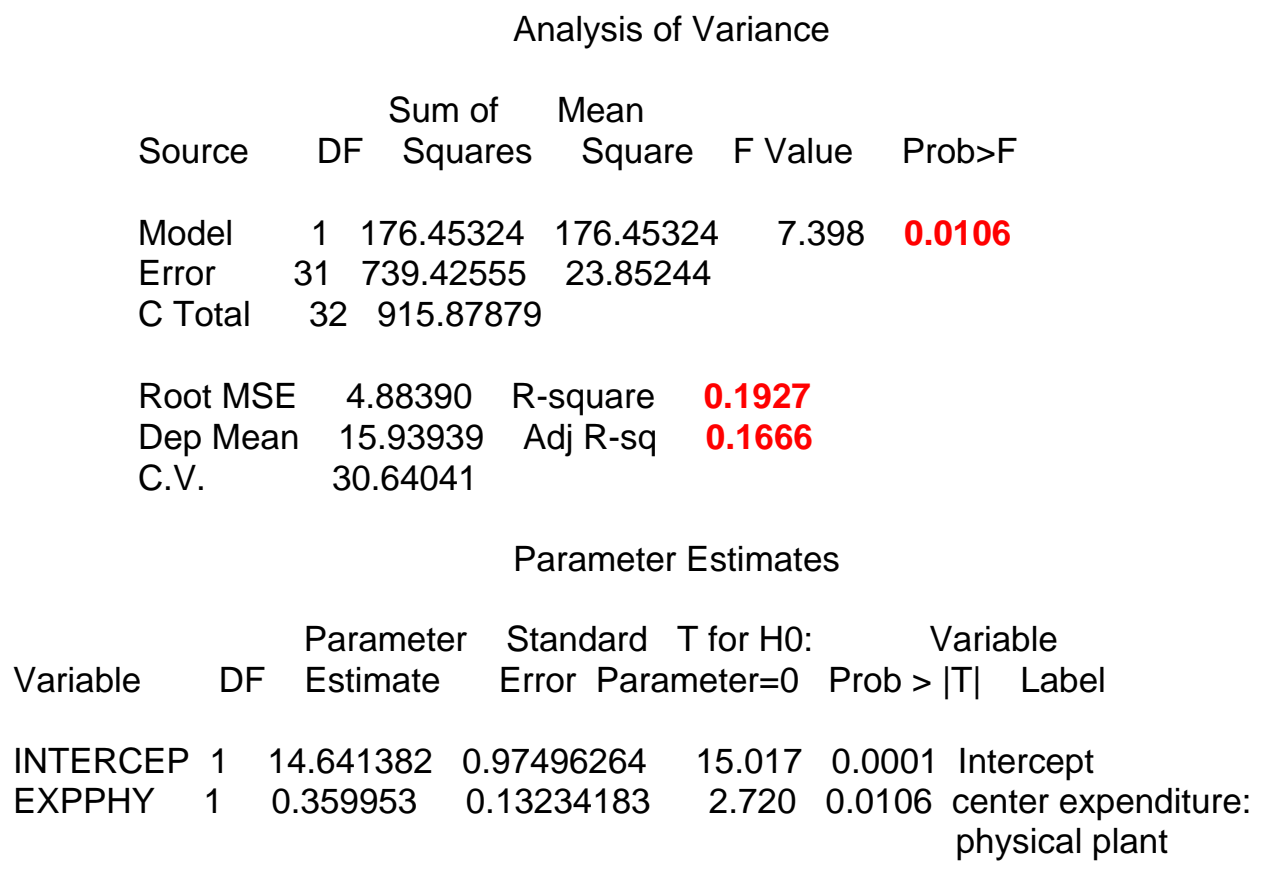




\section{Permanent Faculty}

Model: MODEL1

Dependent Variable: Resource Acquisition

Analysis of Variance

$\begin{array}{lccccc}\text { Source } & \text { DF } & \text { Squares } & \text { Square } & \text { F Value } & \text { Prob }>F \\ & & & & & \\ \text { Model } & 1 & 154.51418 & 154.51418 & 6.841 & 0.0133 \\ \text { Error } & 33 & 745.37154 & 22.58702 & & \\ \text { C Total } & 34 & 899.88571 & & & \end{array}$

$\begin{array}{lccc}\text { Root MSE } & 4.75258 & \text { R-square } & 0.1717 \\ \text { Dep Mean } & 15.94286 & \text { Adj R-sq } & 0.1466 \\ \text { C.V. } & 29.81009 & & \end{array}$

\begin{tabular}{|c|c|c|c|c|c|c|}
\hline \multicolumn{7}{|c|}{ Parameter Estimates } \\
\hline Variable & DF & $\begin{array}{l}\text { Parameter } \\
\text { Estimate }\end{array}$ & $\begin{array}{l}\text { Standard } \\
\text { Error Para }\end{array}$ & $\begin{array}{l}\mathrm{T} \text { for } \mathrm{HO} \text { : } \\
\text { ameter }=0\end{array}$ & Prob $>|\mathrm{T}|$ & $\begin{array}{l}\text { Variable } \\
\text { Label }\end{array}$ \\
\hline INTERCEP & 1 & 14.0203111 & 1.08887764 & 12.876 & 0.0001 & ntercept \\
\hline FACPER & 1 & $0.975204 \quad 0$ & .37285583 & 2.616 & $0.0133 p$ & ermanent faculty \\
\hline
\end{tabular}




\section{Administrative Staff}

Model: MODEL1

Dependent Variable: Resource Acquisition

Analysis of Variance

\begin{tabular}{lccccc} 
& \multicolumn{4}{c}{ Sum of Mean } & \\
Source & DF & Squares & Square & F Value & Prob>F \\
& & & & & \\
Model & 1 & 154.84149 & 154.84149 & 6.699 & 0.0142 \\
Error & 33 & 762.75851 & 23.11389 & & \\
C Total & 34 & 917.60000 & & &
\end{tabular}

$\begin{array}{lccc}\text { Root MSE } & 4.80769 & \text { R-square } & 0.1687 \\ \text { Dep Mean } & 16.20000 & \text { Adj R-sq } & 0.1436 \\ \text { C.V. } & 29.67711 & & \end{array}$

\begin{tabular}{lllllll}
\multicolumn{7}{c}{ Parameter Estimates } \\
Variable & DF & $\begin{array}{l}\text { Parameter } \\
\text { Estimate }\end{array}$ & $\begin{array}{l}\text { Standard } \\
\text { Error Parameter }=0\end{array}$ & Prob $>|\mathrm{T}|$ & $\begin{array}{l}\text { Variable } \\
\text { Label }\end{array}$ \\
& & & & & & \\
INTERCEP & 1 & 13.730215 & 1.25337444 & 10.955 & 0.0001 & Intercept \\
ADMSTA & 1 & 1.509912 & 0.58337065 & 2.588 & 0.0142 & administrative staff
\end{tabular}




\section{Activities: Community Projects}

Model: MODEL1

Dependent Variable: Resource Acquisition

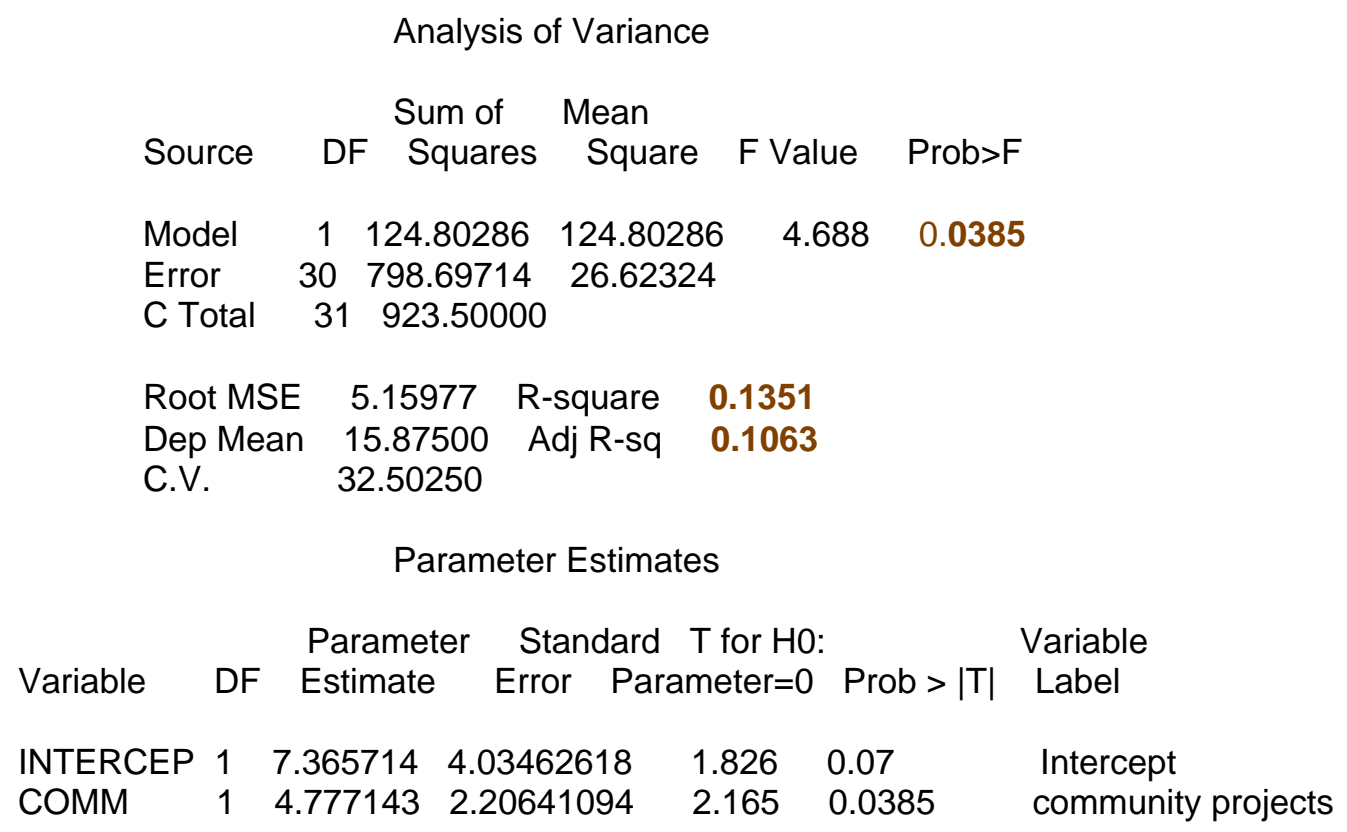


Type of Facility

Model: MODEL1

Dependent Variable: Resource Acquisition

\begin{tabular}{|c|c|c|c|c|c|}
\hline \multicolumn{6}{|c|}{ Analysis of Variance } \\
\hline Source & $\begin{array}{c}\text { Sum of } \\
\text { DF }\end{array}$ & $\begin{array}{c}\text { Mean } \\
\text { Squares }\end{array}$ & Square & F Value & Prob $>F$ \\
\hline $\begin{array}{l}\text { Model } \\
\text { Error } \\
\text { C Total }\end{array}$ & $\begin{array}{cc}1 & 1 \\
36 & 9 \\
37 & \end{array}$ & $\begin{array}{l}120.33333 \\
941.48246 \\
1061.81579\end{array}$ & $\begin{array}{c}120.33333 \\
26.15229\end{array}$ & 4.601 & 0.0388 \\
\hline
\end{tabular}

Root MSE $\quad 5.11393$ R-square $\mathbf{0 . 1 1 3 3}$

Dep Mean 16.28947 Adj R-sq $\mathbf{0 . 0 8 8 7}$

C.V. $\quad 31.39408$

Parameter Estimates

$\begin{array}{llll}\text { Variable } \quad \mathrm{DF} & \begin{array}{l}\text { Parameter } \\ \text { Estimate }\end{array} & \text { Standard Tfor } \mathrm{H} 0 \text { : } & \text { Variable } \\ \text { Error Parameter }=0 \text { Prob }>|\mathrm{T}| & \text { Label }\end{array}$

$\begin{array}{llllll}\text { INTERCEP } 1 & 3.622807 & 5.96304778 & 0.608 & 0.5473 & \text { Intercept }\end{array}$

$\begin{array}{llllll}\text { FACILITY } & 1 & 3.166667 & 1.47626472 & 2.145 & 0.0388\end{array}$ type of facility 
Relationship of the Center to the Institution

Model: MODEL1

Dependent Variable: Resource Acquisition

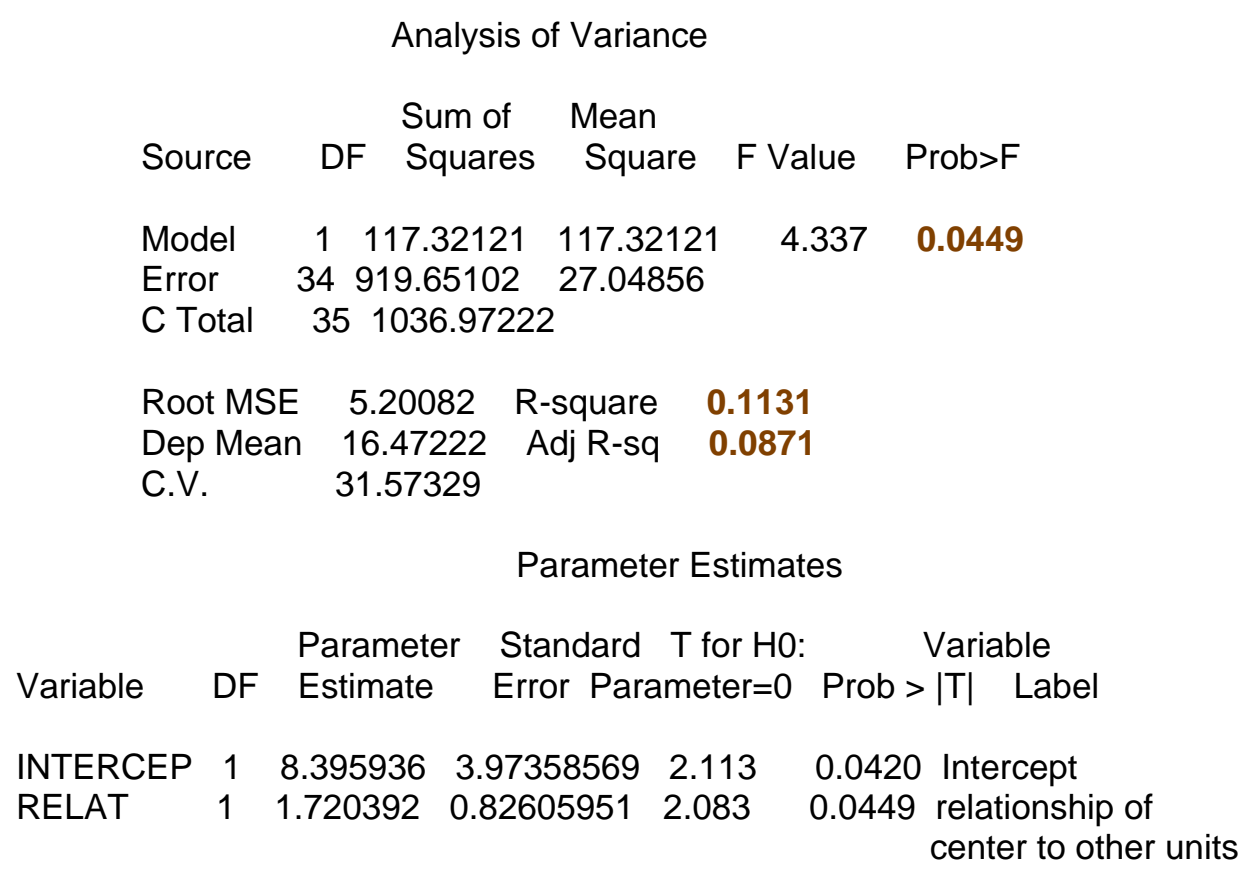




\section{Mission: Research}

Model: MODEL1

Dependent Variable: Resource Acquisition

Analysis of Variance

$\begin{array}{lccccc}\text { Source } & \text { DF } & \begin{array}{c}\text { Sum of } \\ \text { Squares }\end{array} & \begin{array}{c}\text { Mean } \\ \text { Square }\end{array} & \text { F Value } & \text { Prob>F } \\ \text { Model } & 1 & 110.08407 & 110.08407 & 4.202 & 0.0481 \\ \text { Error } & 34 & 890.66593 & 26.19606 & & \\ \text { C Total } & 35 & 1000.75000 & & & \end{array}$

Root MSE $\quad 5.11821$ R-square 0.1100

Dep Mean 16.58333 Adj R-sq 0.0838

C.V. $\quad 30.86357$

Parameter Estimates

\begin{tabular}{lllllll} 
Variable & DF & $\begin{array}{c}\text { Parameter } \\
\text { Estimate }\end{array}$ & \multicolumn{2}{c}{$\begin{array}{c}\text { Standard } \\
\text { Error Parameter }=0\end{array}$} & Prob $>|\mathrm{T}|$ & $\begin{array}{l}\text { Variable } \\
\text { Label }\end{array}$ \\
INTERCEP & 1 & 13.090558 & 1.90544140 & 6.870 & 0.0001 & Intercept \\
MISSRES & 1 & 1.479293 & 0.72162237 & 2.050 & 0.0481 & mission:research
\end{tabular}




$$
\text { Job of Director: Teaching }
$$

Model: MODEL1

Dependent Variable: Resource Acquisition

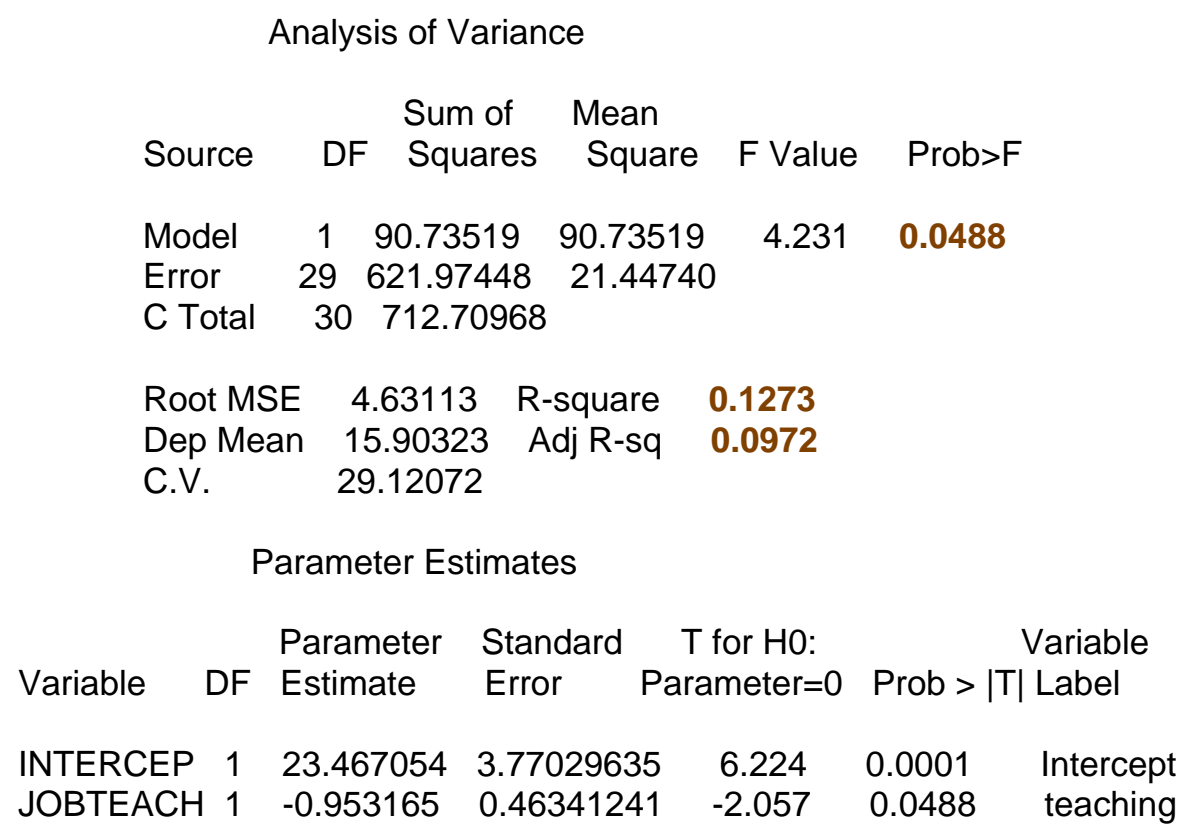




\title{
APPENDIX Q \\ PREDICTOR VARIABLE FOR Career goal satisfaction Likelihood Center will be Permanent
}

\author{
Dependent Variable: CAREER \\ Analysis of Variance

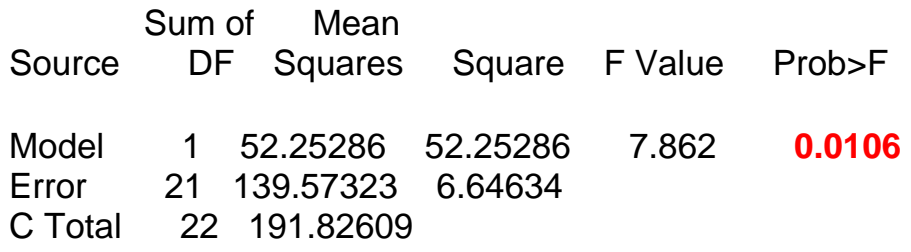 \\ Root MSE $\quad 2.57805 \quad$ R-square $\quad 0.2724$ \\ Dep Mean 28.91304 Adj R-sq 0.2377 \\ C.V. $\quad 8.91657$

\begin{tabular}{|c|c|c|c|c|}
\hline \multicolumn{5}{|c|}{ Parameter Estimates } \\
\hline Variable DF & $\begin{array}{l}\text { Parameter } \\
\text { Estimate }\end{array}$ & $\begin{array}{l}\text { Standard } \mathrm{T} \text { for } \mathrm{H} 0 \text { : } \\
\text { Error Parameter }=0\end{array}$ & Prob $>|\mathrm{T}|$ & $\begin{array}{l}\text { Variable } \\
\text { Label }\end{array}$ \\
\hline INTERCEP 1 & 31.239496 & $0.98863723 \quad 31.599$ & 0.0001 & Intercept \\
\hline PERMAN 1 & -0.849340 & $0.30291295-2.804$ & 0.0106 & $\begin{array}{l}\text { likelihood center } \\
\text { will be permanent }\end{array}$ \\
\hline
\end{tabular}


Job of Director: Budgeting

Model: MODEL1

Dependent Variable: CAREER

Analysis of Variance

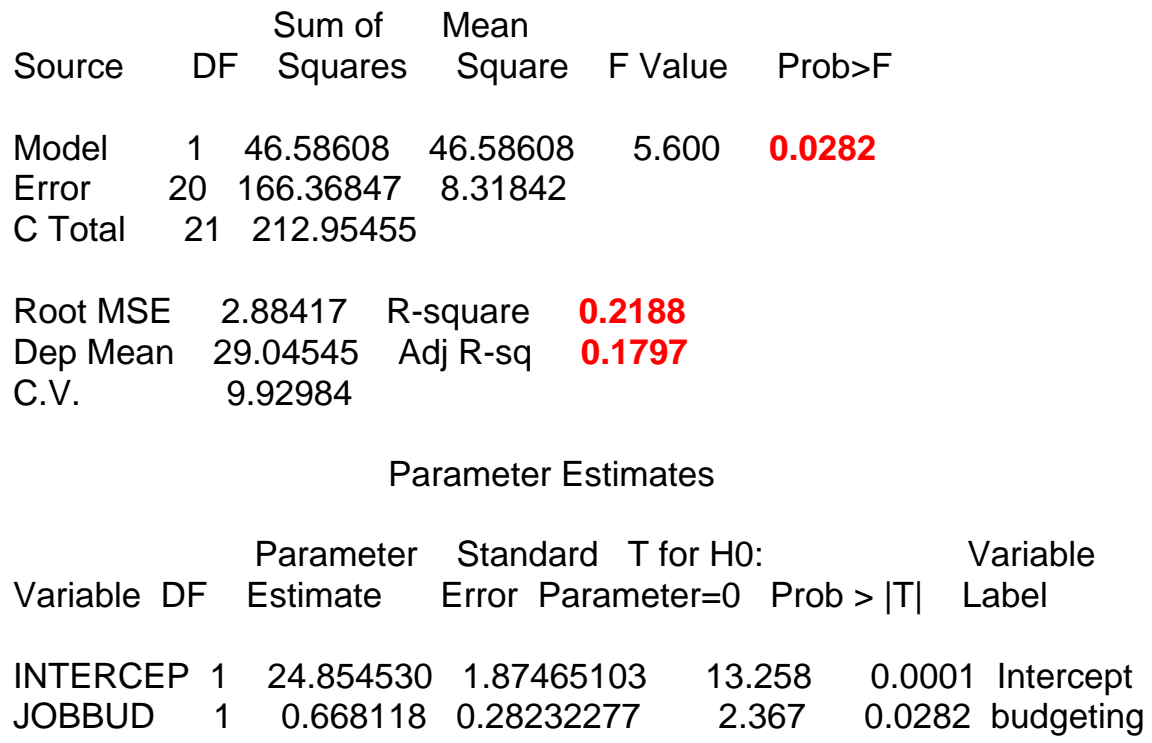




\section{Permanent Faculty}

Model: MODEL1

Dependent Variable: CAREER

Analysis of Variance

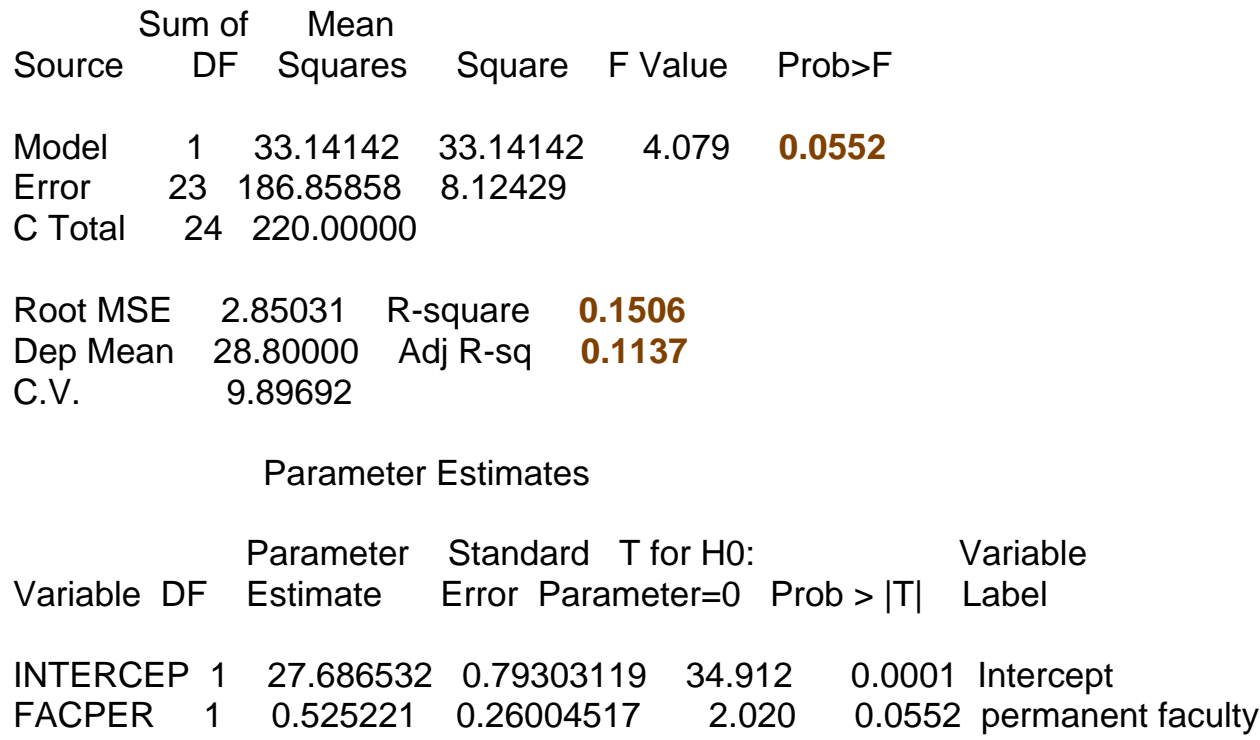




\section{STABILITY FOR FIVE YEARS}

Model: MODEL1

Dependent Variable: CAREER

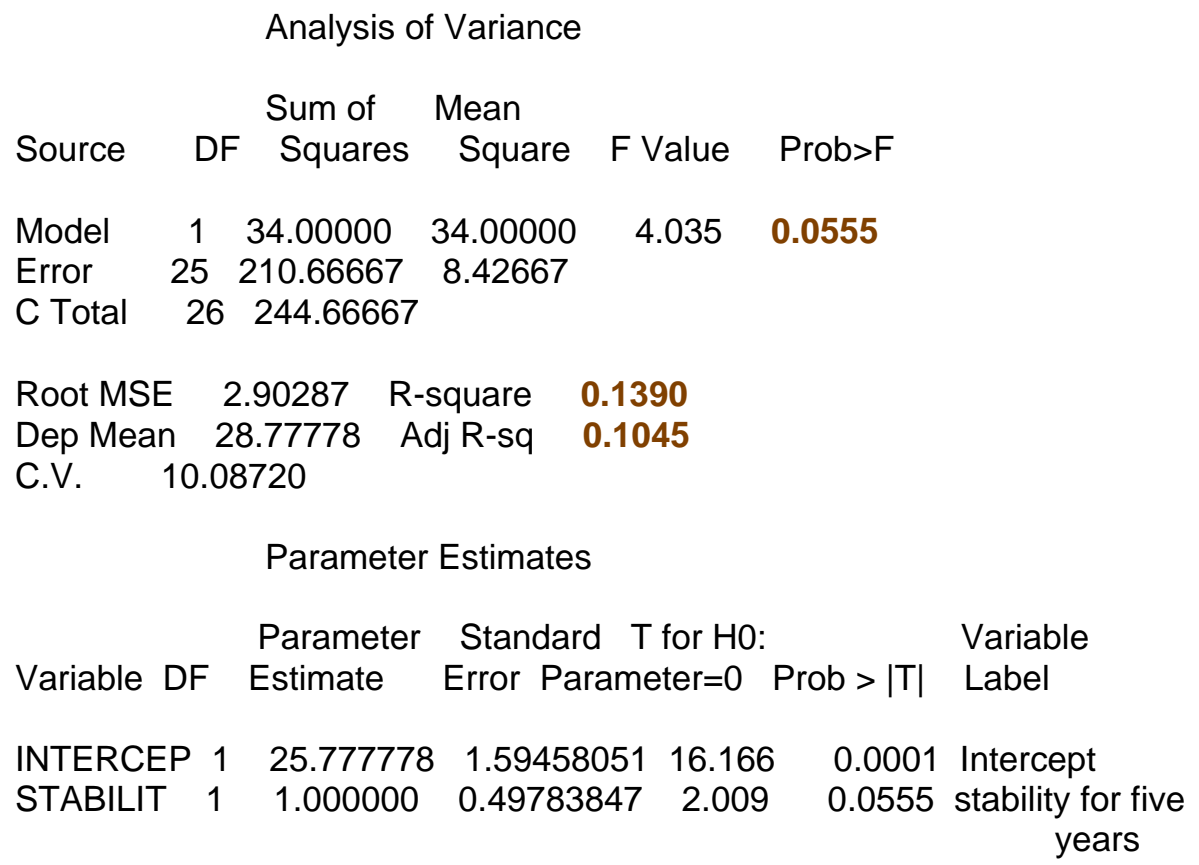




\section{APPENDIX R}

\section{PREDICTOR VARIABLES FOR ORGANIZATIONAL HEALTH}

Model: MODEL1

Adequacy of Space

Dependent Variable: WORK

\begin{tabular}{lccccc}
\multicolumn{5}{c}{ Analysis of Variance } \\
Source & D D & Squares & Square & F Value & Prob>F \\
& & & & & \\
Model & 1 & 109.02514 & 109.02514 & 6.150 & 0.0192 \\
Error & 29 & 514.07163 & 17.72661 & & \\
C Total & 30 & 623.09677 & & &
\end{tabular}

Root MSE $\quad 4.21030 \quad$ R-square $\quad 0.1750$

Dep Mean 24.35484 Adj R-sq 0.1465

C.V. $\quad 17.28732$

Parameter Estimates

\begin{tabular}{|c|c|c|c|c|c|}
\hline Variable DF & $\begin{array}{l}\text { Parameter } \\
\text { Estimate }\end{array}$ & $\begin{array}{l}\text { Standard } \\
\text { Error Param }\end{array}$ & $\begin{array}{l}\Gamma \text { for } \mathrm{H} 0 \text { : } \\
\text { eter }=0\end{array}$ & Prob $>|T|$ & $\begin{array}{l}\text { Variable } \\
\text { Label }\end{array}$ \\
\hline & 19.909929 & & & & \\
\hline ACE 1 & 1.548227 & 0.62428674 & 2.480 & 0.0192 & adequacy of space \\
\hline
\end{tabular}


Whose Resources Faculty Use?

Model: MODEL1

Dependent Variable: WORK

Analysis of Variance

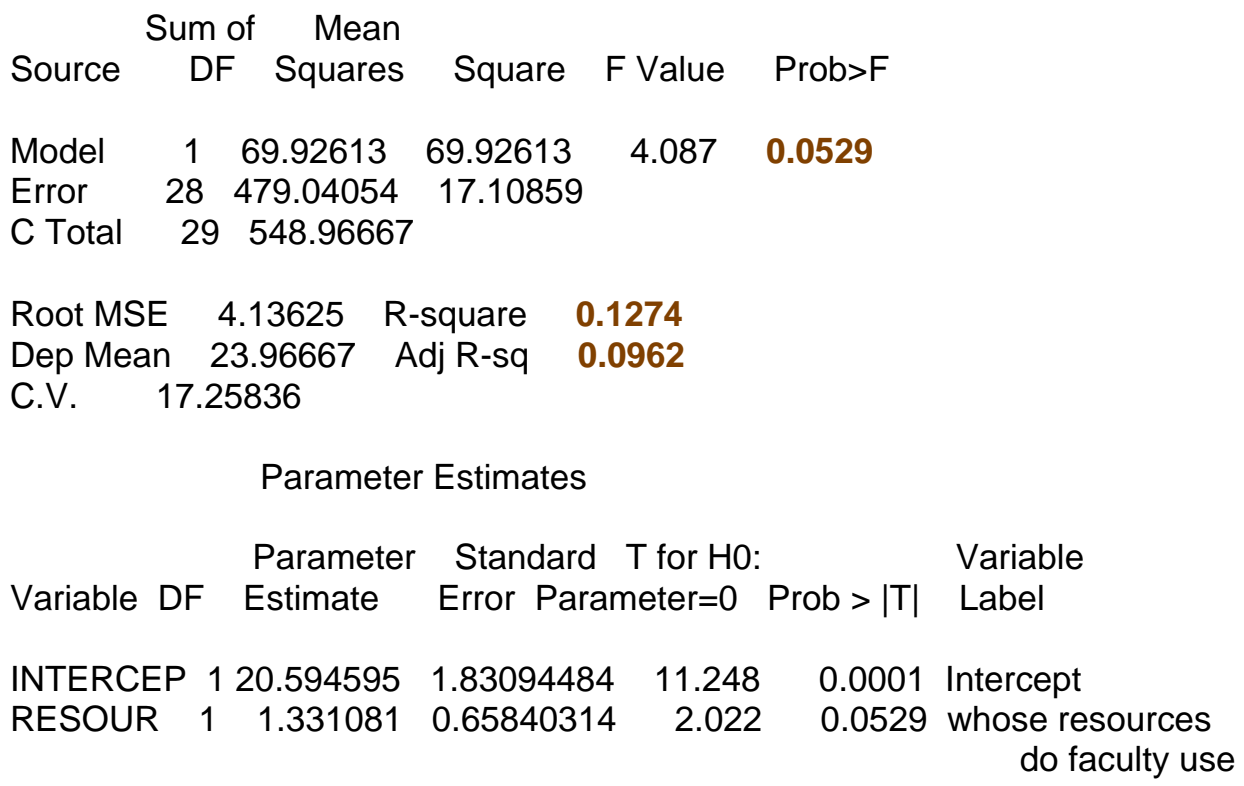




\section{Percentage of Director's Time in Teaching}

Model: MODEL1

Dependent Variable: WORK

Analysis of Variance

\begin{tabular}{|c|c|c|c|c|c|}
\hline Source & $\begin{array}{c}\text { Sum o } \\
\text { DF }\end{array}$ & 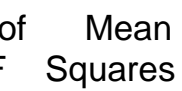 & Square & F Value & Prob $>F$ \\
\hline IVlodel & 1 & 60.32048 & 60.32048 & 3.921 & 0.0569 \\
\hline $\begin{array}{l}\text { Error } \\
\text { C Total }\end{array}$ & $\begin{array}{l}30 \\
31\end{array}$ & $\begin{array}{c}461.55452 \\
521.87500\end{array}$ & 15.38515 & & \\
\hline
\end{tabular}

$\begin{array}{lccc}\text { Root MSE } & 3.92239 & \text { R-square } & \mathbf{0 . 1 1 5 6} \\ \text { Dep Mean } & 23.93750 & \text { Adj R-sq } & \mathbf{0 . 0 8 6 1} \\ \text { C.V. } & 16.38597 & & \end{array}$

16.38597

Parameter Estimates

Parameter Standard T for H0: Variable

Variable DF Estimate Error Parameter $=0$ Prob $>|\mathrm{T}|$ Label

$\begin{array}{llllll}\text { INTERCEP } 1 & 25.580897 & 1.08149495 & 23.653 & 0.0001 & \text { Intercept }\end{array}$

$\begin{array}{llllll}\text { TIMETEA } & 1 & -0.500845 & 0.25294235 & -1.980 & 0.0569 \% \text { teaching }\end{array}$ 
APPENDIX $S$

\title{
PREDICTOR VARIABLES FOR QUALITY OF FACULTY
}

\author{
Model: MODEL1 \\ Goal: Student Satisfaction \\ Dependent Variable: FACULTY \\ Analysis of Variance \\ Source DF $\begin{aligned} & \text { Sum of } \\ & \text { Squares }\end{aligned}$ Square $F$ Value Prob $>F$ \\ $\begin{array}{llllll}\text { Model } & 1 & 201.42605 & 201.42605 & 9.587 & 0.0048\end{array}$ \\ Error $\quad 25 \quad 525.24062 \quad 21.00962$ \\ C Total 26726.66667 \\ Root MSE 4.58363 R-square 0.2772 \\ Dep Mean 20.11111 Adj R-sq $\mathbf{0 . 2 4 8 3}$ \\ C.V. $\quad 22.79151$ \\ Parameter Estimates \\ Parameter Standard $\mathrm{T}$ for $\mathrm{HO}$ : Variable \\ Variable DF Estimate Error Parameter $=0$ Prob $>|T|$ Label \\ $\begin{array}{llllll}\text { INTERCEP } 1 & 25.691279 & 2.00648774 & 12.804 & 0.0001 & \text { Intercept }\end{array}$ \\ $\begin{array}{llllll}\text { GOASTU } & 1 & -0.972029 & 0.31392842 & -3.096 & 0.0048\end{array}$ goals:student \\ satisfaction
}


Job of Director: Fundraising

Model: MODEL1

Dependent Variable: FACULTY

Analysis of Variance

$\begin{array}{lccccc}\text { Source } & \text { DF } & \begin{array}{c}\text { Sum of } \\ \text { Squares }\end{array} & \begin{array}{c}\text { Mean } \\ \text { Square }\end{array} & \text { F Value } & \text { Prob>F } \\ \text { Model } & 1 & 132.58145 & 132.58145 & 6.901 & 0.0134 \\ \text { Error } & 30 & 576.38730 & 19.21291 & & \\ \text { C Total } & 31 & 708.96875 & & & \end{array}$

Root MSE $\quad 4.38325 \quad$ R-square $\quad 0.1870$

Dep Mean 21.03125 Adj R-sq 0.1599

C.V. 20.84162

Parameter Estimates

Parameter Standard $\mathrm{T}$ for $\mathrm{HO}$ : Variable

Variable DF Estimate Error Parameter $=0$ Prob $>|T|$ Label

$\begin{array}{llllll}\text { INTERCEP } 1 & 26.521407 & 2.22898542 & 11.898 & 0.0001 & \text { Intercept }\end{array}$

$\begin{array}{llllll}\text { JOBFUND } & 1 & -0.747596 & 0.28459159 & -2.627 & 0.0134 \text { fundraising }\end{array}$ 


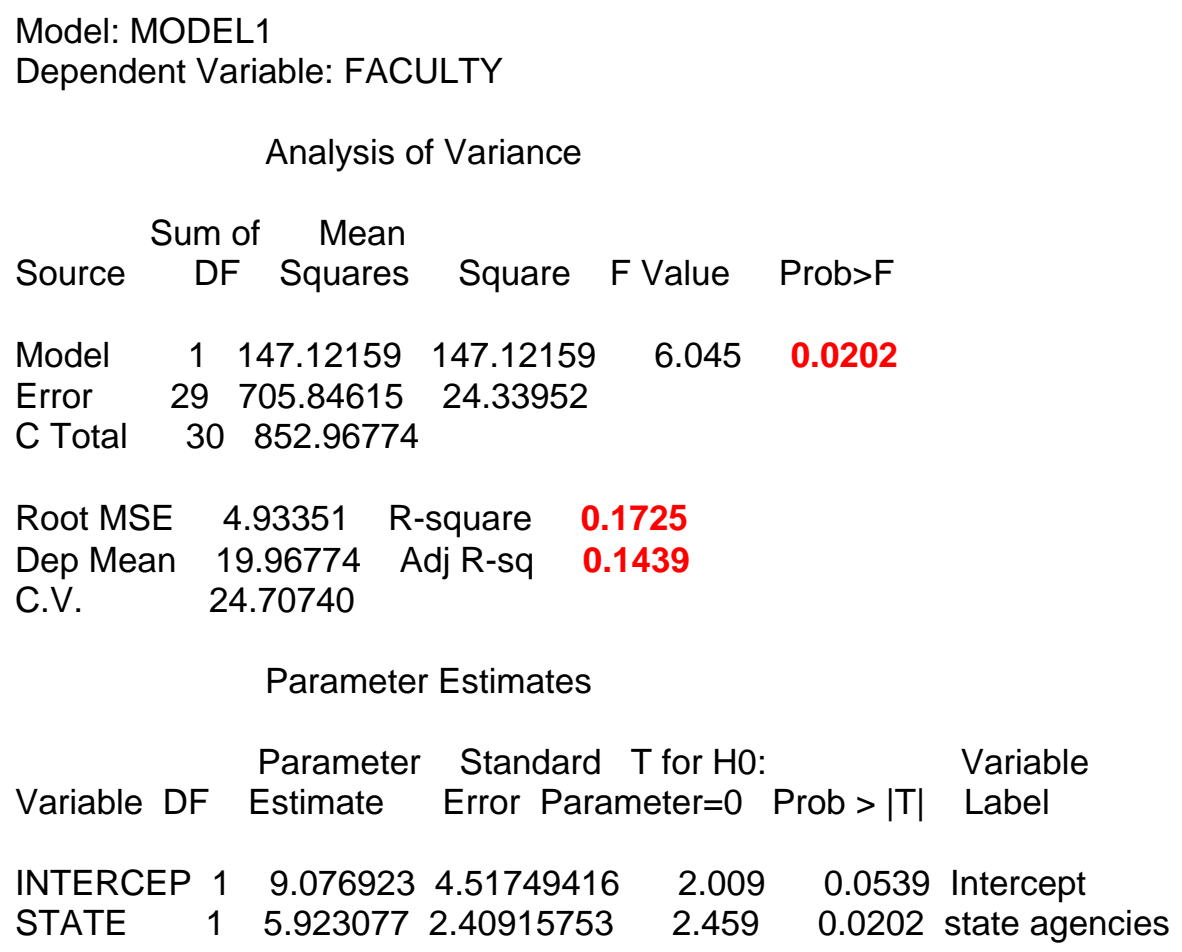




\section{Percentage of Director's Time Fundraising}

Model: MODEL1

Dependent Variable: FACULTY

Analysis of Variance

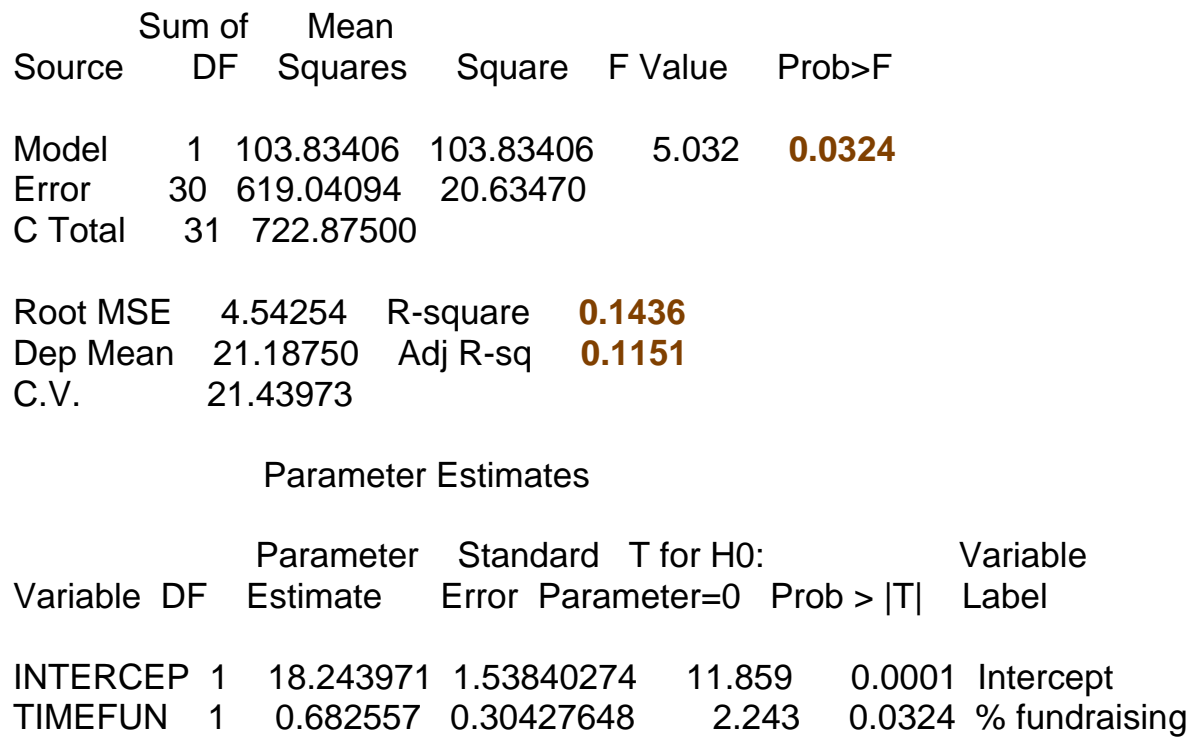


Goal: Interdisciplinary Collaboration

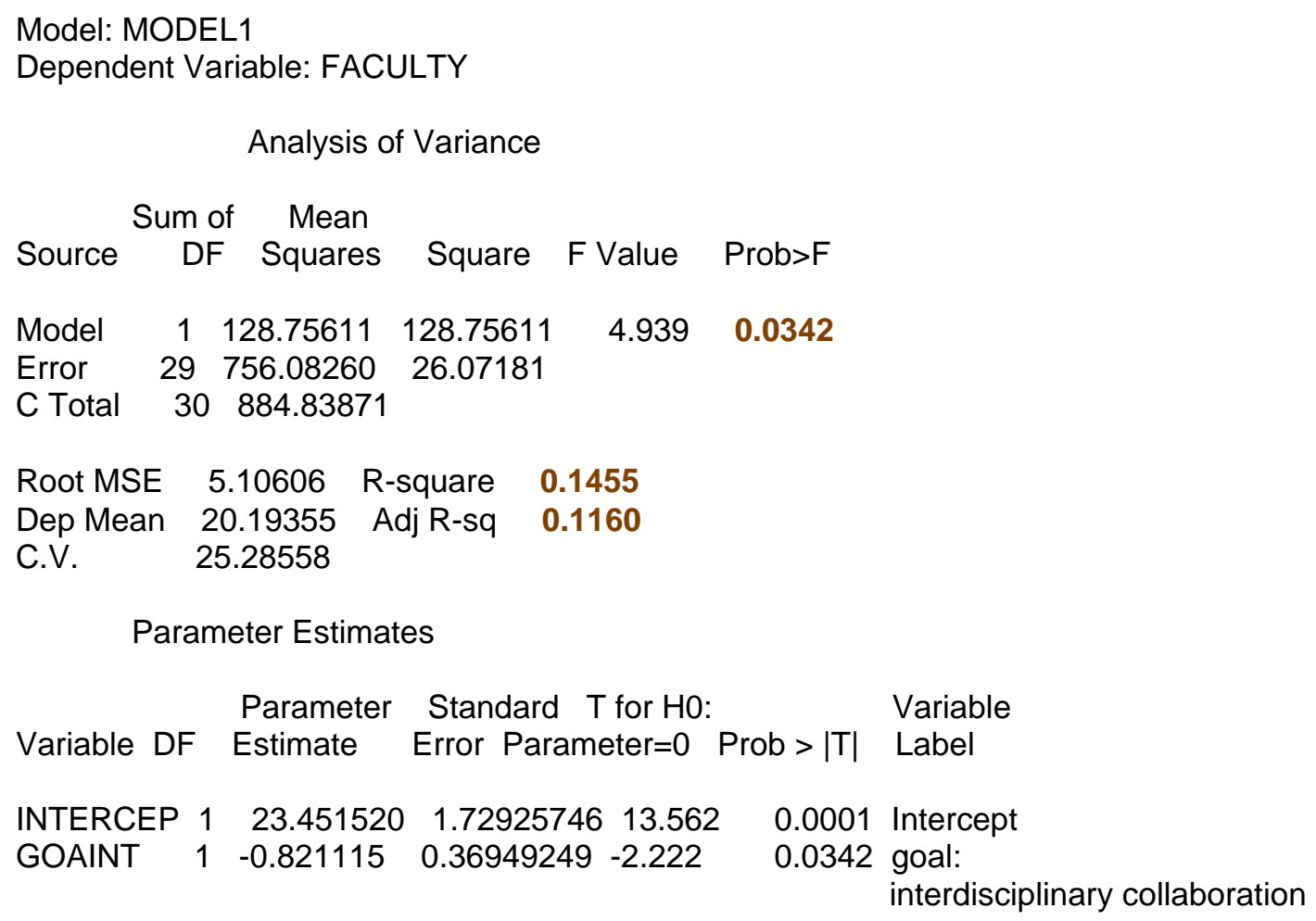




\section{APPENDIX T \\ PREDICTOR VARIABLES FOR NON-ACADEMIC}

Center Mission Compatibility to Mission of Institution

Model: MODEL1

Dependent Variable: NOACAD

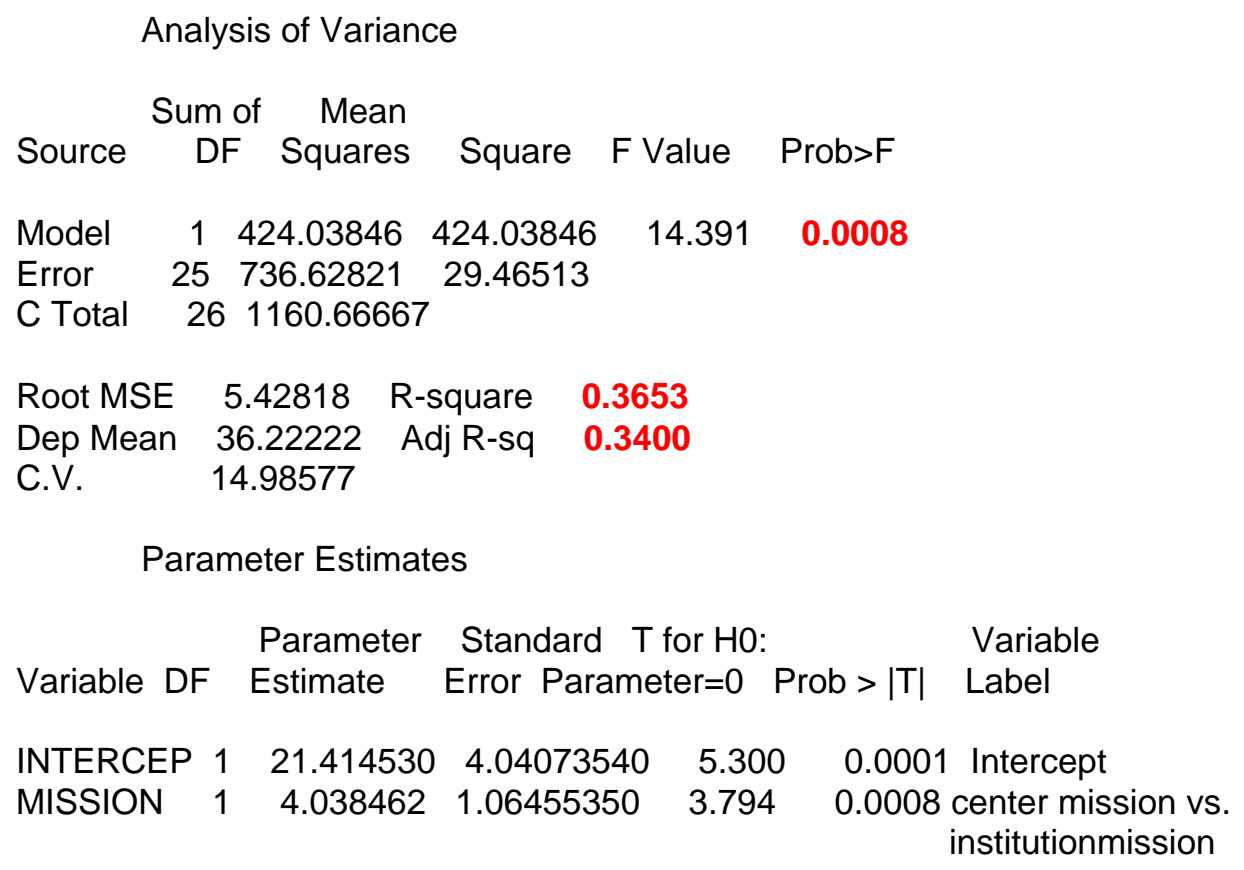




\section{Goal: Personal Development}

Model: MODEL1

Dependent Variable: NOACAD

Analysis of Variance

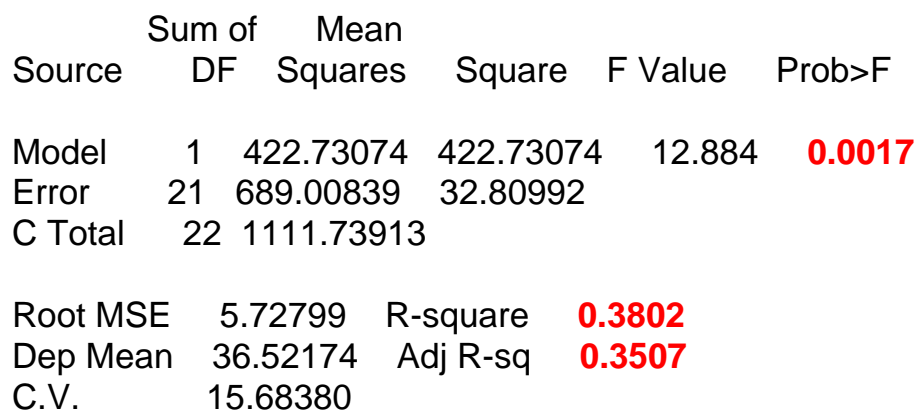

\begin{tabular}{|c|c|c|c|c|c|}
\hline \multicolumn{6}{|c|}{ Parameter Estimates } \\
\hline Variable DF & $\begin{array}{l}\text { Parameter } \\
\text { Estimate }\end{array}$ & $\begin{array}{l}\text { Standard } \mathrm{T} \\
\text { Error Param }\end{array}$ & $\begin{array}{l}\text { T for } \mathrm{HO} \text { : } \\
\text { leter }=0\end{array}$ & Prob $>|\mathrm{T}|$ & $\begin{array}{l}\text { Variable } \\
\text { Label }\end{array}$ \\
\hline INTERCEP 1 & 28.621548 & 2.50412794 & 411.430 & 0.0001 & Intercept \\
\hline GOAPERS 1 & 1.622361 & 0.45197882 & 3.589 & 0.0017 & $\begin{array}{l}\text { goal: personal } \\
\text { development }\end{array}$ \\
\hline
\end{tabular}




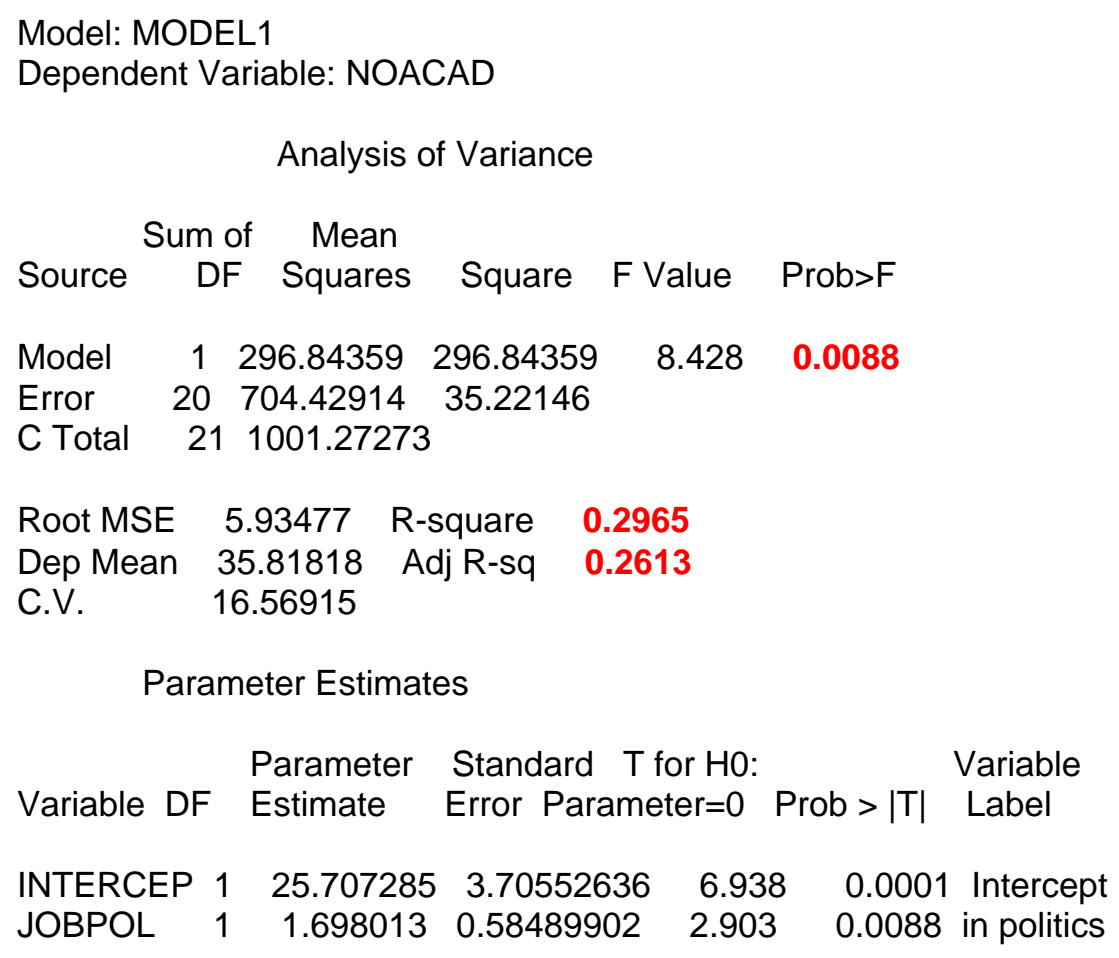


Goal: Academic Development

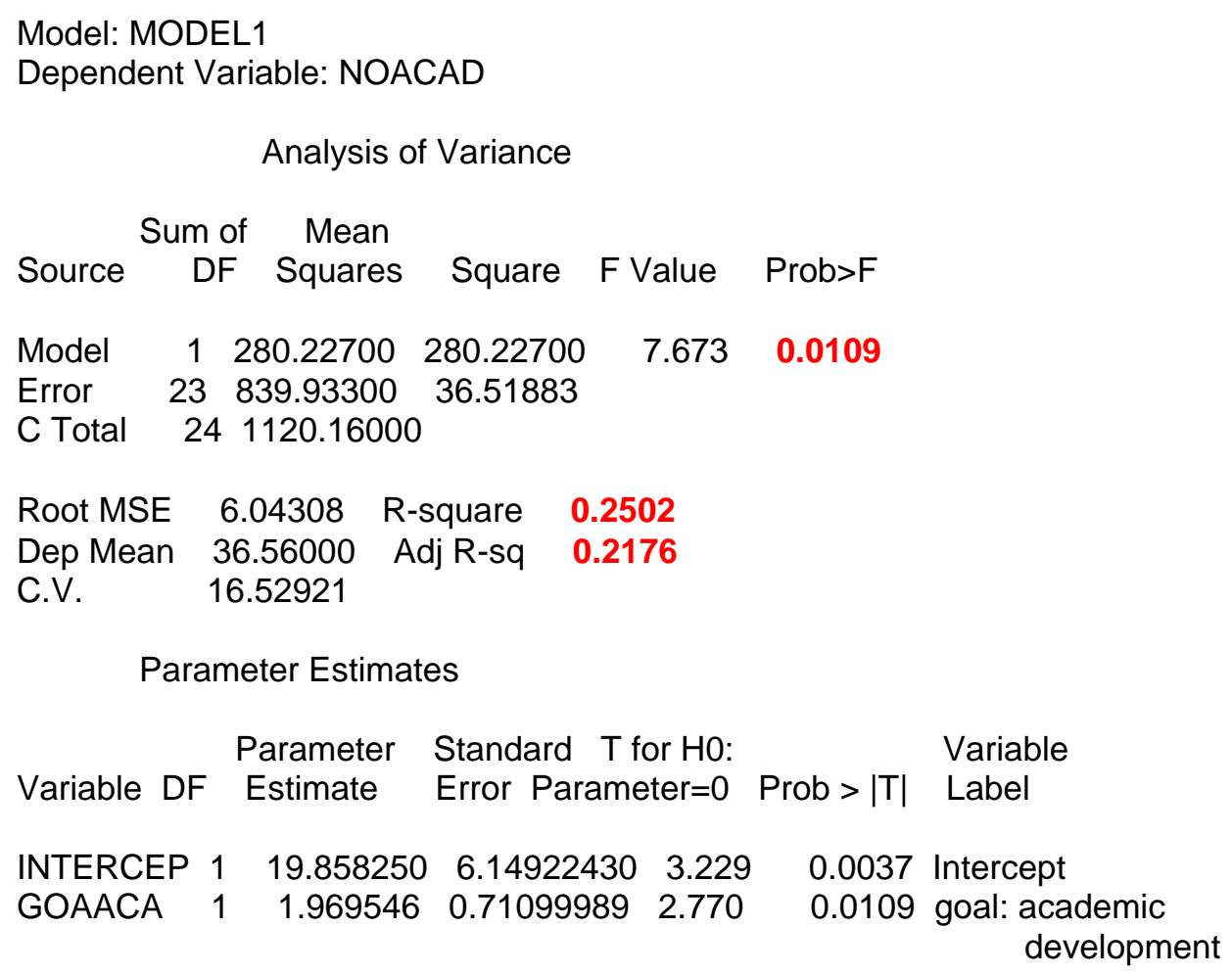


Funding Source: Endowments

Model: MODEL1

Dependent Variable: NOACAD

Analysis of Variance

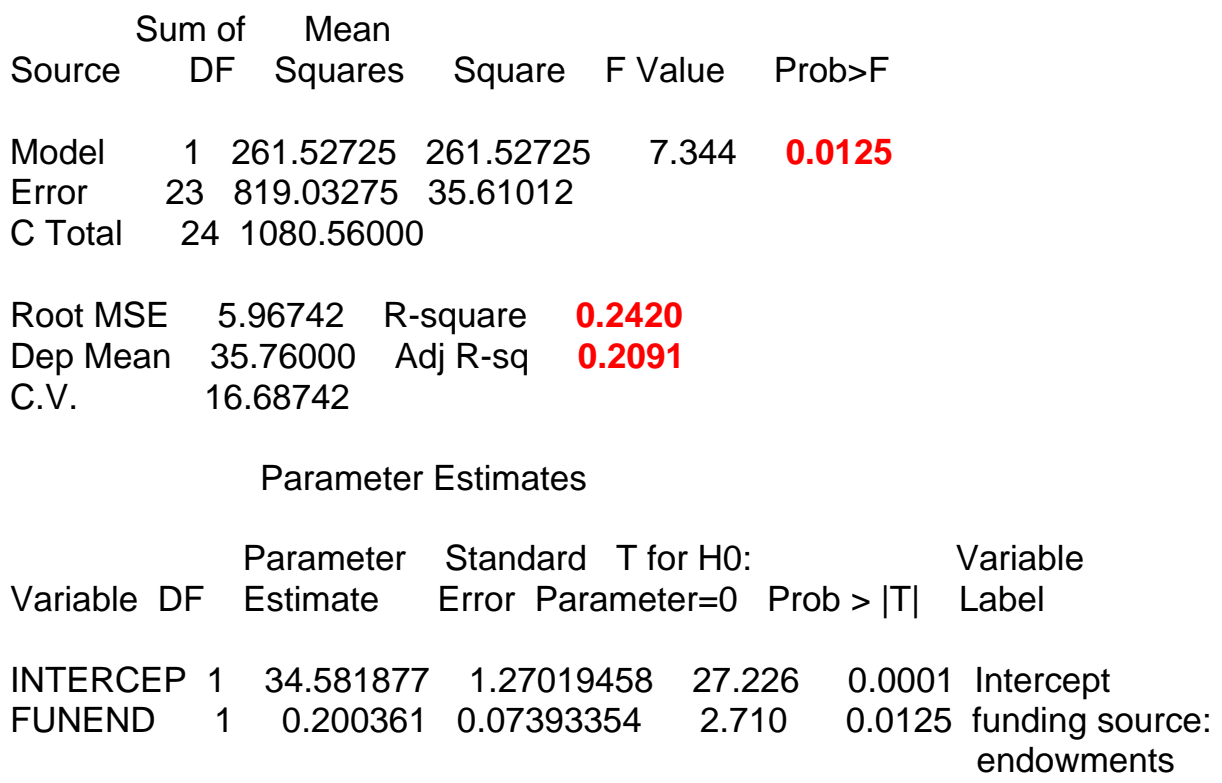


Model: MODEL1

Year of Founding

Dependent Variable: NOACAD

Analysis of Variance

\begin{tabular}{|c|c|c|c|c|c|}
\hline Source & $\begin{array}{c}\text { Sum of } \\
\text { DF }\end{array}$ & $\begin{array}{c}\text { Mean } \\
\text { Squares }\end{array}$ & Square & F Value & Prob $>F$ \\
\hline IVUE! & 1 & 270.62765 & 270.62765 & 7.002 & 0.0148 \\
\hline $\begin{array}{l}\text { rror } \\
\text { Total }\end{array}$ & $\begin{array}{c}22 \\
23\end{array}$ & $\begin{array}{l}850.33068 \\
1120.95833\end{array}$ & 38.65139 & & \\
\hline
\end{tabular}

Root MSE $\quad 6.21702$ R-square $\quad 0.2414$

Dep Mean 36.04167 Adj R-sq $\mathbf{0 . 2 0 6 9}$

C.V. $\quad 17.24955$

Parameter Estimates

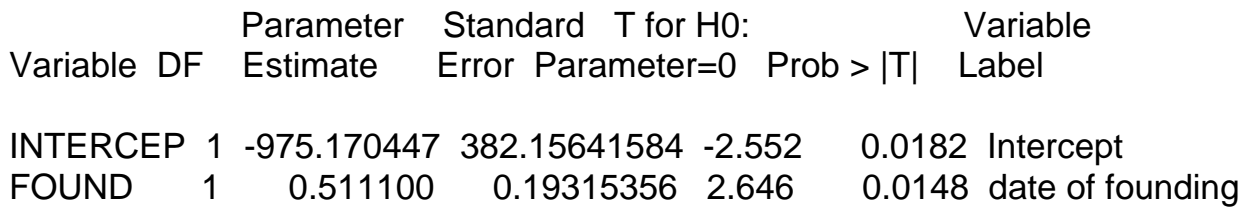


Source of Funding: Federal Funds

Model: MODEL1

Dependent Variable: NOACAD

Analysis of Variance

\begin{tabular}{lccccc}
\multicolumn{5}{c}{ Sum of } & \multicolumn{1}{c}{ Mean } \\
Source & DF & Squares & Square & F Value & Prob>F \\
& & & & & \\
Model & 1 & 247.92239 & 247.92239 & 6.791 & 0.0152 \\
Error & 25 & 912.74428 & 36.50977 & & \\
C Total & 26 & 1160.66667 & & &
\end{tabular}

Root MSE $6.04233 \quad$ R-square 0.2136

Dep Mean 36.22222 Adj R-sq $\mathbf{0 . 1 8 2 1}$

C.V. $\quad 16.68128$

Parameter Estimates

Parameter Standard T for H0: Variable

Variable DF Estimate Error Parameter $=0$ Prob $>|T|$ Label

$\begin{array}{llllll}\text { INTERCEP } 1 & 39.216157 & 1.63469447 & 23.990 & 0.0001 & \text { Intercept }\end{array}$

$\begin{array}{llllll}\text { FUNGRA } & 1 & -0.092279 & 0.03541185 & -2.606 & 0.0152\end{array}$ funding source:

federal funds 
Goal: Acquiring Resources

Model: MODEL1

Dependent Variable: NOACAD

Analysis of Variance

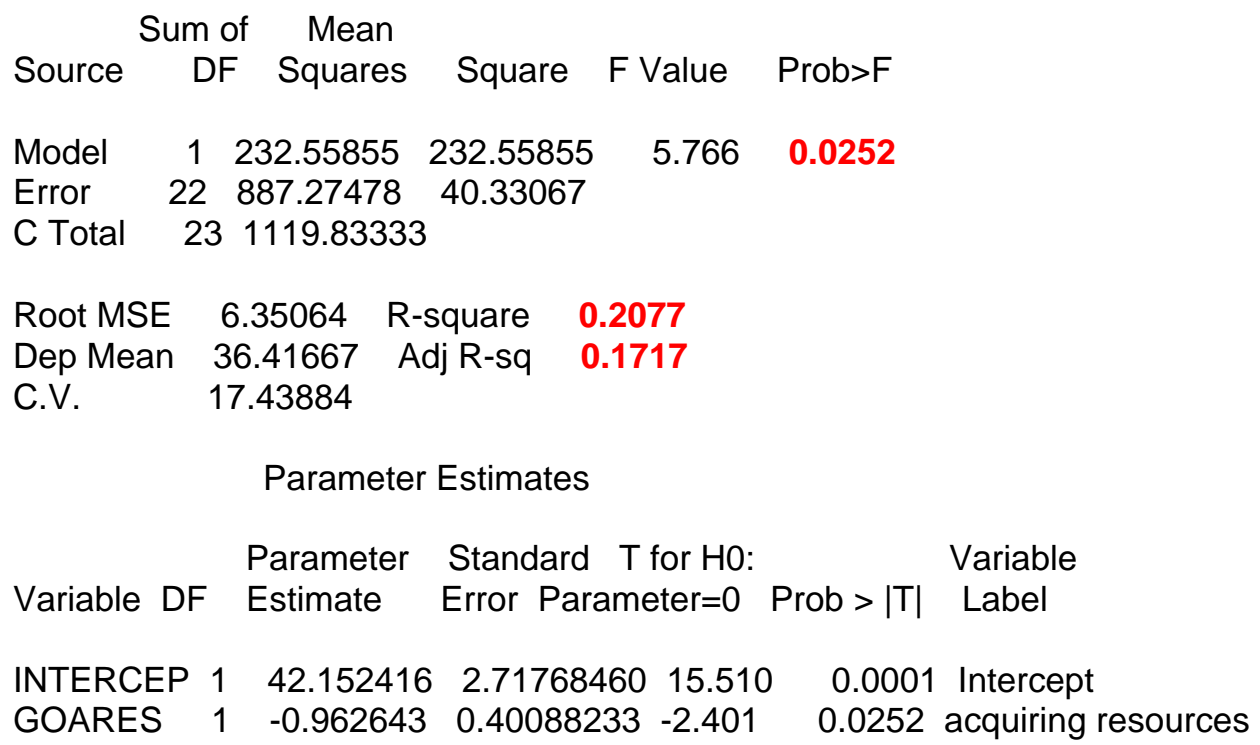


Mission: Instruction

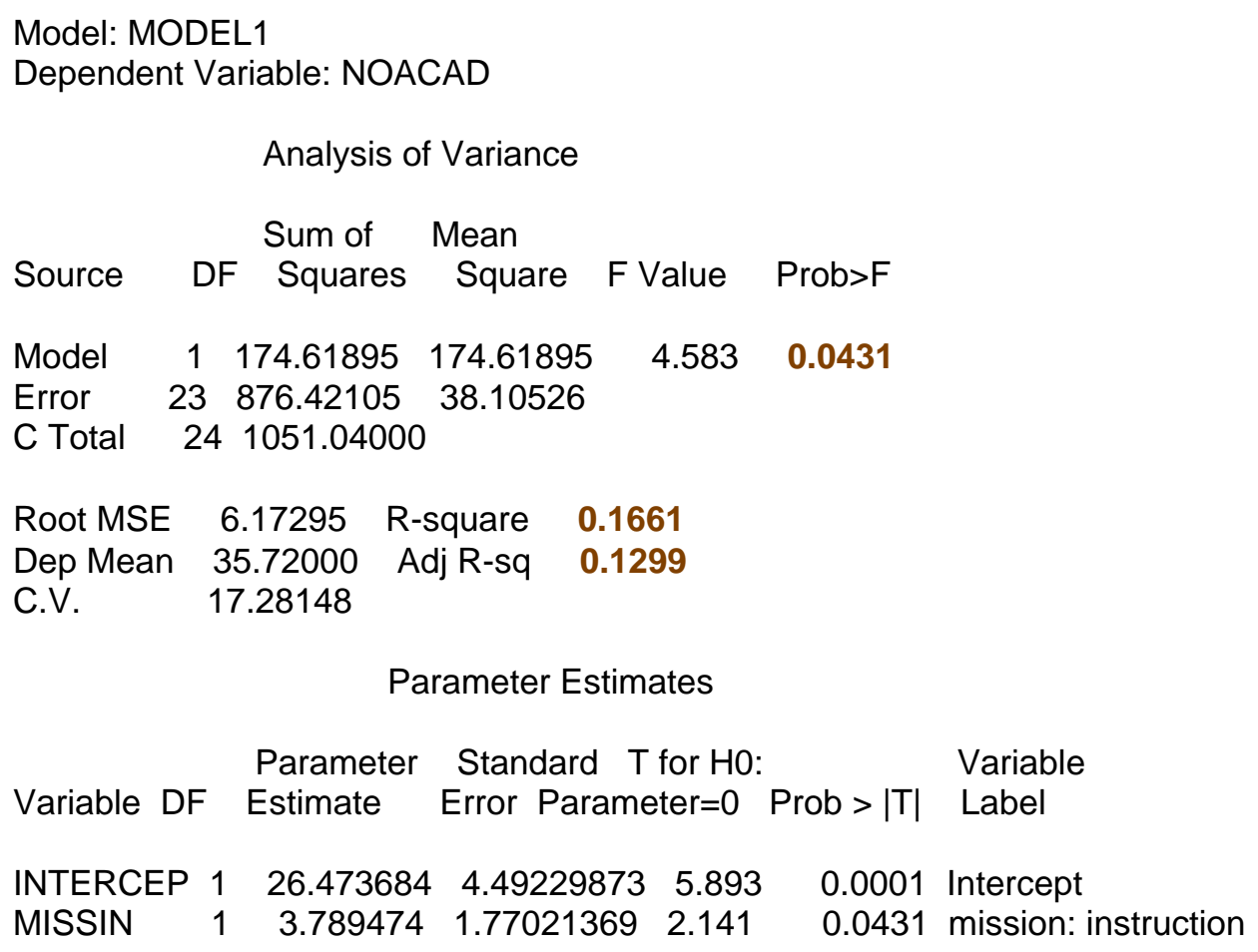


Activity: Adult Education

Model: MODEL1

Dependent Variable: NOACAD

Analysis of Variance

$\begin{array}{lcccccc}\text { Source } & \text { DF } & \begin{array}{c}\text { Sum of } \\ \text { Squares }\end{array} & \begin{array}{c}\text { Mean } \\ \text { Square }\end{array} & \text { F Value } & \text { Prob>F } \\ \text { Model } & 1 & 142.23377 & 142.23377 & 4.130 & 0.0556 \\ \text { Error } & 20 & 688.85714 & 34.44286 & & \\ \text { C Total } & 21 & 831.09091 & & & \end{array}$

Root MSE $\quad 5.86880 \quad$ R-square $\quad 0.1711$

Dep Mean 36.36364 Adj R-sq 0.1297

C.V. $\quad 16.13921$

Parameter Estimates

Parameter Standard T for H0: Variable

Variable DF Estimate Error Parameter $=0$ Prob $>|\mathrm{T}|$ Label

$\begin{array}{llllll}\text { INTERCEP } 1 & 27.714286 & 4.43639861 & 6.247 & 0.0001 & \text { Intercept }\end{array}$

$\begin{array}{llllll}\text { ADLED } & 1 & 5.285714 & 2.60106925 & 2.032 & 0.0556\end{array}$ adult education 


\section{APPENDIX U \\ PREDICTOR VARIABLES FOR THE DOMAIN OF FACULTY AND STAFF JOB SATISFACTION}

Goal: Academic Development

Model: MODEL1

Dependent Variable: JOB

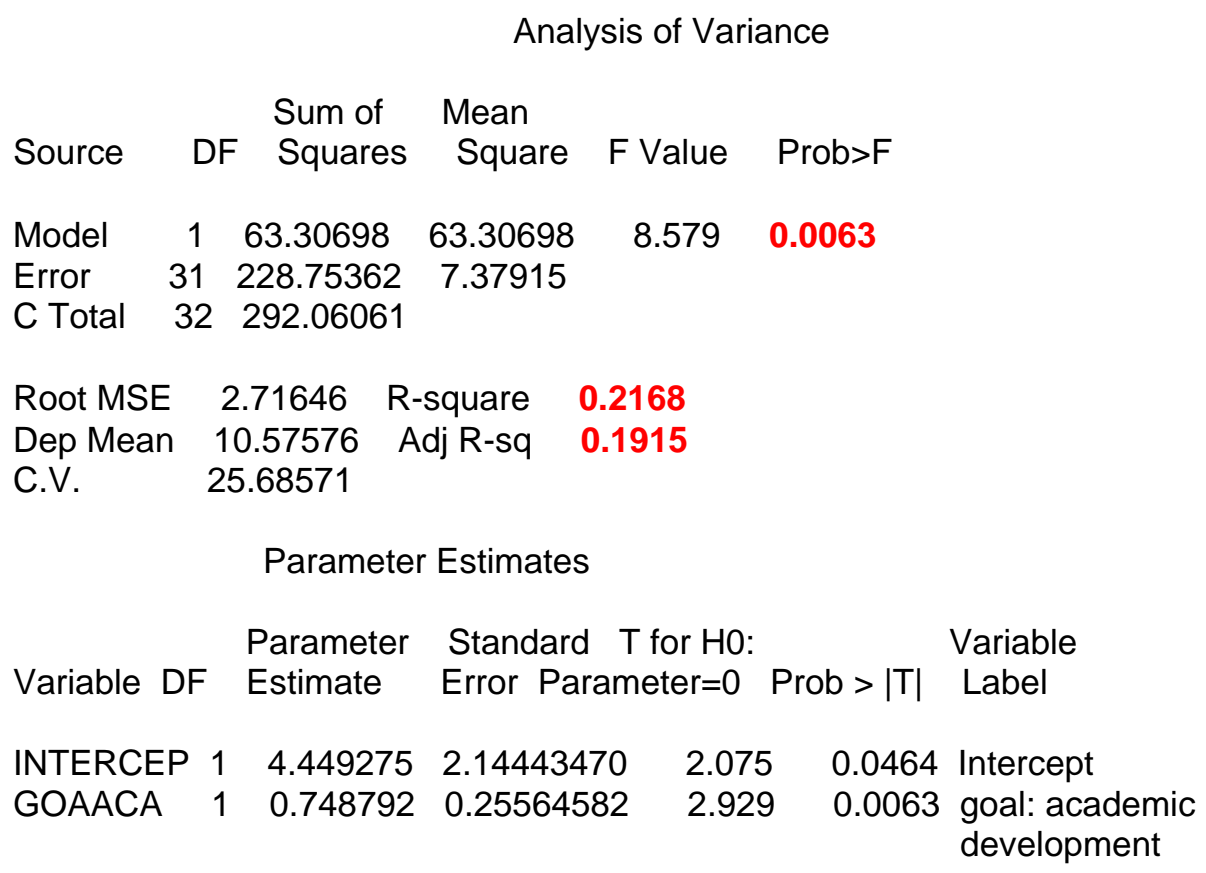


To Whom the Director Reports

Model: MODEL1

Dependent Variable: JOB

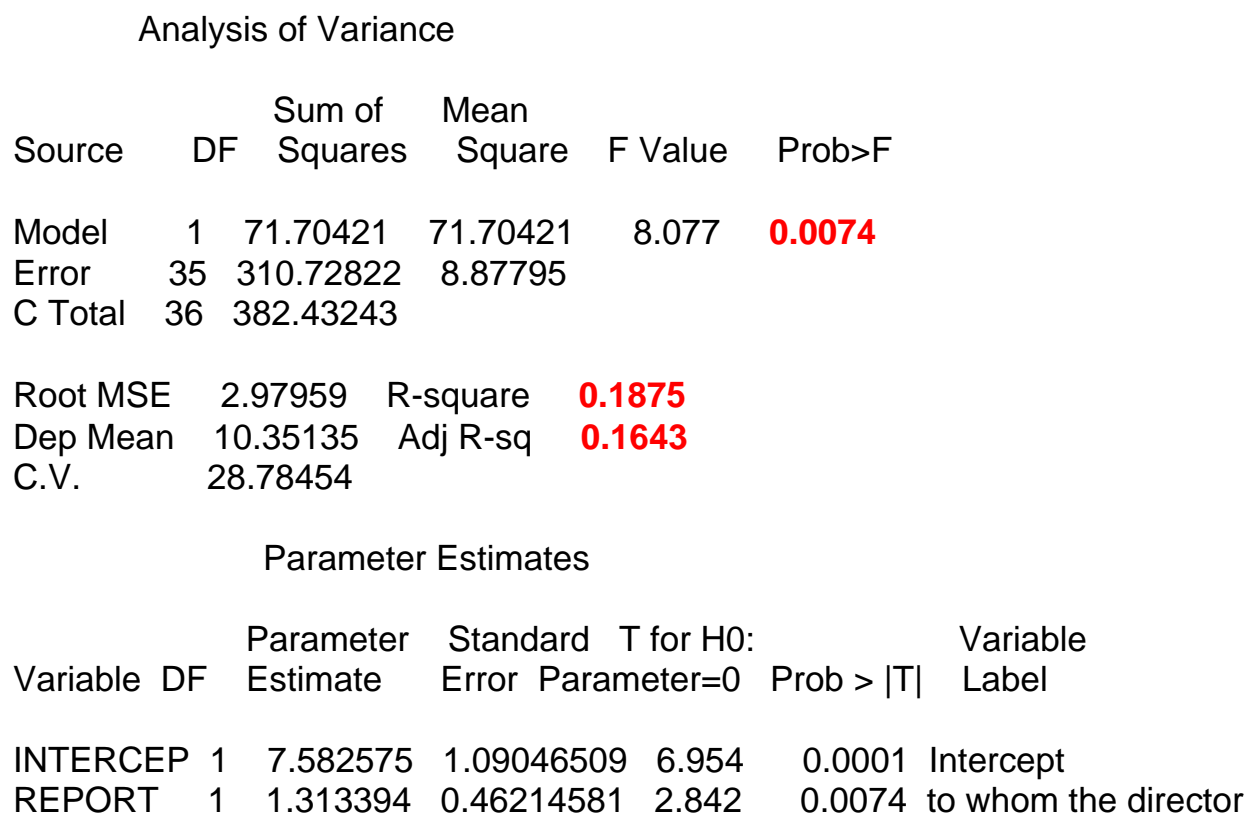


Mission: Instruction

Model: MODEL1

Dependent Variable: JOB

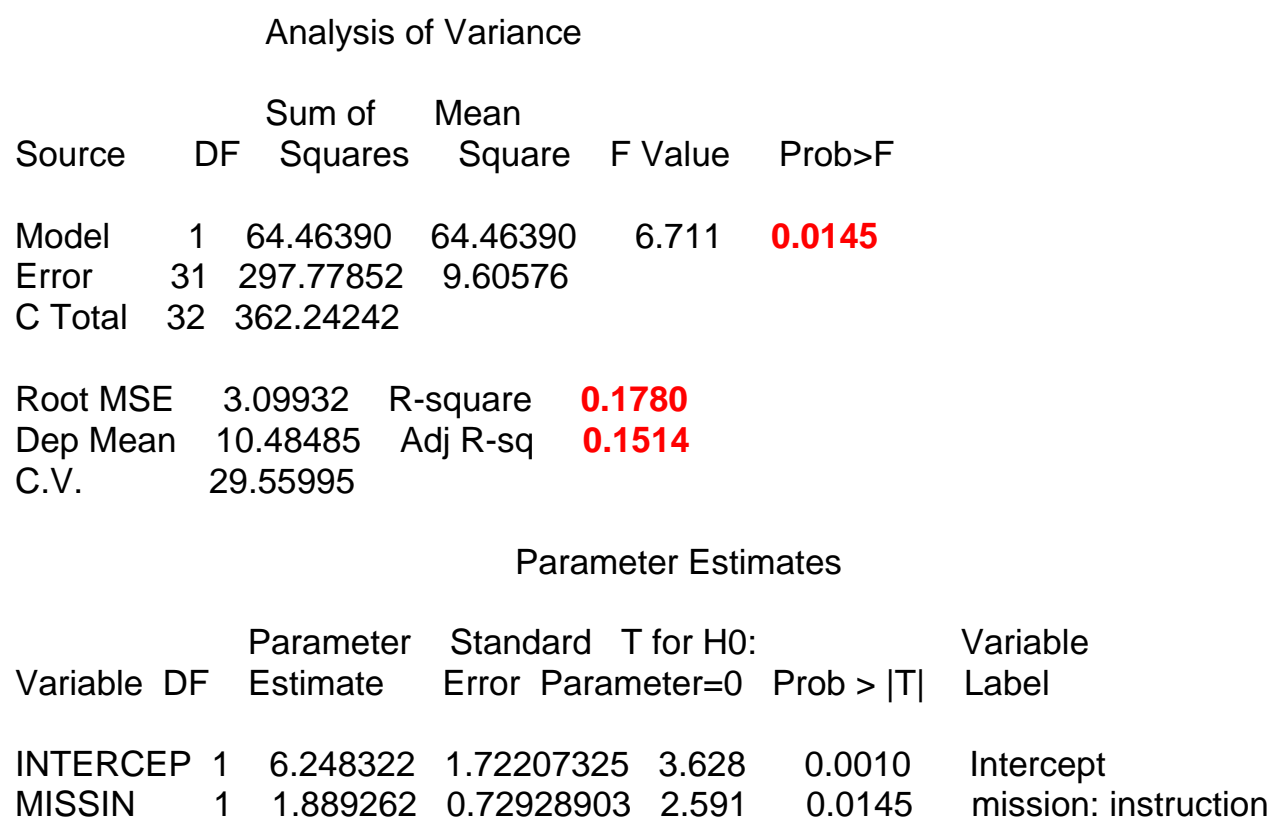


Percentage of Director's Time in Political Activity

Model: MODEL1

Dependent Variable: JOB

Analysis of Variance

\begin{tabular}{|c|c|c|c|c|c|}
\hline Source & $\begin{array}{r}\text { Sum o } \\
\text { DF }\end{array}$ & $\begin{array}{c}\text { Mean } \\
\text { Squares }\end{array}$ & Square & F Value & Prob $>F$ \\
\hline $\begin{array}{l}\text { Model } \\
\text { Error } \\
\text { C Total }\end{array}$ & $\begin{array}{c}1 \\
26 \\
27\end{array}$ & $\begin{array}{c}49.25463 \\
198.85251 \\
248.10714\end{array}$ & $\begin{array}{c}49.25463 \\
7.64817 \\
\end{array}$ & 6.440 & 0.0175 \\
\hline $\begin{array}{l}\text { Root MS } \\
\text { Dep Mea } \\
\text { C.V. }\end{array}$ & $\begin{array}{l}\text { SE } \\
\text { an } \\
27.1\end{array}$ & $\begin{array}{ll}2.76553 & \mathrm{R} \\
10.17857 & \mathrm{~A} \\
17015 & \end{array}$ & $\begin{array}{l}\text {-square } \\
\text { ddj R-sq }\end{array}$ & $\begin{array}{l}0.1985 \\
0.1677\end{array}$ & \\
\hline
\end{tabular}

Parameter Estimates

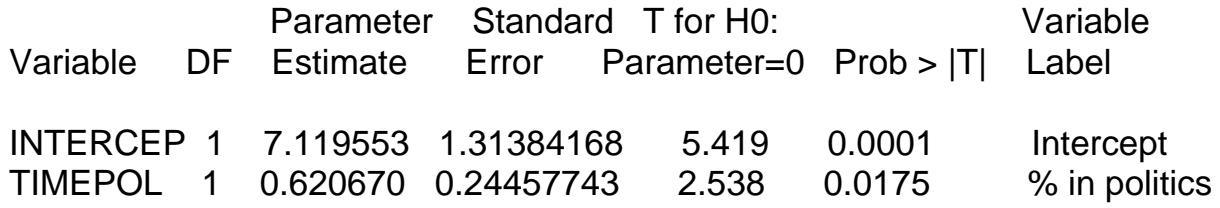


Model: MODEL1

Goal: Community Interaction

Dependent Variable: JOB

Analysis of Variance

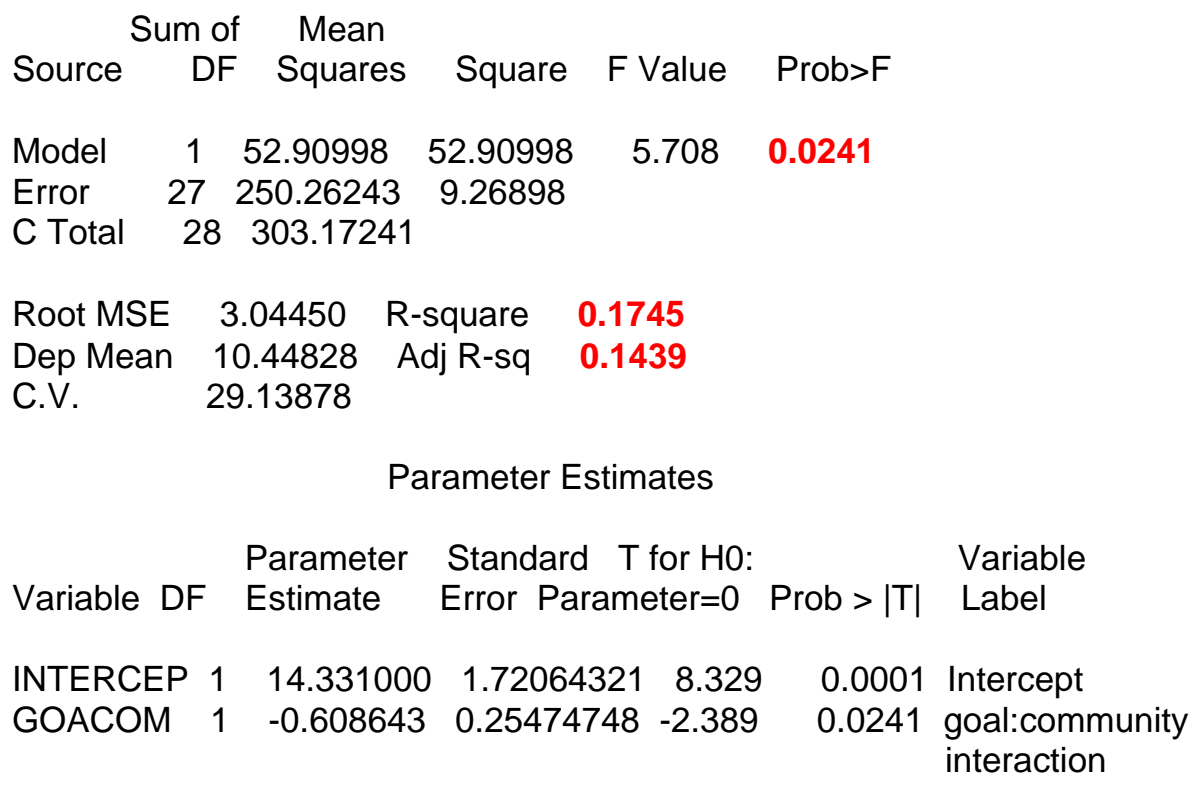


Activities with State Agencies

Model: MODEL1

Dependent Variable: JOB

Analysis of Variance

\begin{tabular}{lrrrrr}
\multicolumn{7}{c}{$\begin{array}{c}\text { Sum of } \\
\text { Source }\end{array}$} & DF & $\begin{array}{c}\text { Mean } \\
\text { Squares }\end{array}$ & Square & F Value & Prob>F \\
& & & & & \\
Model & 1 & 42.32481 & 42.32481 & 5.591 & 0.0250 \\
Error & 29 & 219.54615 & 7.57056 & & \\
C Total & 30 & 261.87097 & & & \\
& & & & & \\
Root MSE & 2.75146 & R-square & 0.1616 & \\
Dep Mean & 9.93548 & Adj R-sq & 0.1327 & \\
C.V. & 27.69331 & & &
\end{tabular}

Parameter Estimates

\begin{tabular}{lcccrcl} 
Variable DF & $\begin{array}{c}\text { Parameter } \\
\text { Estimate }\end{array}$ & \multicolumn{2}{c}{$\begin{array}{c}\text { Standard T for HO: } \\
\text { Error }\end{array}$ Parameter=0 } & Prob $>|\mathrm{T}|$ & $\begin{array}{l}\text { Variable } \\
\text { Label }\end{array}$ \\
INTERCEP & 1 & 15.776923 & 2.51944853 & 6.262 & 0.0001 & Intercept \\
STATE & 1 & -3.176923 & 1.34360957 & -2.364 & 0.0250 & state agencies
\end{tabular}




\section{Activities: Community Projects}

Model: MODEL1

Dependent Variable: JOB

Analysis of Variance

$\begin{array}{lccccc}\text { Source } & \text { D D } & \begin{array}{c}\text { Mean } \\ \text { Squares }\end{array} & \text { Square } & \text { F Value } & \text { Prob>F } \\ \text { Model } & 1 & 38.69394 & 38.69394 & 4.952 & 0.0343 \\ \text { Error } & 28 & 218.77273 & 7.81331 & & \\ \text { C Total } & 29 & 257.46667 & & & \\ & & & & & \\ \text { Root MSE } & 2.79523 & \text { R-square } & 0.1503 & \\ \text { Dep Mean } & 9.86667 & \text { Adj R-sq } & 0.1199 & \\ \text { C.V. } 28.33004 & & & & \end{array}$

Parameter Estimates

$\begin{array}{lcccccc}\text { Variable DF } & \begin{array}{c}\text { Parameter } \\ \text { Estimate }\end{array} & \begin{array}{c}\text { Standard T for H0: } \\ \text { Error Parameter=0 }\end{array} & \text { Prob }>|\mathrm{T}| & \begin{array}{c}\text { Variable } \\ \text { Label }\end{array} \\ \text { INTERCEP } & 1 & 14.318182 & 2.06441429 & 6.936 & 0.0001 & \text { Intercept } \\ \text { COMM } & 1 & -2.568182 & 1.15404267 & -2.225 & 0.0343 & \text { community projects }\end{array}$


Relationship between Director and the Subdivisions

Model: MODEL1

Dependent Variable: JOB

Analysis of Variance

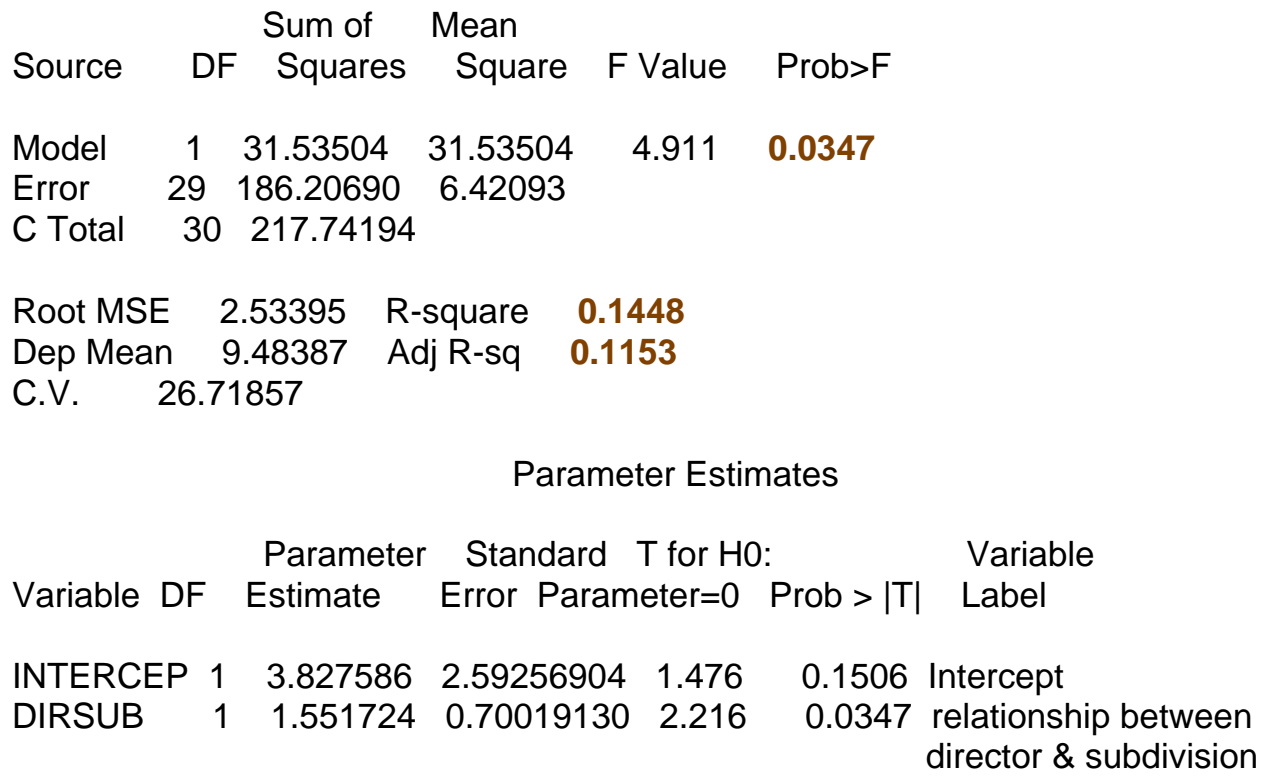


Academic Appointment of the Director

Model: MODEL1
Dependent Variable: JOB

Analysis of Variance

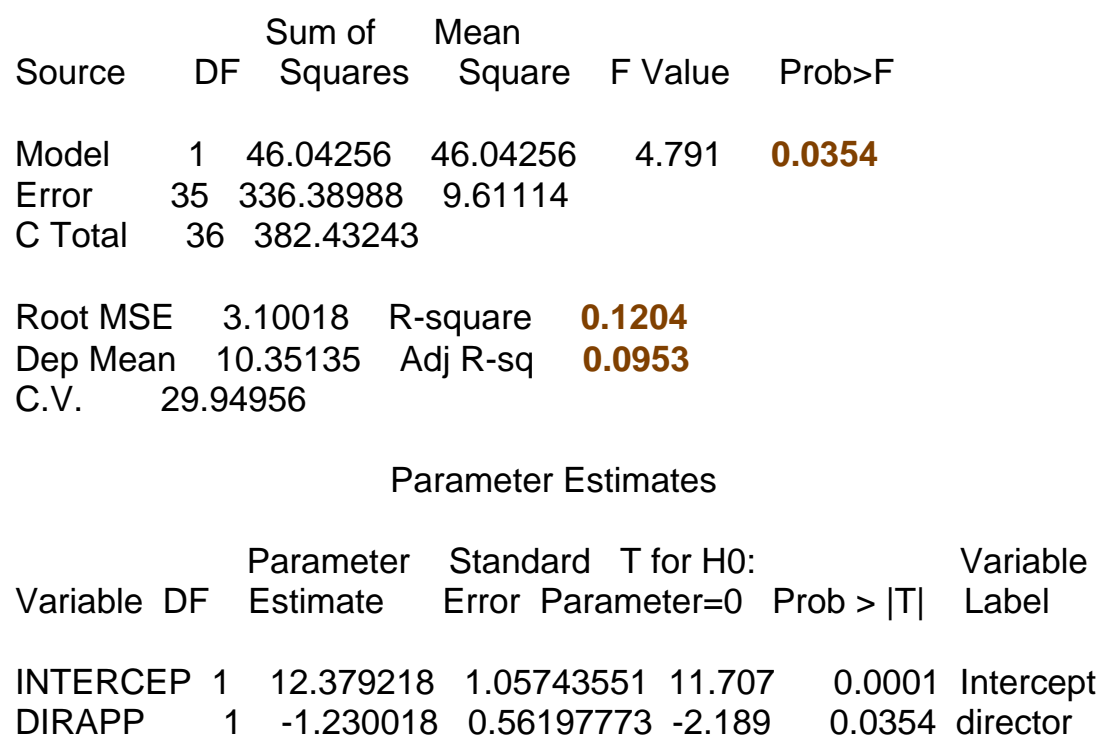

appointments 
Adequacy of Space

Model: MODEL1

Dependent Variable: JOB

Analysis of Variance

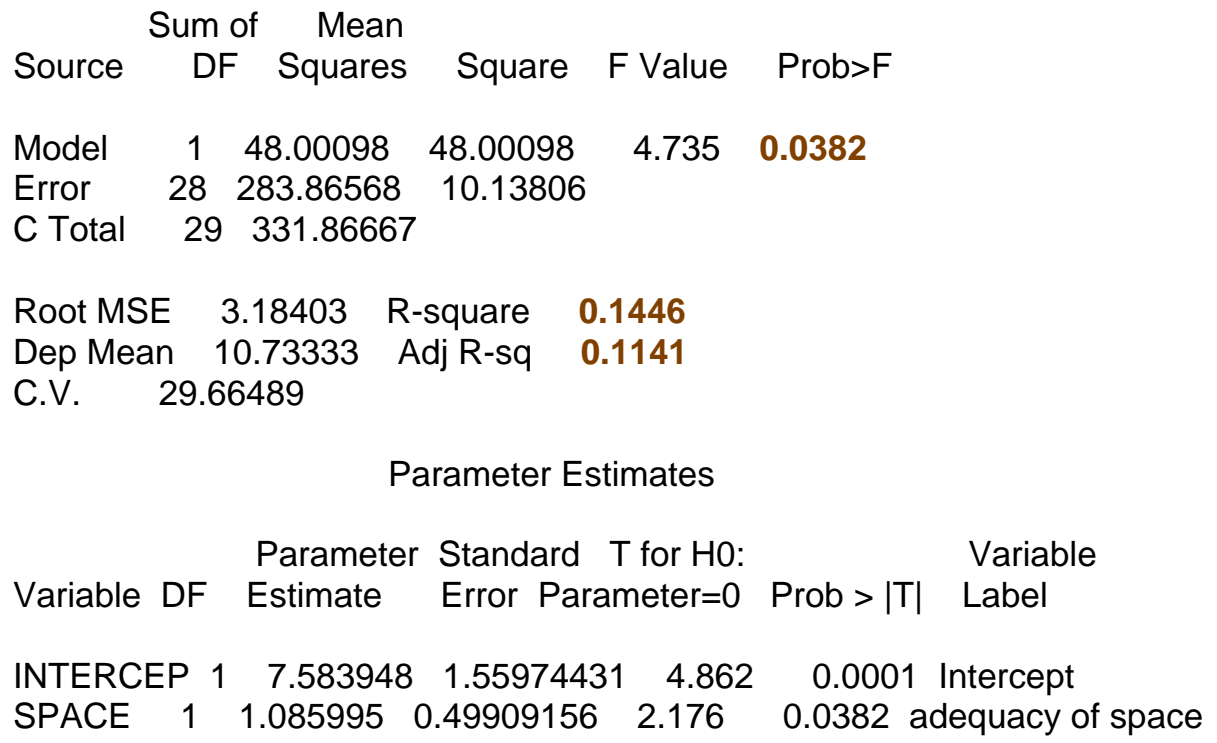




\section{ALLISON HALE NICHOLS \\ 1000 Grand Street \\ Morgantown, WV 26505 \\ home: (304) 291-1322 \\ work: (412) 648-7152 \\ E-mail: anichol@pitt.edu}

\section{EDUCATION}

Ed.D.

Graduate Certificate

M.A.

B.S.

Educational Leadership

West Virginia University

Morgantown, W.V.

Dissertation Topic: Domains of Organizational Effectiveness of

Gerontology Centers

Gerontology

West Virginia University

Morgantown, W.V.

Communications--Print Media

Wheaton College

Wheaton, Illinois

Biblical Studies and Christian Education

Philadelphia College of Bible

Langhorn, PA 
WORK

EXPERIENCE

1998-present

$1997-1998$

$1993-1998$

Evaluator/Researcher/Development Officer

Generations Together

University of Pittsburgh

Pittsburgh, PA

Evaluation of intergenerational programs, research, grant writing, training, model program development

Program Manager

West Virginia University Center on Aging

Research Unit

PO Box 9126

Morgantown, WV

Duties related to the administration of the Research Unit of the Center on Aging including: budget management for four grantfunded projects, supervision of a secretary, coordination of activities for four projects of the Research unit, committee membership, grant writing and administration, and coordination of cooperative activities with the Administrative Unit of the Center on Aging.

Program Manager

TRANSFER Project

Department of Behavioral Medicine and Psychiatry

and Center on Aging

West Virginia University School of Medicine

Morgantown, W.V.

Duties include: workshop coordination; community/agency

communication; training material preparation; budget overview;

supervision of secretary; workshop presentations; grant preparation; committee representation.

September 1987 -

February 1993

\section{Program Associate}

Gerontology Center, West Virginia University, Morgantown, W.V. 26506.

Duties included grant proposal writing and administration, assisting faculty with grant proposals, literature searches, background 
research, communication with funding agencies, facilitating task forces.

December 1991

- April, 1992

1989- present

\section{Project Administrator for Church in Rural} Aging Networks: Education and Collaborative Projects Grant

Responsibilities include curriculum preparation, workshop design and implementation, data collection and research article preparation, workshop presentations, and other duties necessary for daily administration of the project.

Lecturer - Introduction to Gerontology course (MDS 50), W.V.U.

October 1988 June 1990

\section{Coordinator}

Model Curriculum in Geriatric Education Project

The Ohio Valley Appalachia Regional Geriatric Center (OVAR/GEC). OVAR/GEC is a consortium of universities concerned with the enhancement of geriatric education of which West Virginia University was a member institution.

Duties include: Coordinating the planning of five model curriculum workshops presented by each of the member institutions on WVU's campus over a two-year period and five curriculum workshops presented by W.V.U. at the member institutions, such as preparing notebook material, bibliographies, and audio visuals, booking rooms, refreshments, lodging, etc.

June 1987 -

August 1987

Copy Editor for "Giving Care" a training manual caregivers of Alzheimer's Disease patients.

Duties include: some writing, preparation of copy for publication, and writing script for slide presentation.

January, 1987 May, 1987

\section{Graduate Research Assistant on State-wide} Alzheimer's Training Grant

Gerontology Center, West Virginia University

Part of a five-member team giving 30 workshops entitled, "Caring for the Memory-Impaired Patient and Yourself" to professional and private caregivers statewide. Responsibilities 
include: writing and editing training manuals, publicity, creating and producing visual aides, teaching workshop sections.

April 1977 -

August, 1985

July 1971 -

October, 1976

\section{Staff Assistant/Medical Education \\ Mount Auburn Hospital \\ Cambridge, MA 02238}

Planned yearly and daily work schedules for $30+$ medical residents at a Harvard Medical School affiliated hospital. Planned and implemented a hospital-based second-year HMS clinical course. Responsible for record-keeping and tabulation of continuing education credits for medical staff. Served as liaison between HMS and hospital concerning houseofficer training issues. Wrote a DHEW grant for the training of primary care residents. Edited articles for professional journals. Wrote policy proposals. Wrote script for promotional video. Assisted manager with departmental budget. Served as secretary to medical staff education committee. Supervised one secretary, including yearly evaluations. Implemented and later supervised the interview process for internships in Internal Medicine.

\section{Publication Editor for TEEN POWER}

Scripture Press Publications, Inc.

Wheaton, Illinois, 60187

Edited an 8-page Sunday school magazine for junior high youths. Selected and edited all articles submitted by authors. Wrote original articles including cartoon sequences. Communicated with authors by phone and letter. Represented the company at numerous publishing and writers conferences. Interviewed subjects for stories and wrote articles from the interviews. Worked with artists and printers.

\section{MEMBERSHIPS AND HONORS}

$1998-$

1997-

$1997-$
Chair, Nomination Committee, North Central West Virginia Alzheimer's Chapter, Board of Directors

Member, North Central West Virginia Alzheimer's Chapter Board of Directors

Chair, Education Committee, North Central West Virginia Alzheimer's Chapter Board of Directors 
$1997-$

1996-

1995- 1996

1994-Present

1992 - Present

1991-1993

1991-1993

1990

$1983-1985$

1974
Member, International Rural Aging Project Committee, WVU Center on Aging

Member, Program Development Committee, Association of Gerontology in Higher Education

Member, Research Committee, Association of Gerontology in Higher Education

Member, Rural Aging Subcommittee, Gerontological Society of America

Member, Gerontological Society of America

Member, Community Living Initiatives Corporation, Morgantown, WV

Member, Council for Planned Approach to Community Health, Morgantown, W.V.

Certificate, Model Curriculum Series in Geriatric Education

Certificate Program in Technical Communications

University of Lowell, Lowell, MA

Certificate in Layout Design, Printer's Institute, Chicago, IL

\section{PUBLICATIONS and RESEARCH}

Nichols, A. (completed). "Domains of organizational effectiveness of gerontology centers in higher education." Dissertation research to fulfill requirement for Ed.D., Education Administration.

Rankin, ED, Keefover, RW, and Nichols, AH. (November 2, 1996). Training rural health care professionals in assessment and care of dementia. Gerontology and Geriatrics Education, $33-48$.

Nichols, A. (1995). Planning and implementing a statewide collaborative gerontology education program for religious professionals in rural areas. Journal for Religious Gerontology. $\underline{9}$, 2, 51-67.

Nichols, A. (1986). "The transition to caregiving by older adults." A research paper done to fulfill requirement for Gerontology Graduate Certificate. 


\section{PRESENTATIONS/TEACHING}

Nichols, A. "Evaluation of Intergenerational Programs", The Sixth Intergenerational Training Institute, Generations Together, Pittsburgh, PA. June 18, 1998

Nichols, A. "Domains of Organizational Effectiveness in Gerontology Center" Presentation at the Association for Gerontology in Higher Education Annual Meeting, Winston Salem, NC, February 21, 1998.

Nichols, A, Rankin, E. The TRANSFER Project--Training rural health care and social service providers in assessment and care of dementia. Presentation at the Gerontological Society of America Annual Meeting, November 17, 1997.

Nichols, A. "Training Rural Alzheimer's Disease Networks for Education and Referral" Workshop -- Summer Institute on Aging, West Virginia University School of Social Work, June, 1997.

Nichols, A. "Introduction to Alzheimer's Disease." Introduction to Gerontology MDS 50 course, West Virginia University, October 9, 10, 1996.

Nichols, A. "Introduction to Alzheimer's Disease." Introduction to Gerontology MDS 50 course, West Virginia University, April 9, 1996.

Nichols, A. "Alzheimer's Disease" Sociology of Aging Course, W.V.U, April 1, 1996.

Rankin, E., Keefover, R. and Nichols, A. "Training Rural Alzheimer's Networking Services for Education and Referral: Training materials and educational strategies." To be presented at the Association for Gerontology in Higher Education Annual Meeting, Philadelphia, PA, March, 1996.

Douglas, V. and Nichols, A. "Prevention and Elders." Facilitated a discussion group at the Prevention Research Center Symposium," at West Virginia University, December, 1995.

Nichols, A. (1993-present) "Creating a resource directory for older adult services." The TRANSFER Project workshops, Dept. of Behavioral Medicine and Psychiatry, WVU. School of Medicine.

Nichols, A. (1993-present). "Accessing services for Alzheimer's disease in rural areas." The TRANSFER Project workshops, Dept. of Behavioral Medicine and Psychiatry, W.V.U. School of Medicine.

Nichols, A. "A historical perspective on institutes and centers: A comparison of gerontology with other fields of study." Presented at the Association for Gerontology in Higher Education Annual Meeting, Fort Worth, TX, February, 1995

Nichols, A., Rankin, E., Keefover, R., \& Briggs, R. "Training rural Alzheimer's networking 
services for education and referral." Presented at the Association for Gerontology in Higher Education Annual Meeting, Cleveland, OH, March, 1994.

Nichols, A. "Employment and Aging" Presented to the Introduction to Gerontology MDS 50 course at West Virginia University, 1991-1994.

Schneider, V., Briggs, R., Nichols, A. "The Church and Rural Aging Networks for Education and Collaborative Efforts Project". Presented at the Association of Gerontology in Higher Education Annual Meeting, Baltimore, MD., February, 28, 1990.

Nichols, A. Presentation on "Social Issues of Aging" CRANECE Project, in Princeton, W.V., 1991.

Nichols, A. Presentations to caregivers on environmental home safety, communication with the memory-impaired patient, difficult behaviors, elder abuse and stress reduction. Alzheimer's Disease Caregiver Training Project, WVU. Gerontology Center, 1986. 